\title{
Review of Hybrid Laminar Flow Control Systems
}

\author{
K.S.G. Krishnan ${ }^{1}$, O. Bertram ${ }^{1}$, O. Seibel ${ }^{1}$ \\ ${ }^{1}$ German Aerospace Center (DLR), Lilienthalplatz, 38108, Braunschweig, Germany
}

\begin{abstract}
The aeronautic community always strived for fuel efficient aircraft and presently, the need for ecofriendly aircraft is even more, especially with the tremendous growth of air traffic and growing environmental concerns. Some of the important drivers for such interests include high fuel prices, less emissions requirements, need for more environment friendly aircraft to lessen the global warming effects. Hybrid laminar flow control (HLFC) technology is promising and offers possibility to achieve these goals. This technology was researched for decades for its application in transport aircraft, and it has achieved a new level of maturity towards integration and safety and maintenance aspects. This paper aims to give an overview of HLFC systems research and associated flight tests in the past years both in the US and in Europe. The review makes it possible to distinguish between the successful approaches and the less successful or outdated approaches in HLFC research. Furthermore, the technology status shall try to produce first estimations regarding the mass, power consumption and performance of HLFC systems as well as estimations regarding maintenance requirements and possible subsystem definitions.
\end{abstract}

Keywords: hybrid laminar flow control, system design, suction system, flight tests, windtunnel tests.

\section{Introduction}

Aircraft manufacturers as well as research organisations try to reduce the fuel burn of aircrafts for many years and the ambitious environmental goals of ACARE's Vision 2020 and Flightpath 2050 lead to an even higher focus on the efficiency of aircraft. There are different ways to reduce the fuel burn and thus the emission of carbon dioxide and nitrogen oxides of aircraft like new engine technology, improved system integration as well as improved aerodynamics. Flow control by means of keeping the flow laminar over wetted surfaces as long as possible during cruise is one way of reducing the overall fuel burn. The laminar flow control technology for aircraft was first experimentally tested in wind tunnels in the late 1930s in the US [1]. The research activities in the US as well as in Europe continued until the early 1960s when the interest in this topic decreased. Due to the oil embargo by the OPEC in the 1970s and the resulting rapid increase of fuel prices, the research on laminar flow control system was revived. New technology led to significant achievements during wind tunnel and flight experiments but still major manufacturing issues and other operational obstacles prohibited an economic installation of the fuel saving technology on new aircraft [2].

Flow control is defined by Liddle [3] as the modification of local flow parameters without external geometric change. High-lift systems are therefore not considered as flow control since the geometry is changed when the systems are deployed to increase wing area and camber resulting in a higher lift coefficient as well as maximum angles of attack. Flow control can be divided into Laminar Flow (Control) and Turbulence Manipulation as depicted in figure 1. Turbulence Manipulation can be further divided into Active Flow Separation Control by means of actuators (AFSC) and Passive Turbulent Flow Control. Passive Turbulent Flow 
Control devices are mainly applied to reduce the skin-friction drag of turbulent flows by energising the boundary layer. Examples for this kind of flow control are riblets and vortex generators. With AFSC it is tried to control the boundary layer development and to delay separation effects to enhance control surface effectiveness for flaps, rudders and elevators to name only a few [4]. An enhanced rudder efficiency (e.g. through higher deflection angles without separation) can lead to a decreased wetted area of the vertical tail plane which results in reduced skin friction drag during all flight phases. Since a failure of such an AFSC system applied to a smaller sized rudder may be catastrophic for the design condition (one engine inoperative at low speeds), stringent reliability requirements must be met.

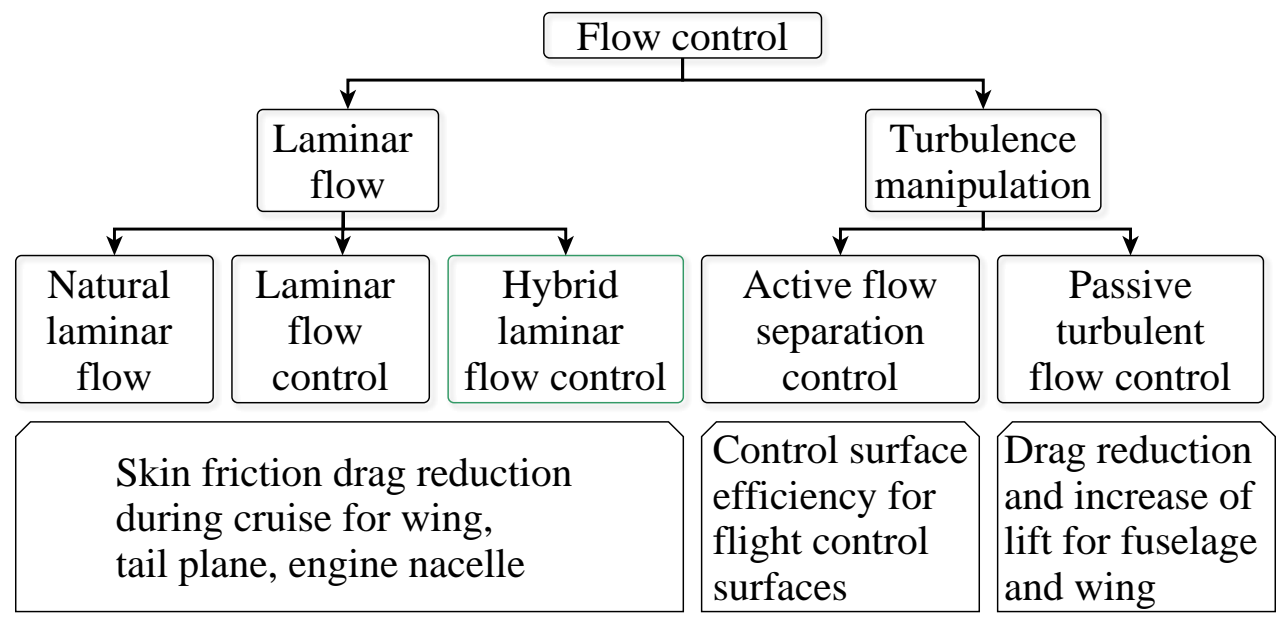

Fig 1. Different types of Flow Control applications

Laminar Flow systems aim at delaying the transition from laminar to turbulent airflow over wings, tail planes or nacelles as far aft as possible to reduce the overall aircraft drag. It can be divided into full Laminar Flow Control (LFC), Natural Laminar Flow (NLF) and Hybrid Laminar Flow Control (HLFC) as a combination of the first two methods. HLFC combines a moderate amount of suction at the leading edge with a following suitable pressure gradient. This reduces the overall complexity and weight of the suction system and does not interfere with the main part of the wing. Nevertheless, it requires a suitable shape of the succeeding main wing geometry which might have to be reworked for retrofit applications.

Henke [5] points out, that the development of an HLFC system is a highly interdisciplinary task. For the A320 fin flight test performed in 1998, four different groups were identified: The aerodynamics group will specify the suction distribution. The system and structure groups will then have to develop hardware to achieve the requirements from the aerodynamics and, finally, the flight test preparation group has to integrate the developed hardware for the flight test. If a group has to modify something, this has an effect on the other groups. If the system is applied to the leading edge of a wing, it even needs to share the space with the leading edge part of the high-lift system or the ice protection system resulting in increased complexity and the participation of even more disciplines. The limited space is depicted in figure 2, where the suction system and instrumentation for the flight test of the Do 228 test vehicle is shown (although more complex than necessary due to the testing of different anticontamination devices as well as different ice protection systems). In section 2 , the research methodology is explained, section 3 explains the fundamental aerodynamics behind laminar flow control systems, section 4 gives overview of the HLFC system design and issues, and 
section 5 covers the progress made so far with emphasis on various analytical studies and flight tests that have been performed throughout the World.

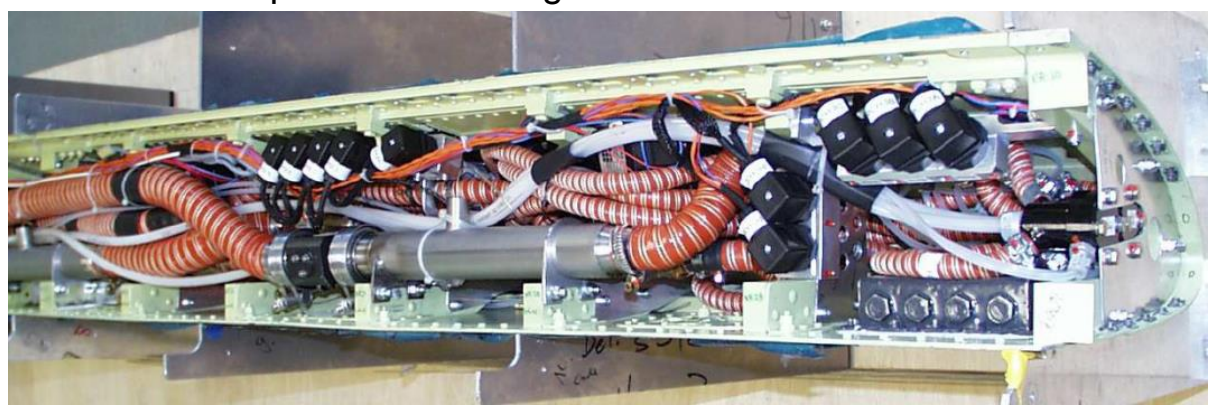

Fig 2. Leading edge of the Do 228 test aircraft equipped for HLFC flight test [83]

\section{Research Methodology}

The starting point of the literature research was the literature provided by the predecessors on the topic. Further literature was found based on the referenced sources as well as literature which referenced the already available sources using google scholar and google search. The key words "Hybrid Laminar flow control" and "laminar flow control" were utilized in the search engine. Further research papers regarding the particular topic were found, once research institutions and researchers focusing on specific tasks in the development of HLFC systems were identified. Research projects were identified through the acknowledgements in papers as well as through current project proposals mentioning other projects. For the US projects, the document server from NASA was searched regarding relevant documentation.

\section{Aerodynamic fundamentals}

\subsection{Laminar flow}

Osborne Reynolds in 1883 was the first to demonstrate two states of fluid flow, which he termed "direct" and "sinuous" but now it is respectively called laminar and turbulent [6]. In laminar flow, the fluid layers slide smoothly over each other, in a streamlined fashion, and typically occurs only under low velocity conditions. The linear dye trace in figure 3 shows that the fluid particles follow the streamline exactly in a laminar region.

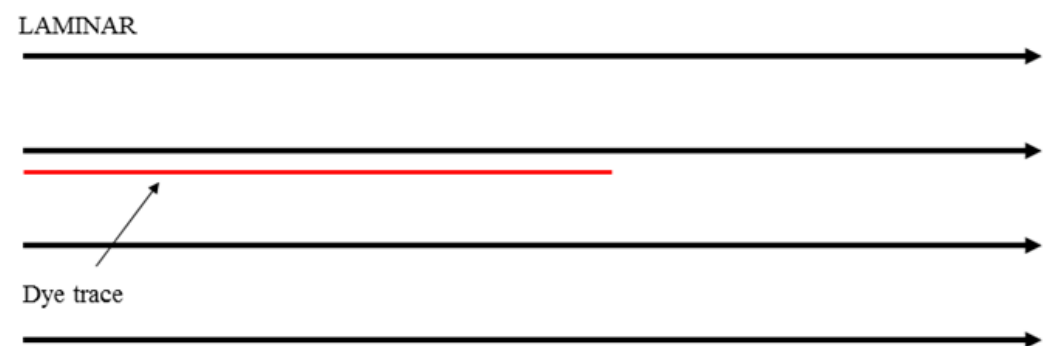

Fig 3. Dye trace in laminar flow [82]

\subsection{Turbulent flow}

Turbulent flow is a complex process, and is actually more likely to occur than laminar flow in many practical situations. It still remains the least understood area of fluid mechanics [7] 
The turbulent flow involves randomly fluctuating parameters. In turbulent flow, the fluid exhibits erratic motion, eddies of many sizes are superimposed onto the mean flow. The dye trace path in figure 4 shows that the path is dictated by both the mean flow (i.e. streamlines) and the erratic flows (i.e. eddies). These eddies cause the dye to spread laterally, and make the dye filament to diffuse across streamlines. Reynolds observed that a change from laminar to turbulent occurs whenever the velocity of flow was increased and formulated the dimensionless quantity called Reynolds number $\mathrm{Re}=\rho \mathrm{Vl} / \mu$, where $\rho$ is the density , $\mathrm{V}$ the velocity, I the length scale and $\mu$ the viscosity of the fluid. Starting at the critical Reynolds number, where the flow transitions from a laminar state into a turbulent one, the flow becomes more turbulent at higher Reynolds number.

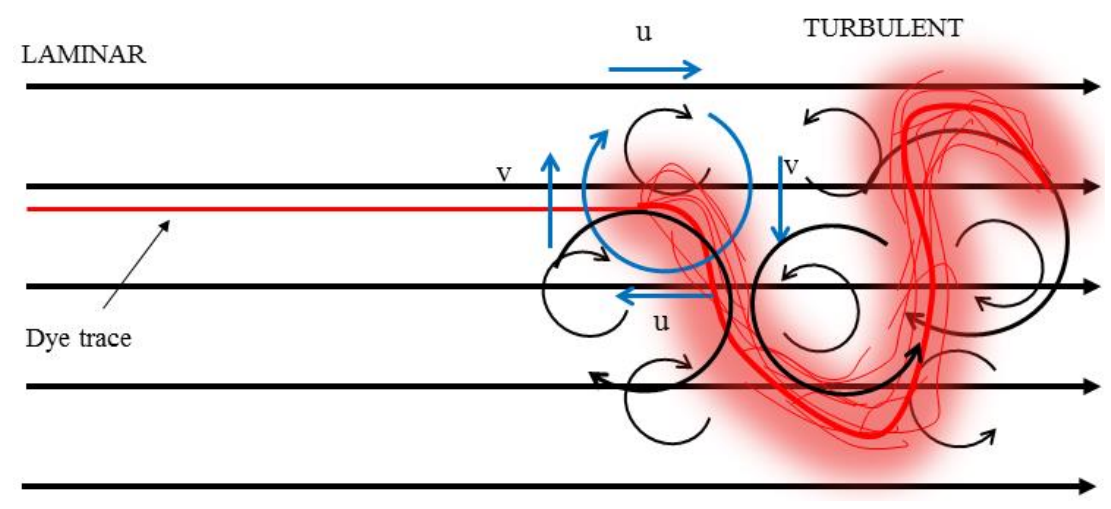

Fig 4. Dye trace in turbulent flow [82]

\subsection{Boundary layer concept}

The concept of boundary layer was first proposed by Prandtl in the year 1904 in the city Göttingen. He argued that fluid flow consists of two parts: flow closer to the surface (viscous part) and the flow away from the surface (inviscid part). In the thin boundary layer closer to the surface, viscous forces (effects of friction) are dominant. Outside the boundary layer the flow is inviscid as shown in figure 5. The hypothesis of the adhesion of the fluid to the walls, or zero relative velocity between fluid and wall gave a very satisfying explanation for the process in the boundary layer [8].

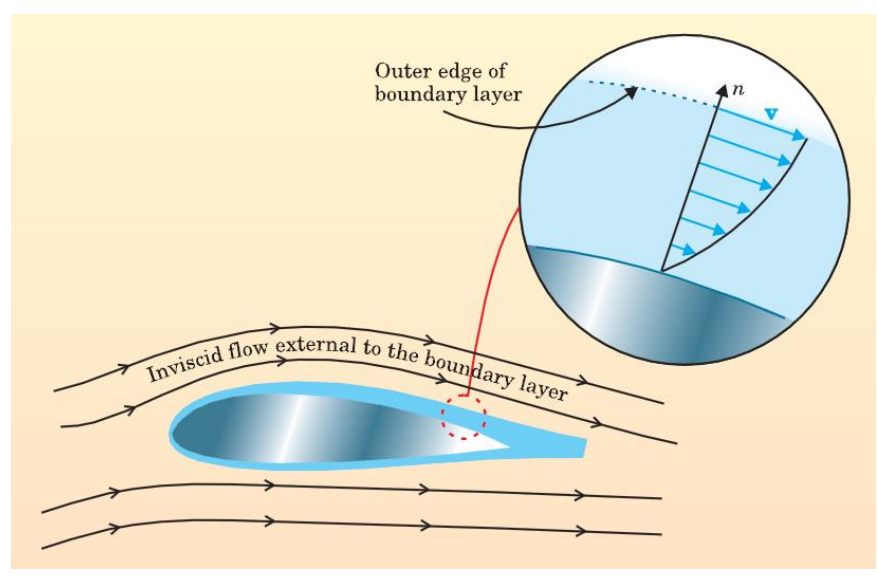

Fig 5. Fluid flow over an airfoil surface consisting of two parts [77]

The characteristic velocity profiles through the laminar and turbulent boundary layers are shown in figure 6 , where $y$ is the distance from the wall scaled by the boundary layer 
thickness $\delta, u$ is the velocity scaled by the velocity outside the boundary layer $U, \tau$ is the shear stress and $\mu$ the absolute viscosity. It can be seen that the velocity gradient is greater in the turbulent flow, the shear stress $\tau$, which represents the skin friction, is substantially greater in the turbulent layer [6].

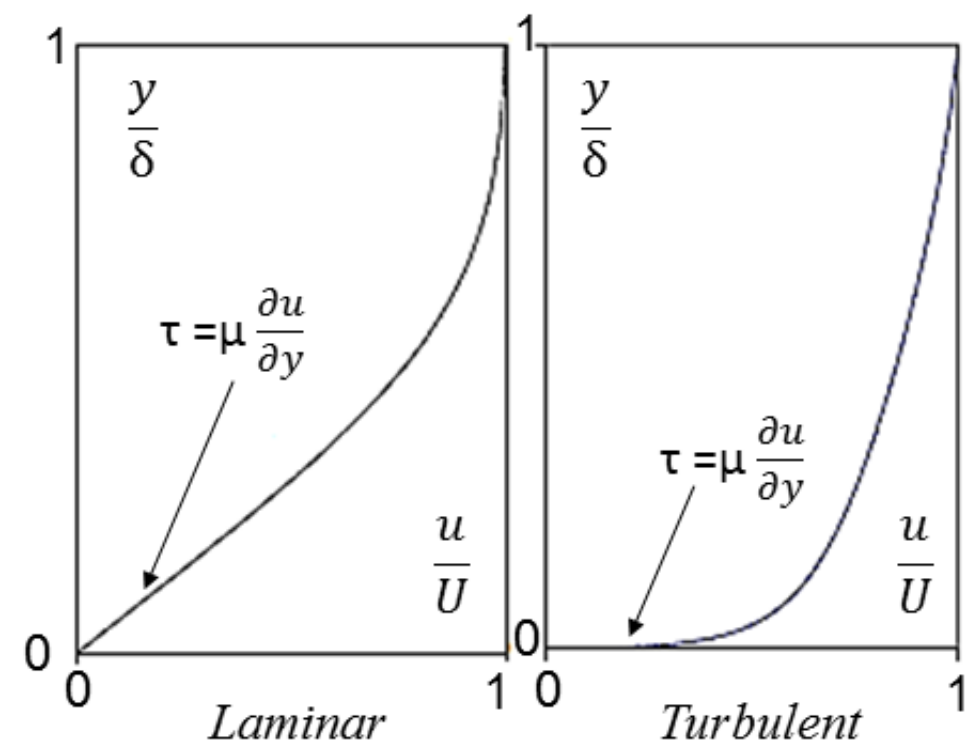

Fig 6. Laminar and turbulent boundary layer velocity profiles [6]

\subsection{Laminar Turbulent transition}

Reynolds in his experiment observed that the flow characteristics changes from laminar to turbulent whenever the critical value of Reynolds number is reached.. The transition from laminar to turbulent occurs whenever there is an instability caused in the flow, as represented in Figure 7.

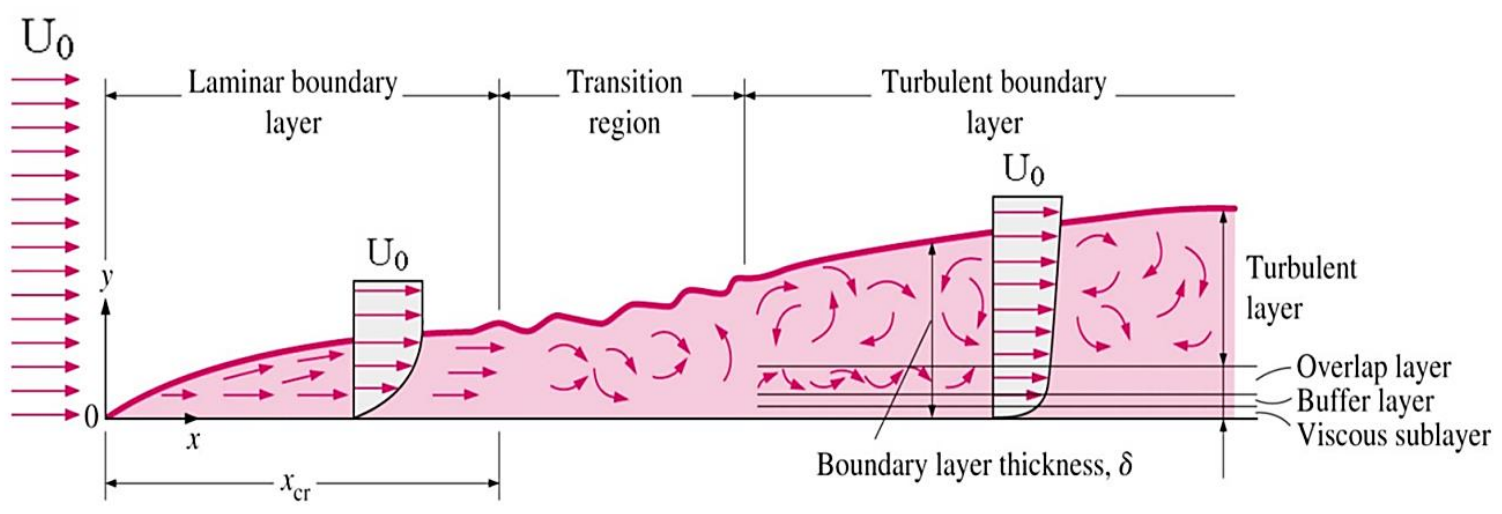

Fig 7: Laminar to turbulent transition (from [9])

Instability mechanisms which are mainly responsible for the laminar - turbulent transition are:

- Tollmien-Schlichting instability:

Tollmien in 1929 and Schlichting in 1932 discovered convective traveling-wave instabilities. This instability (Figure 8 ) typically occurs in the mid-chord region, the 
viscosity plays a major role in determining the stability limits. This wave can be visualized by imagining the water waves created as pebbles thrown in a lake [2]. The boundary-layer flow is similar to the water waves, except that under certain critical parameters such as Reynolds number, this wave (instability) grows in strength, which leads to turbulent flow.

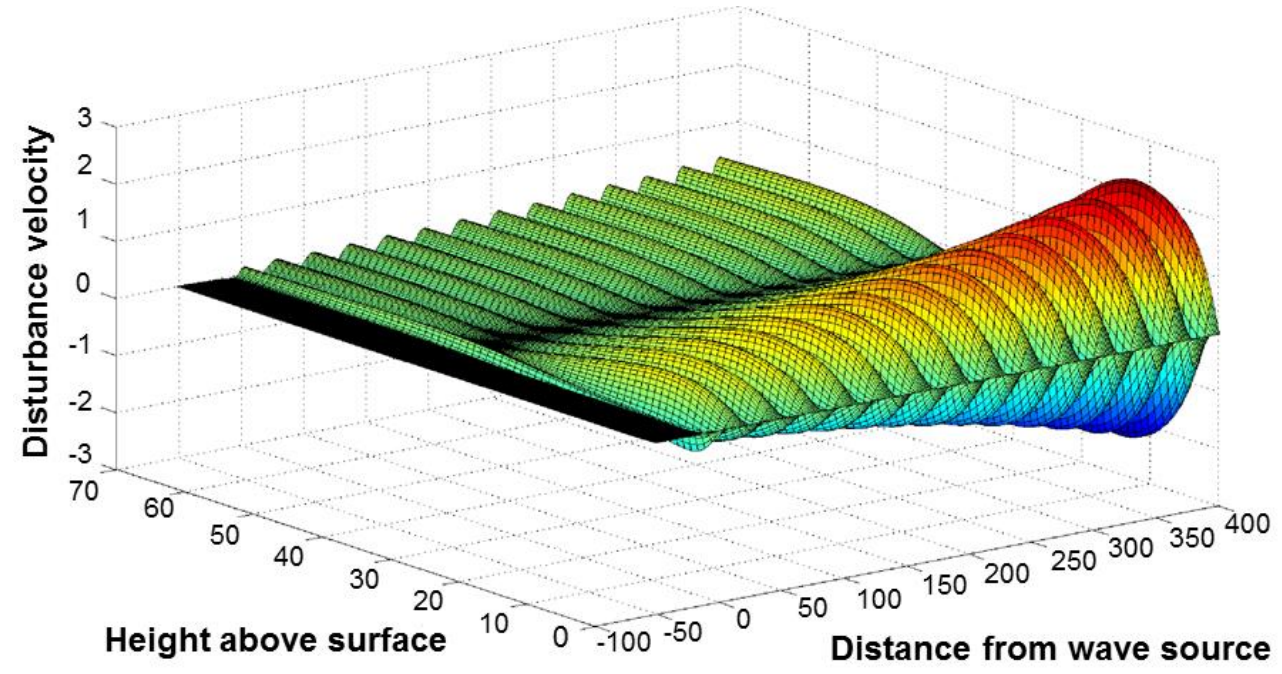

Fig 8: Tollmien-Schlichting waves (Image courtesy: [10])

- Crossflow (CF) instability:

This phenomenon was discovered during early work on the flow over swept wing aircraft, and is characterized by co-rotating vortices as shown in Figure 9. The CF instability occurs in the strong pressure gradient regions on a swept wing. The combination of pressure gradient and wing sweep deflects the inviscid-flow streamlines inboard. At a certain sweep angle, the transition moves upstream suddenly near the leading edge. This three dimensional effect make the design of swept wings complex, as the CF is extremely sensitive to the sweep angle [11]. This also means a good laminar airfoil in two-dimensional flow can have very poor laminar properties when it has particular sweep angle. The suction through perforated walls is an efficient means to avoid CF.

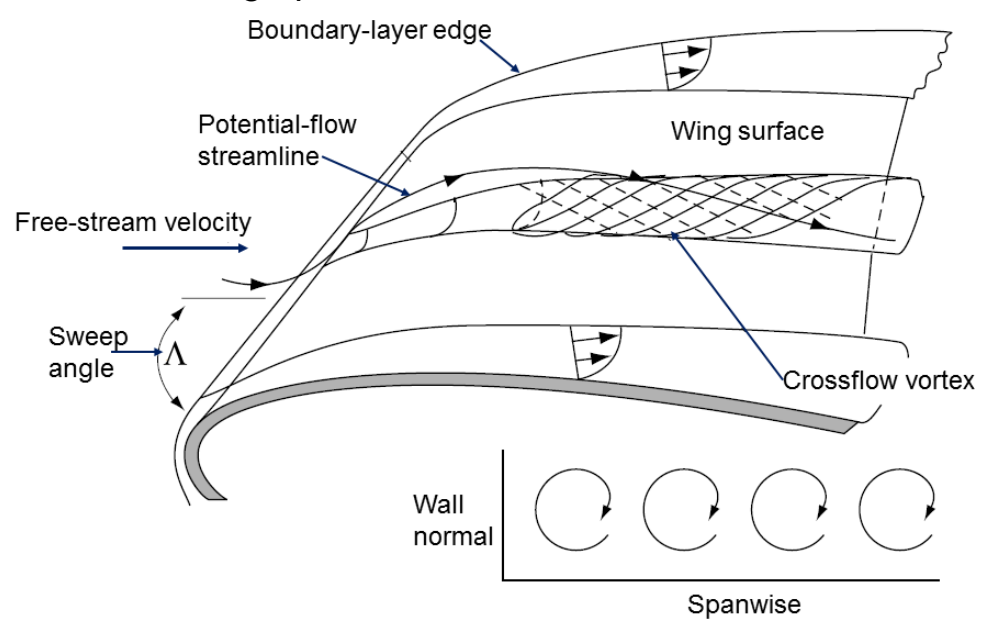

Fig 9: Sketch of Crossflow vortices over swept wing [2] 
- Attachment line transition:

The transition is also triggered whenever there is leading edge contamination due to the turbulence from the fuselage (Figure 10). This turbulence can sweep onto the Attachment Line $(A A)$ and engulf the whole wing in turbulence. One way to prevent such occurrence is by use of the so-called Gaster bump (Figure 11), which acts as turbulence diverter protecting the remaining wing from the turbulent fuselage. The test article shown in Figure 11 is a modified JetStar airplane [12].

In case of HLFC application, strong suction can be applied at the fuselage-wing juncture to prevent Attachment Line contamination.

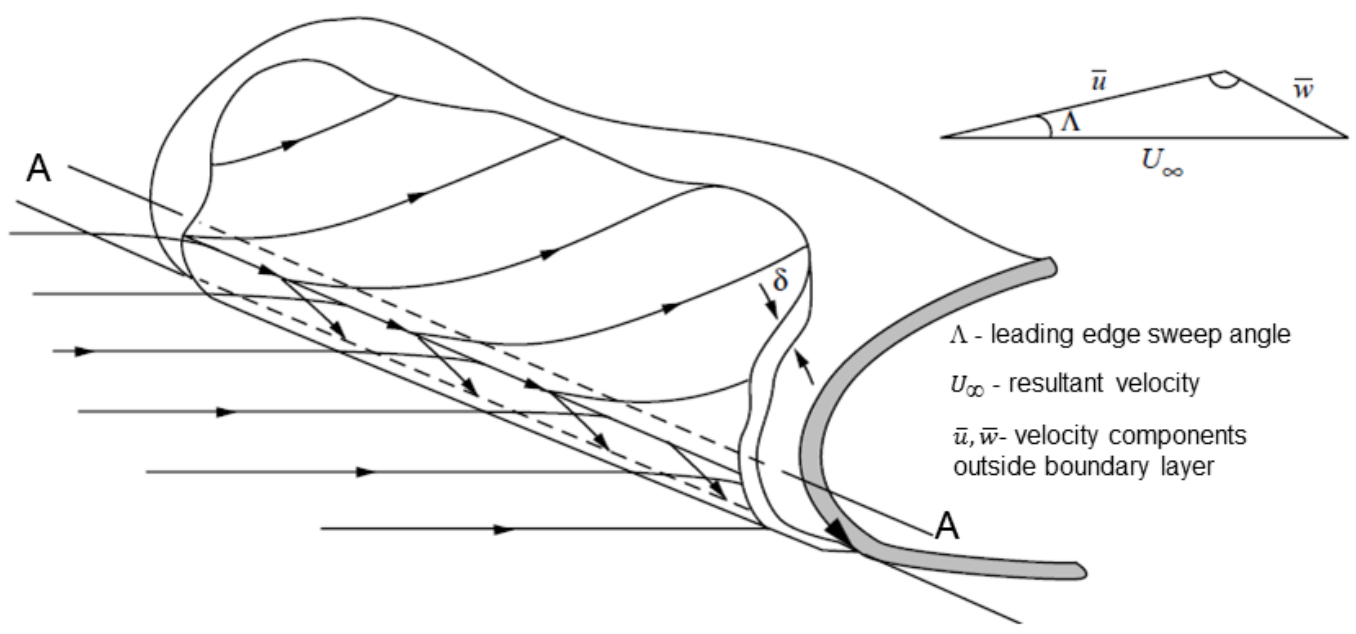

Fig 10: Attachment Line flow sketch over leading edge due to interference from fuselage turbulence [2]

Front View

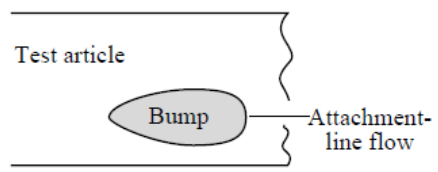

Top View

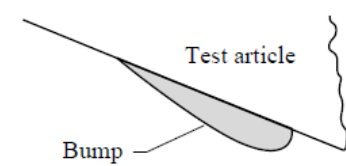

Gaster bump
Side View

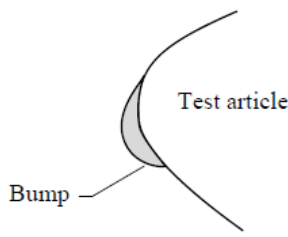

Fig 11: Device used to prevent Attachment Line contamination [2]

\subsection{Transition Prediction Methods}

The transition prediction is very complex and involves various mechanisms which depend on the applied scenario. Since it involves the prediction of start of turbulent flow, it gets complicated as the turbulence phenomenon is still not well understood. The development of robust and reliable transition models is still a challenging task. The recent advancements in high performance computing enable the usage of powerful simulation tools for research and design in these areas. Over the years, there was a considerable growth in the field of transition prediction methods, which can be categorized broadly into three types.

A. Stability theory approach 


\section{B. Statistical modelling approach \\ C. DNS and LES transition simulations approach}

\section{A. Stability theory approach:}

The stability theory mainly deals with the disturbance sine waves propagating in the boundary layer parallel to the wall, which are essentially Tollmien-Schlichting (T-S) waves [13]. In the freestream, these disturbances die off exponentially, and the amplitudes are small, so that the linear stability theory could be applied. In principle, the sinusoidal disturbances are introduced into the Navier-Stokes equation to compute the unstable frequencies [14].

One of the most standard transition prediction methods based on the linear stability theory (LST) is the $\mathrm{e}^{\mathrm{N}}$ method. It was developed by Smith and Gamberoni [15] and van Ingen [16]. This method is proven to be successful for transition prediction in case of two and three dimensional boundary layers. The steps involved in the $\mathrm{e}^{\mathrm{N}}$ method [17] consist of:

- accurate computation of mean boundary layer profiles,

- computation of linear amplification rate by an appropriate stability model and

- integration of growth rate from the onset of instability $x_{0}$ to the transition location $x_{T}$.

The value of the integration from $x_{0}$ to $x_{T}$ is equal to the exponent in $e^{N}$ and is called the "N-factor". It is computed by considering the disturbances in the form of monochromatic waves, but in reality, these disturbances occur in the form of "wave-packets".

Limitations of the $e^{N}$ method include inability to predict transition when non-linear effects like cross-flow, surface roughness induced transitions are involved. The nonlinear effects are completely ignored in this method. This aspect was reflected in the uncertainty faced in the Boeing 757 HLFC flight tests [18], as explained later in section 5.1. The LST transition prediction methods are quite unsatisfactory for use in swept wing flows. There was a need for another strong method to predict especially the Crossflow disturbances. The Harmonic Linear Navier-Stokes (HLNS) method [19] was found significant for this purpose. The HLNS method involves the following steps:

- Expansion about a steady based flow and substitution in the three dimensional Navier-Stokes equation

- The disturbance equation is then formulated which is important for initial stages of computation

- The equations are formulated in the form of a block penta-diagonal system

- The system of equations is solved using standard recursion

In spite of the above mentioned drawbacks, the $e^{N}$ method is the most suitable for practical industrial applications. Another method which is also based on linear theory and includes the weakly non-linear effects is the Parabolized Stability Equation (PSE) method, proposed by Herbert and Bertolotti [20].The disturbances are represented as double Fourier expansions containing discrete normal modes which are both two and three dimensional. The PSE equation system consists of coupled equations with initial and boundary conditions. Though robust and providing good understanding of weakly 
non-linear instabilities, the PSE method fails to address strong non-linear instabilities [14] and onset of transition prediction in three dimensional flows in practical applications.

\section{B. Statistical modelling approach:}

The basis of the statistical modelling approach was laid down by Emmons [21] and Dhawan and Narasimha [22]. Some of the important methods using this approach include the low Reynolds number turbulence models, intermittency transport method and laminar fluctuation energy method.

The low Reynolds number turbulence model for transition simulation was based on the wall damping capability in the boundary layers [23]. These models are developed mainly to address turbulence aspects which occur at low Reynold's numbers due to diffusion effects in the freestream, such as bypass transition. The transition prediction was considered during calibration in many low Reynolds number models [24] including k$\omega$ model [25] k- $\varepsilon$ model [26] and Leylek's transition model [27]. These models suffer a close interaction between transition capability and viscous sublayer modelling which prevents to model both these phenomena independently. Also, none of the above mentioned turbulence models were able to give reliable results for any randomly chosen Reynolds number [24].

The intermittency concept introduced by Dhawan and Narasimha [22] is based on the fluctuating nature of the flow between laminar and turbulent regimes. This is confirmed in many detailed investigations of the transition process. This means that the flow becomes intermittent and alternates. To study the physical nature of such a flow, the intermittency factor $y$ was introduced, which is the fraction of time in which the flow remains turbulent during the transition phase. This factor can be determined by algebraic models [28], or by transport equation [29, 30]. The start and evolution of transition can be imposed by setting the intermittent factors from zero to unity. The drawback of this approach for transition prediction is that, it neglects the interaction between turbulent and non-turbulent flows during transition. Nevertheless, the intermittency concept coupled with globally averaged Navier-Stokes offer flexibility and the statistical modelling method is the most suitable for computation and modeling complex flows with transition.

The bypass transition can also be caused due to high amplitude streamwise fluctuations. Another approach based on this concept was first proposed by Walters and Leylek [27]. These streamwise fluctuations were called laminar kinetic energy denoted by $K_{L}$. It was first proposed by Mayle and Schulz [31], and hence this approach for transition modelling was called the laminar kinetic energy or laminar fluctuation energy method. Another type of energy in the near wall region called the turbulence energy can be divided into large scale energy and small scale energy [24]. The small scale leads to turbulent production and the large scale mostly contributes to non-turbulent fluctuations or laminar fluctuations $\left(K_{L}\right)$. The onset of transition in the Walters and Leyleks model was determined by the parameters such as kinetic eddy viscosity, the wall distance and a turbulent kinetic energy parameter.

The drawback of using the laminar fluctuation energy approach is that in fully turbulent flows, the calibration will affect the result, and also this model is not flexible for many different transition mechanisms and industrial applications. 
C. DNS and LES transient simulations approach:

In principle, using the Direct Numerical Simulation (DNS) approach the laminar flow breakdown, the development of turbulent spots and the transition to turbulent flow can be accurately simulated [24]. Also, DNS solves the full unsteady Navier - Stokes equation. A big advantage of DNS approach is that there is no requirement of closure by a turbulence model, as there is no averaging of Reynold's number. However, DNS requires very fine grid for its computation. Therefore the computational costs are really high and also very high performance computing is required for performing calculations. Even simple geometries require a very fine grid [32] and hence the DNS cannot be applied to engineering applications involving complex geometries, as the computational costs are very high. This limits the DNS approach to research purposes only.

The LES is an alternate approach to DNS with reduced computational costs. In LES computations, the large scale eddies are fully solved and using the Smagorinsky's eddy viscosity approach [33], the small scale eddies are modelled [24]. The main drawback in the LES is the over dependency on the Smagorinsk's constant, because it is used for the calibration of sub-grid eddy viscosity. Nevertheless, this problem is encountered using Germano's dynamic sub-grid model [34], which nullify the effects of sub-grid eddy viscosity.

One of the main advantages of the DNS and LES based approaches over others is their applicability to many different problems. Unlike other approaches, DNS is capable of simulating many types of transition simulation such as bypass transition, natural transition and separation-induced transition. The various transition prediction methods with their uses and limitations are summarized in Table 1. 
Table 1: Summary of various transition prediction methods

\begin{tabular}{|c|c|c|}
\hline $\begin{array}{l}\text { Transition } \\
\text { Prediction } \\
\text { Methods }\end{array}$ & Uses / Benefits & Drawbacks / Limitations \\
\hline $\mathrm{e}^{\mathrm{N}}$ method & $\begin{array}{l}\text { - Proven method for successful } \\
\text { transition prediction for 2D and } \\
\text { 3D boundary layers. } \\
\text { - Most suitable method for } \\
\text { industrial applications. }\end{array}$ & $\begin{array}{l}\text { - Non-linear mechanisms are not } \\
\text { accounted for. Hence, the } \\
\text { transition caused by non-linear } \\
\text { effects cannot be predicted. } \\
\text { - It has got compatibility issues with } \\
\text { most CFD methods. }\end{array}$ \\
\hline PSE method & $\begin{array}{l}\text { - Non-linear mechanisms are } \\
\text { taken into account. } \\
\text { - Less time consuming than DNS } \\
\text { method } \\
\text { - Numerically robust code, so } \\
\text { applications can include } \\
\text { practical (non-ideal) cases. }\end{array}$ & $\begin{array}{l}\text { - Some strong non-linear } \\
\text { instabilities are not taken into } \\
\text { account in this method. } \\
\text { - Predicting transition in 3D flows is } \\
\text { difficult, since growth of } \\
\text { disturbance amplitude is difficult } \\
\text { to calculate along the streamlines. }\end{array}$ \\
\hline $\begin{array}{l}\text { Low Reynolds } \\
\text { number } \\
\text { turbulence } \\
\text { models }\end{array}$ & $\begin{array}{l}\text { - Useful in simulating bypass } \\
\text { transition due to diffusion } \\
\text { effects in the freestream. }\end{array}$ & $\begin{array}{l}\text { - Results obtained are sensitive to } \\
\text { boundary conditions, grid } \\
\text { resolution etc. }\end{array}$ \\
\hline $\begin{array}{l}\text { Intermittency } \\
\text { transport method }\end{array}$ & $\begin{array}{l}\text { - Used in special purpose } \\
\text { turbomachinery codes. }\end{array}$ & $\begin{array}{l}\text { - Not used in general CFD codes } \\
\text { due to the evaluation of boundary } \\
\text { layer thickness and free stream } \\
\text { conditions by non-local operations } \\
\text {. }\end{array}$ \\
\hline $\begin{array}{l}\text { Laminar } \\
\text { fluctuation } \\
\text { energy method }\end{array}$ & $\begin{array}{l}\text { - This method needs only local } \\
\text { flow quantities for transition } \\
\text { prediction and is validated } \\
\text { based on low Reynolds } \\
\text { number } \mathrm{k}-\varepsilon \text { model. }\end{array}$ & $\begin{array}{l}\text { - In fully turbulent flows, the } \\
\text { transition model gets affected by } \\
\text { calibration. } \\
\text { - The flexibility is not good enough } \\
\text { for wide range of transition } \\
\text { mechanisms and practical } \\
\text { applications. }\end{array}$ \\
\hline $\begin{array}{l}\text { Direct Numerical } \\
\text { Simulations } \\
\text { (DNS) }\end{array}$ & $\begin{array}{l}\text { - This method fully solves the } \\
\text { unsteady Navier-Stokes } \\
\text { equation } \\
\text { - It doesn't require any } \\
\text { turbulence models unlike other } \\
\text { methods } \\
\text { - It has the ability to simulate the } \\
\text { entire transition process and all } \\
\text { kinds of transition processes. }\end{array}$ & $\begin{array}{l}\text { - It requires very fine mesh to } \\
\text { capture turbulent flows in small } \\
\text { scale. } \\
\text { - High computing costs which } \\
\text { prohibits its usage in practical } \\
\text { applications at high Reynolds } \\
\text { number. }\end{array}$ \\
\hline $\begin{array}{l}\text { Large Eddy } \\
\text { Simulations } \\
\text { (LES) }\end{array}$ & $\begin{array}{l}\text { - Reduced computational costs } \\
\text { when compared to DNS } \\
\text { method. } \\
\text { - Used in academics as research } \\
\text { tools. }\end{array}$ & $\begin{array}{l}\text { - This method is very sensitive to } \\
\text { the value of the Smagorinsky } \\
\text { constant which is used to } \\
\text { calibrate subgrid eddy viscosity. } \\
\text { - }\end{array}$ \\
\hline
\end{tabular}




\section{HLFC System design review and issues}

To laminarise the flow over wing, horizontal or vertical tail plane and engine nacelles, different technologies are possible. They all have one aspect in common: in order for the flow to stay laminar, the surface quality regarding manufacturing tolerances (steps, gaps and overlap) and roughness has to be very high since even insect residues greater than a critical height can transition the flow from laminar to turbulent. This also restricts the size of steps, gaps and overlaps for laminar joints [35].

First of all, the flow can be laminarised by shaping the respective geometry - this is called Natural Laminar Flow. Schrauf [36] states that by applying a suitable pressure gradient to a NLF glove of a Fokker F100 aircraft, laminarity can be achieved as long as the leading edge sweep angle stays below $23^{\circ}$, the Mach number does not exceed 0.75 and the Reynolds number is less than $25 \cdot 10^{6}$. Above those values, Crossflow instability as well as Attachment Line instability become dominant and cannot be controlled anymore by merely shaping the geometry [37].

For higher flight Reynolds numbers as well as wing sweep angles, Laminar Flow Control by means of suction through discrete slots or a continuously perforated outer skin can be applied to the geometries to laminarise the flow by influencing the boundary layer. With this technology, the flow can be laminarised over the whole chord of the respective geometry because the aerodynamic instability mechanisms, which usually trigger the transition from laminar to turbulent flow, are damped. On the other hand, a LFC suction system adds additional mass, power consumption and complexity to the aircraft. Furthermore, structural issues arise when interfering with the wing box and available space for fuel in the wings is decreased [38].

A combination of the two mentioned techniques is called Hybrid Laminar Flow Control. It combines suction at the leading edge of the geometries (up to the front spar at $10-20 \%$ of the chord) to decrease Crossflow and Attachment Line instabilities with a favorable pressure gradient for the remaining airfoil. This simplifies the suction system and thus decreases the weight, power consumption as well as maintenance requirements compared to a full LFC suction system. Furthermore, structural issues are avoided since the suction system does not interfere with the wing box section. On the other hand, it is usually not possible to keep the flow laminar over the whole chord. Still, the airflow can be laminarised to more than $50 \%$ of the chord length upon a suitable pressure gradient. Figure 12 depicts schematically the difference between the flows over a conventional turbulent wing, a NLF wing, a LFC wing and finally over a HLFC wing [35]. 


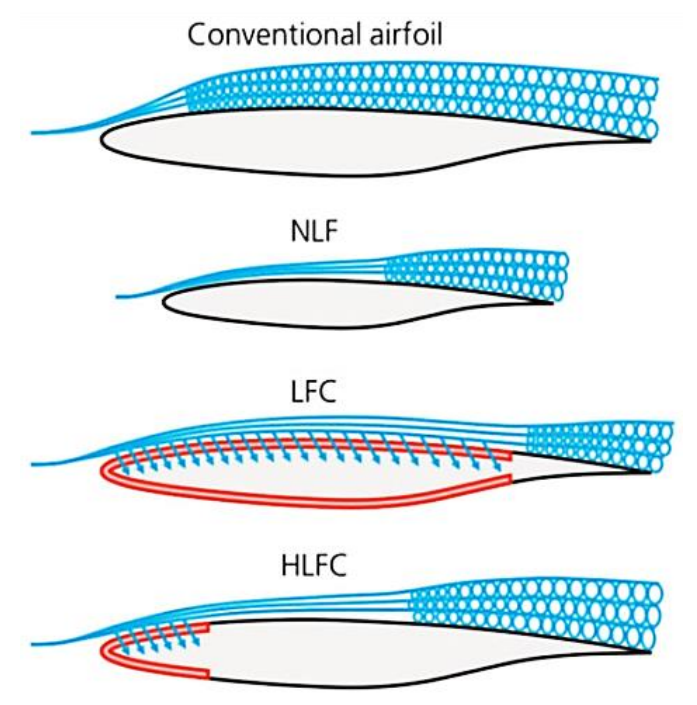

Fig 12: Schematic difference between NLF, LFC and HLFC [81]

The HLFC system design is a highly multidisciplinary approach. Disciplines like the aerodynamics, structures, manufacturing, systems as well as flight dynamics and overall mission evaluations have to work together to maximize the benefits of the HLFC system and to fulfill the customer needs/requirements. For efficient cooperation, interfaces between the disciplines have to be specified and formats for data exchange need to be defined. Figure 13 depicts the inputs to the systems discipline from several other involved disciplines and the generated outputs in the preliminary HLFC design phase. The output form systems serve as input to the overall aircraft assessment.

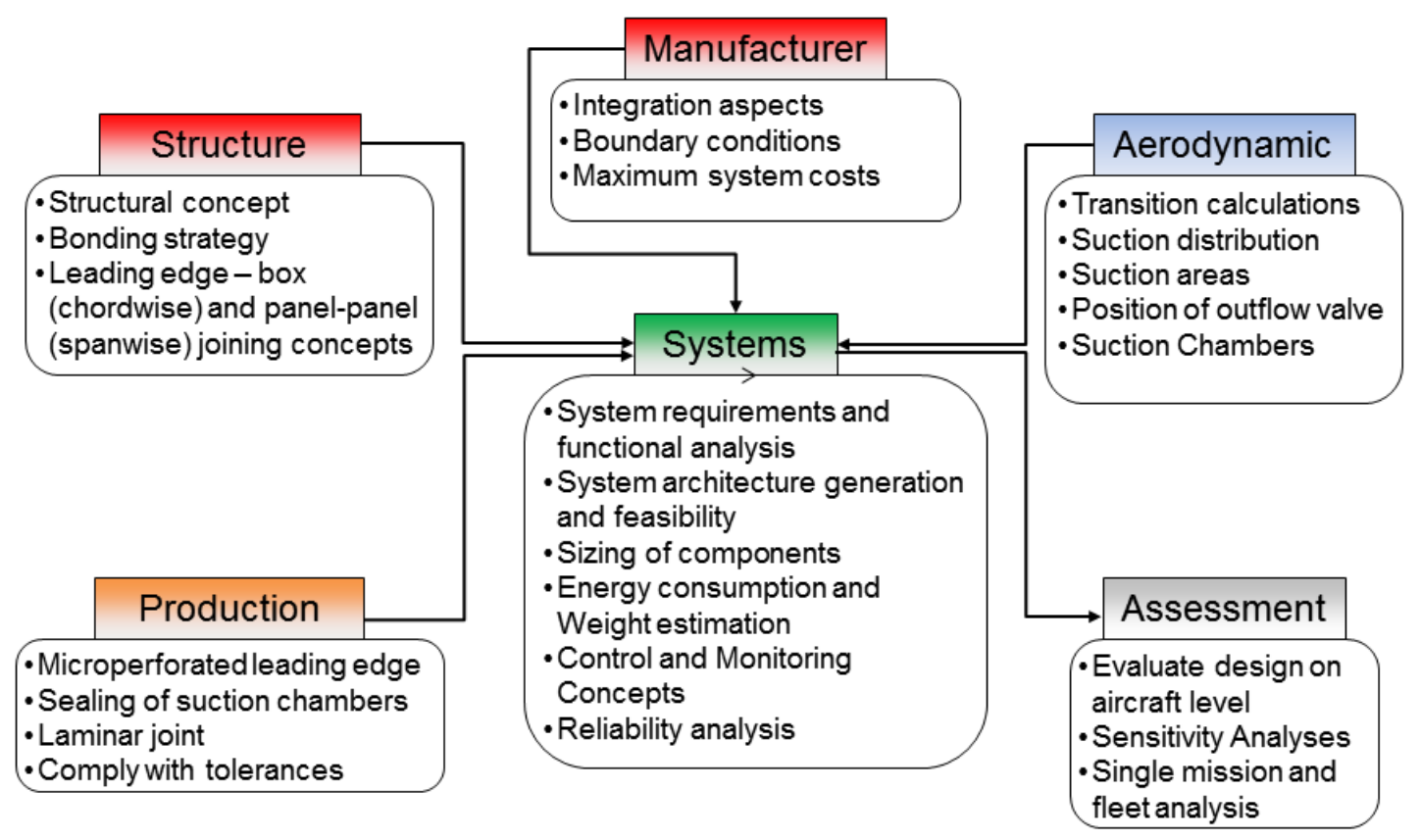

Fig 13: Inputs to systems engineering and generated outputs during preliminary design phase 
The HLFC system consists of various sub-systems as shown in figure 14.

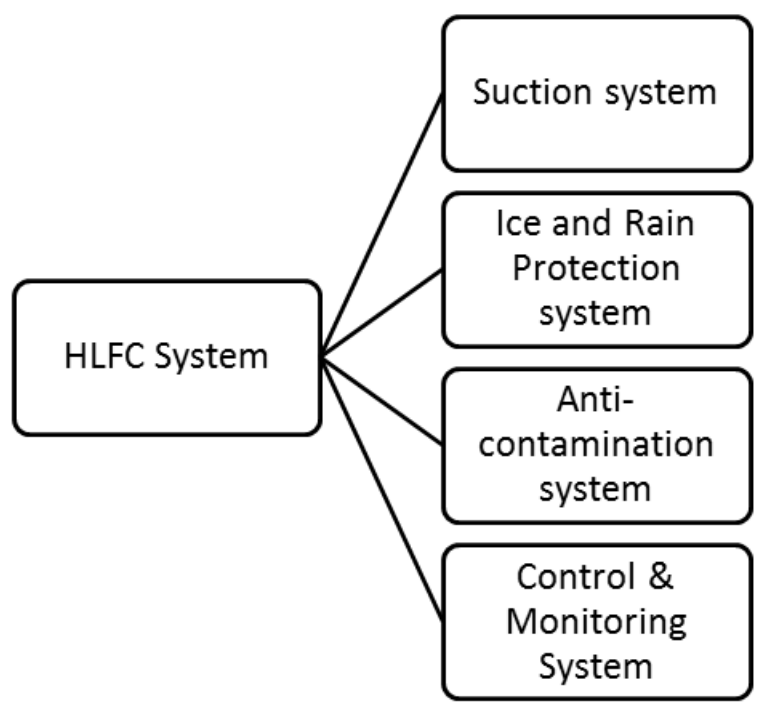

Fig 14: HLFC system breakdown

The following sub-sections reviews each sub-system in detail with some emphasis on the safety and reliability aspects, as it plays an important role in the systems development.

\subsection{Suction system}

Besides other methods to laminarise the flow over airfoils, laminarising it by suction has been under investigation for quite some time and seems to be the most favourable method for fast flying airplanes with a conventional (swept wing) configuration. By removing air from the boundary layer e.g. through a perforated surface, its velocity profile is modified which improves the stability. Furthermore, the boundary layer thickness is reduced which also positively influences the associated Reynolds number [39]. This chapter focusses on more recent advancements in the design and calculation of the suction system parameters. For a historic overview, references [1,2 and 39] are recommended. Young [35] covered many topics addressed in this report up to the year 2002 and is also recommended for further details.

To remove air from the boundary layer, the respective surface can either be slotted or perforated, allowing air to flow through it in case of an existing pressure difference between the surface and the chamber underneath the surface. After the air passes the surface, it has to be channelled and guided to an outflow position or to an aircraft system which utilises the air. The necessary pressure difference between the outside flow and the suction chambers can either be achieved by an active system using a turbo-engine (like a compressor driven by an electric motor or a jet engine driven by bleed air) or by a passive system using the natural pressure difference between the outflow and inflow position.

The active architecture has been under investigation for a long time for aircraft wings, tail planes and engine nacelles and its effectiveness has been proven in several wind tunnel as well as flight test trials (see section 5). Its advantage in contrast to a passive system is a presumably higher laminar efficiency on the account of increased system weight, power consumption as well as maintenance cost and complexity. Nevertheless, the actual 
difference between a heavier but more effective complex active system and a simpler less effective passive system has not yet been evaluated.

The passive architecture has yet mainly been investigated for the horizontal and vertical tail plane. According to several news articles, Boeing most likely applied a passive suction system, which was patented under the number US 7866609 B2 (date of patent: $11^{\text {th }}$ of January 2011), in combination with a door assembly, which was patented under the numbers US 8245976 B2 (date pf patent: $21^{\text {st }}$ August 2012) and US 8484894 B2 (date of patent: $16^{\text {th }}$ of July 2013) to the Boeing 787-9 aircraft for the first time in commercial airline history as shown in Figure 15 and 16 [40]. The suction is achieved by opening the door assembly. As the door opens, a suction force is applied on the porous surface, which draws portion of the boundary layer through the pores, thereby delaying transition. The door assembly is deemed to be powered by an actuator. Schrauf [41] states that Airbus wants to flight test a simplified passive suction system on the middle leading-edge box of the VTP of an Airbus A320 aircraft in the context of the European AFLoNext (Active Flow- Loads \& Noise control for next generation wing) project. Besides the passive system, an active system using an already certified fan is also going to be flight tested to evaluate the performance difference between the active and the passive suction system.
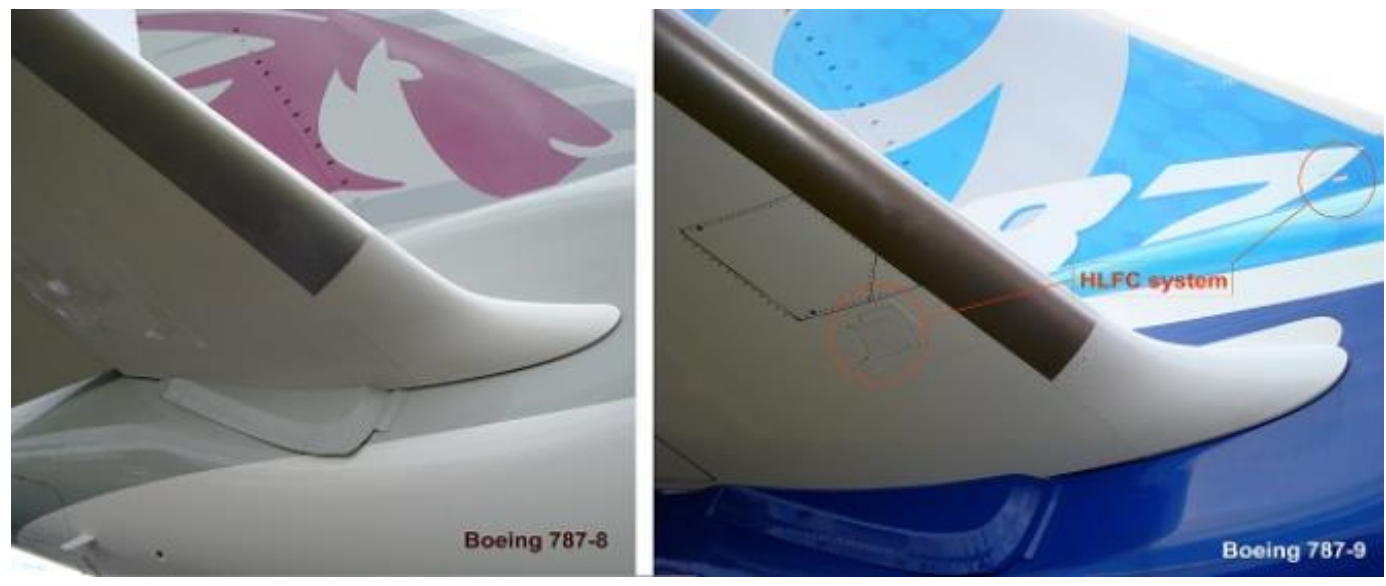

Fig 15: Difference in the VTP and HTP between the B787-8 and -9 [40]
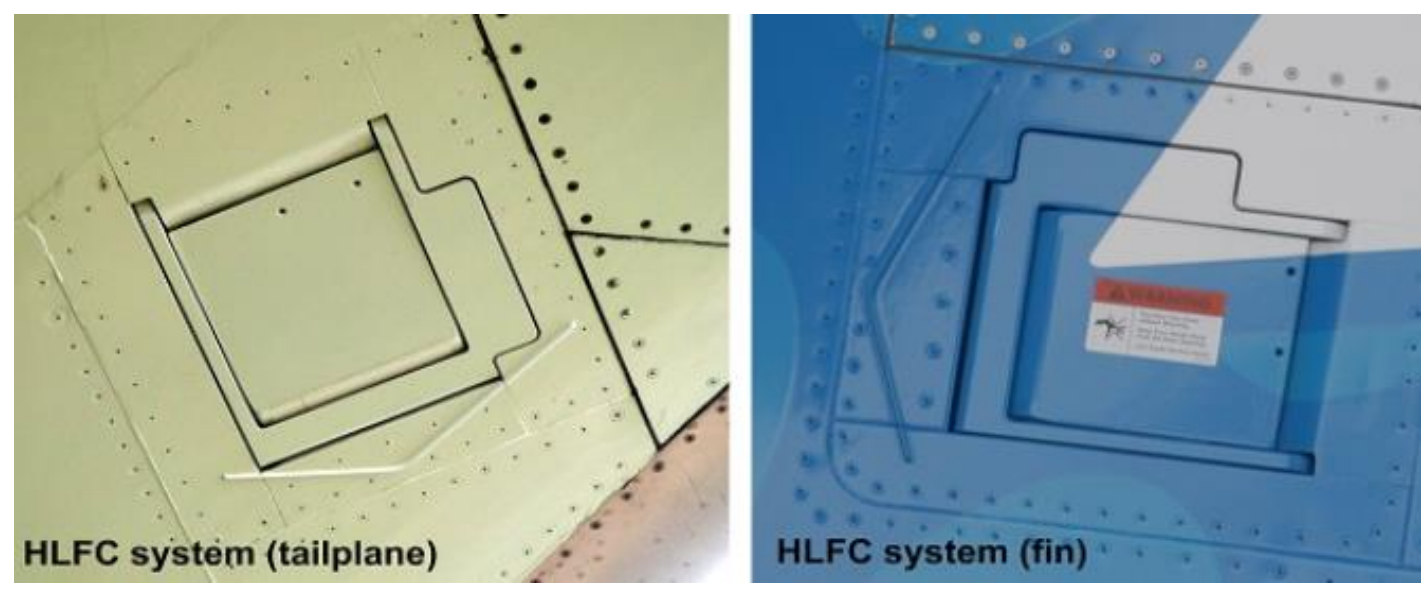

Fig 16: Close-up of the HLFC outflow position of the B787-9 [40]

In 2011, Pe performed a Synthesis and Topology Study of HLFC System Architectures in the preliminary aircraft design phase for a long-range study aircraft in the context of the 
German HIGHER-LE project [42]. He presented a sizing methodology for the estimation of component and system parameters (power consumption, mass and size) for a given active suction system architecture during the aircraft preliminary design phase, which is depicted in Figure 17. As input parameters into the system sizing methodology he specifies the wing and airfoil geometry, the pressure coefficient $C_{p}$ and the suction coefficient $C_{q}$ where

$$
\begin{aligned}
C_{p} & =\frac{p_{s}-p_{\infty}}{\frac{1}{2} \rho_{\infty} v_{\infty}^{2}} \\
C_{q} & =\frac{w_{s}}{v_{\infty}}
\end{aligned}
$$

with $p$ as the pressure, $\rho$ as the density, $v$ as the velocity, $w$ as the suction velocity through the porous surface, the index $s$ denoting the condition at the suction surface and the index $\infty$ denoting the free-stream conditions.

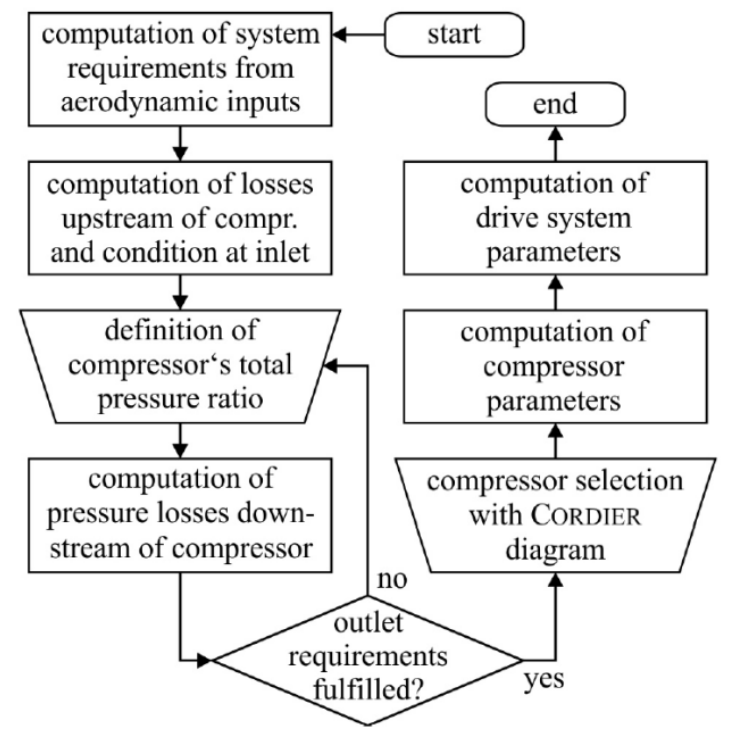

Fig 17: Flow chart of sizing methodology for HLFC suction systems [42]

The main step in the design of an active and electric HLFC suction system is the preliminary sizing of the compressor, which is usually done using the Cordier-Diagram [42]. The compressors are sized through internal pressure losses in the ducting network and plenum chambers as well as the requirements at the suction surfaces and at the system outlet. Therefore, all pressure losses in the ducting network have to be estimated prior to the selection of a suitable compressor. Once the compressor parameters are known, its drive system can be designed and the overall power consumption as well as additional system mass can be estimated.

During the European ALTTA project, the simplified suction system using a single duct (for the vertical and horizontal tail plane the leading edge box can be used as the plenum chamber if it is sealed) in combination with a double structure was developed which is schematically depicted in Figure 18. The pressure loss from the suction surface(s) to the plenum chamber is the sum of the losses through the porous surface $\Delta p_{s c}$ and through the metering holes $\Delta p_{c p}$. According to Bieler [43] the losses through an electron beam drilled porous surface (conical hole geometry) can be modelled by equation 3 : 


$$
\Delta p_{s c}=A \cdot \mu_{s} \cdot w_{s}+B \cdot \rho_{s} \cdot w_{s}^{2}
$$

where A and B reflect loss characteristics, $\mu$ the dynamic viscosity, $\rho$ the density and $w$ the suction velocity. Using equation 4

$$
T_{S}=T_{\infty}+r \cdot T_{\infty} \cdot \frac{\kappa-1}{2} \cdot M a_{\infty}^{2}
$$

to calculate the temperature $T$ at the surface and estimating the density by using the ideal gas law, the flow condition at the surface is fully determined [42]. In the above formula, $r$ is the recovery factor, $\kappa$ the isentropic exponent and $M a$ the Mach number. Furthermore, a "Flowmeter" was designed at German Aerospace Center (DLR) with which it is possible, to measure the pressure drop characteristics as a function of mass flow rates for different test articles under realistic conditions with respect to outside pressure and temperature [44].

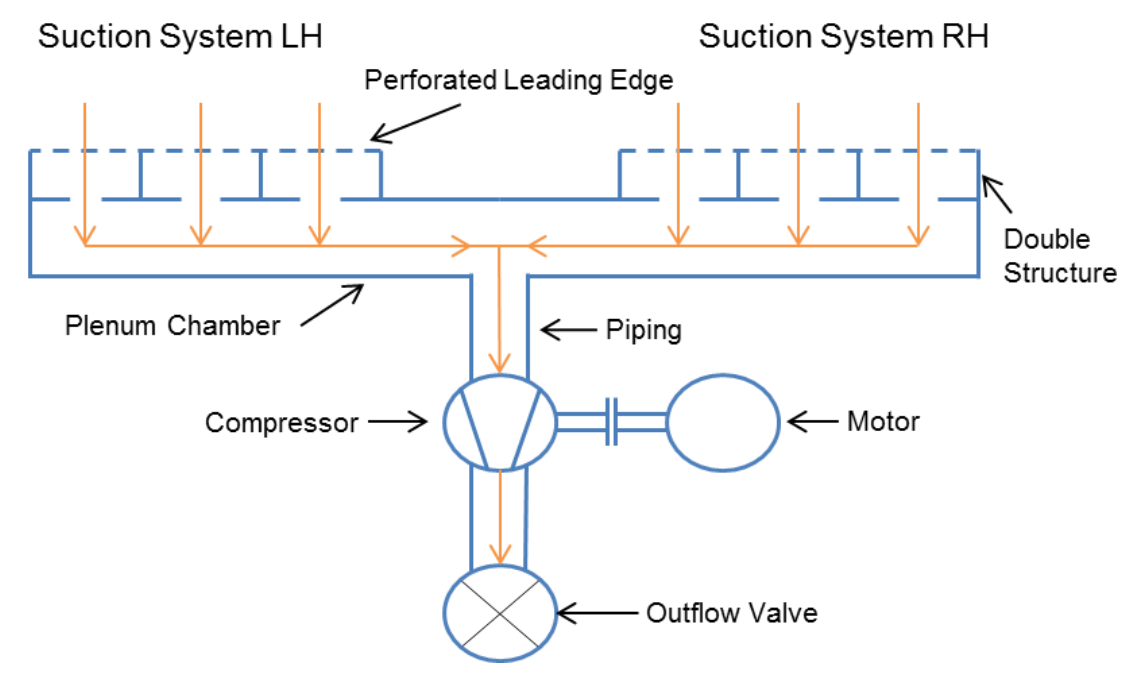

Fig 18: Schematic representation of the simplified suction system (ALTTA-concept)

$\mathrm{Pe}$ [42] also states that in the early design phases, the exact geometry of the double structure chambers and metering hole diameters is usually not yet defined. He suggests an estimation to calculate the plenum pressure $p_{p}$ with reasonable values for $\Delta p_{c p}$ :

$$
p_{p}=\min \left(p_{s}-\Delta p_{s c}\right)-\Delta p_{c p}
$$

Once the air has reached the plenum chamber, further losses have to be considered on the way to the compressor or outlet. Pe [42] suggests to divide the chamber into $\mathrm{n}$ parts, where $\mathrm{n}$ is the number of ribs the flow is passing through. In a next step he models the leading edge box with a formula for a rectangular tube, since the divergence angle of the leading edge box between two ribs is very small (see model in Figure 19). The pressure loss for each rib is calculated using the geometry depending pressure loss coefficient $\zeta$ by

$$
\Delta p_{\text {rib }}=\zeta \cdot \rho \cdot \frac{w^{2}}{2}
$$




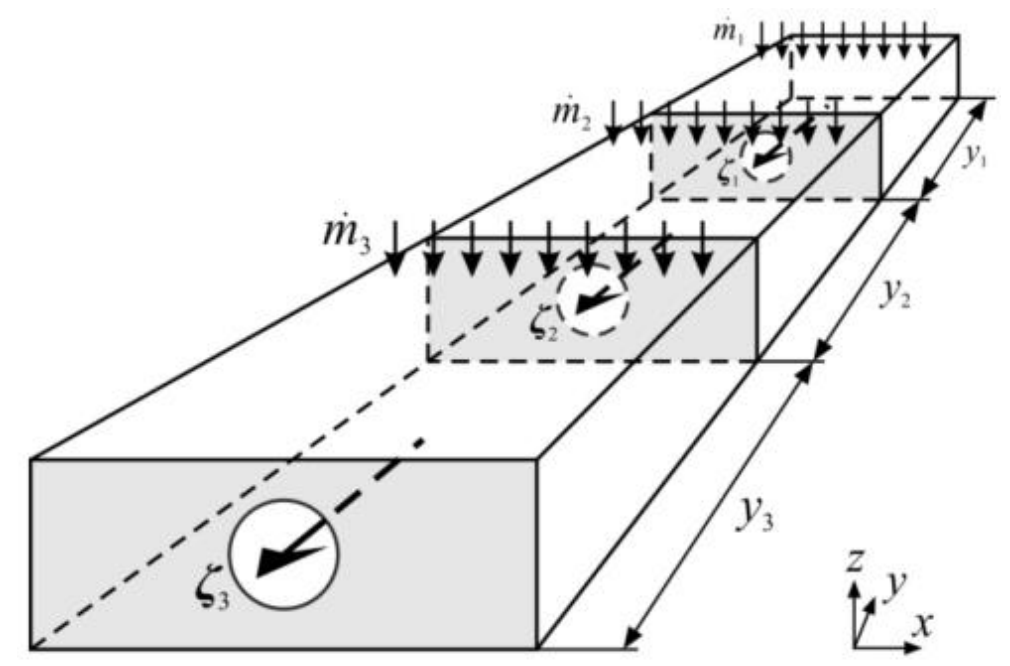

Fig 19: Pressure loss model for the plenum chamber Pe [42]

Since all pressure conditions upstream the compressor are now known, the compressor can be selected using the Cordier-diagram. The power the motor has to finally supply comes from the shaft power of the compressor divided by the efficiency of the motor as well as by the efficiency of the frequency converter. Afterwards, the compressor, induction motor and frequency converter masses have to be estimated, for example by using a linear regression analysis if previous project data is available. The mass of the ducting and the wiring result from the length as well as the surface area times a correction factor for brackets and couplings [42].

Using the above mentioned formulas for the preliminary assessment of the suction system $\mathrm{Pe}$ [42] assessed the difference in the number of compressors for the wings as well as tail planes (see Figure 20/21). He concluded that for a long-range HLFC research baseline aircraft it is most beneficial (in terms of electrical power usage and additional system weight) to have one compressor for each side of the wing as well as one compressor for all tail planes. The power consumption for the wing's one compressor design is higher than the two compressor design power consumption. The blade diameter of the compressor had to be decreased in order for the compressor to fit inside the leading edge which also decreased the efficiency of the compressor as shown in the Cordier-diagram. Nevertheless it could be advantageous to have separate compressors for the horizontal and vertical tail plane as well as multiple compressors for each side of the wing in terms of system reliability. 

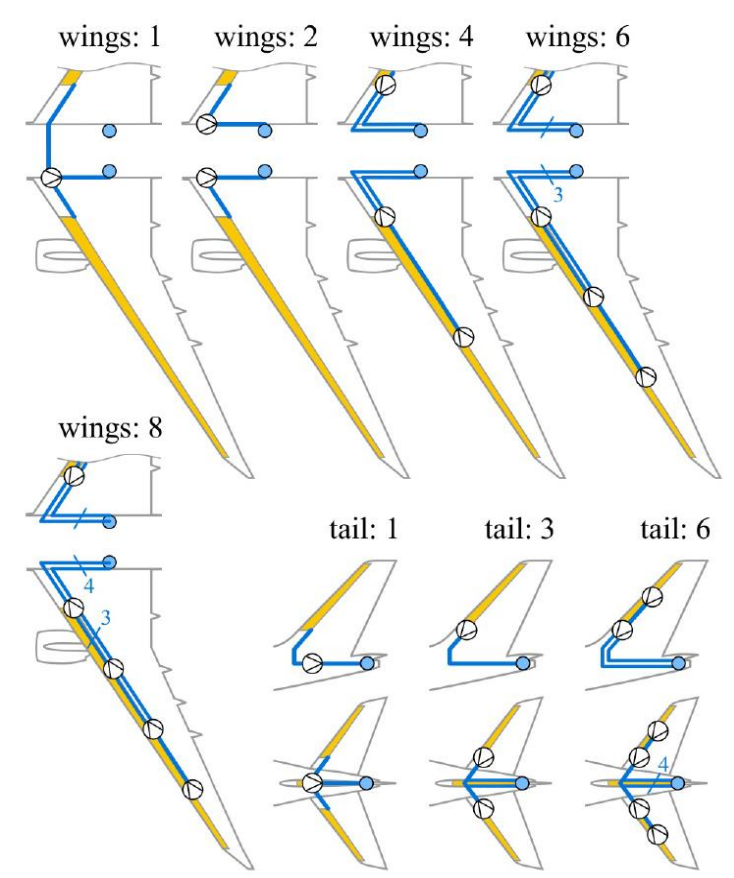

Fig 20: Suction system concepts assessed by Pe [42] for long-range aircraft
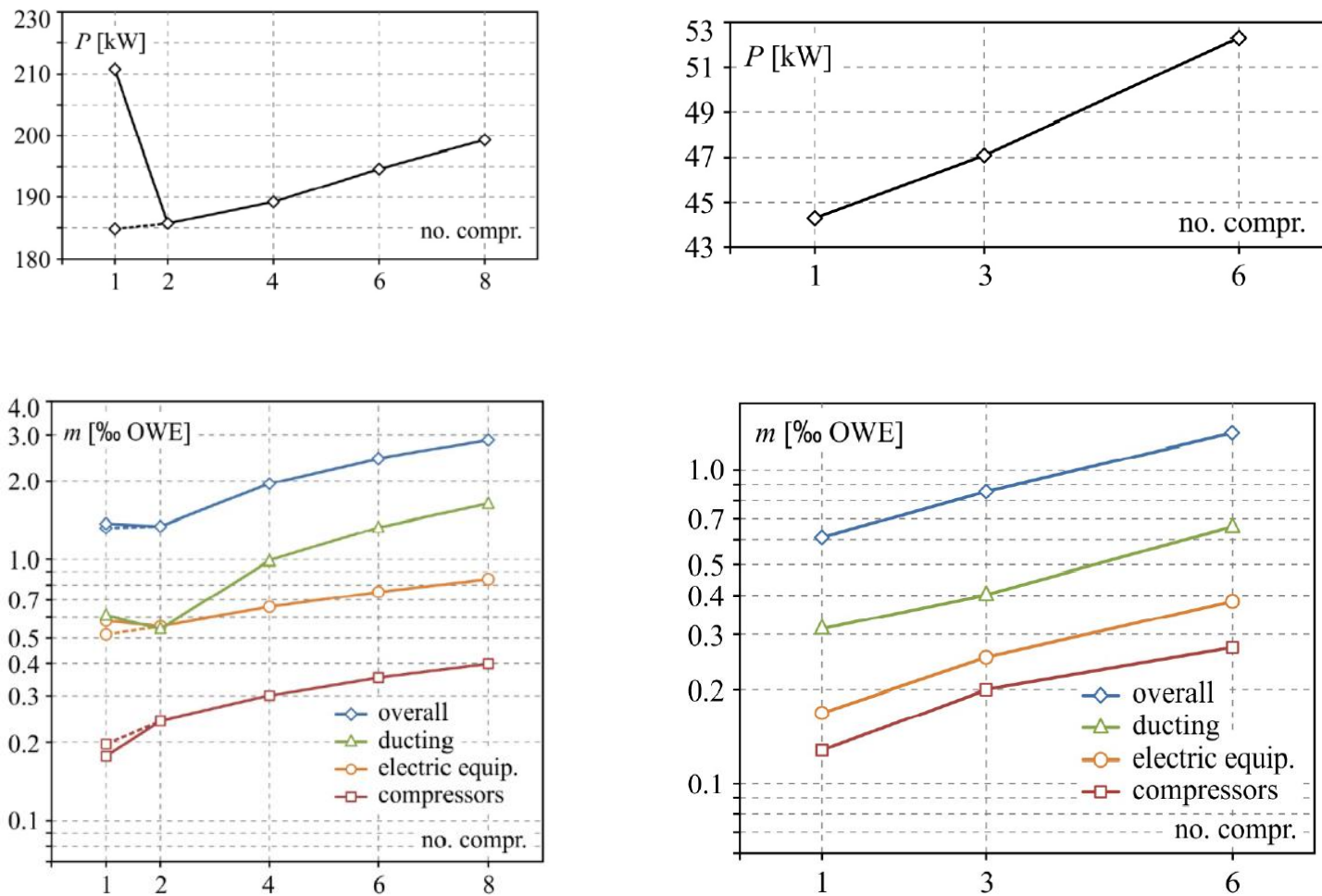

Fig 21: Difference in power consumption (upper) and mass estimation (lower) for different number of compressors for the wing (left) and tail planes (right) from Pe [42]

In the recent past the suction system including the chambering to obtain the desired suction distribution in span- and chordwise direction has been simplified to reduce the 
overall weight as well as complexity. The European ALTTA project (Application of Hybrid Laminar Flow Technology on Transport Aircraft) led to a simplified suction system, which is depicted in Figure 22. In this concept the whole leading edge is the suction duct in which one plenum pressure is applied. Therefore the need for separate piping is avoided on the account of a necessary sealing between the chambers as well as between the plenum chamber and the complete leading edge. The actual suction distribution at the surface is controlled through the chambers, which are created by stringers, in combination with an orifice to adjust the pressure in the suction chambers [45].

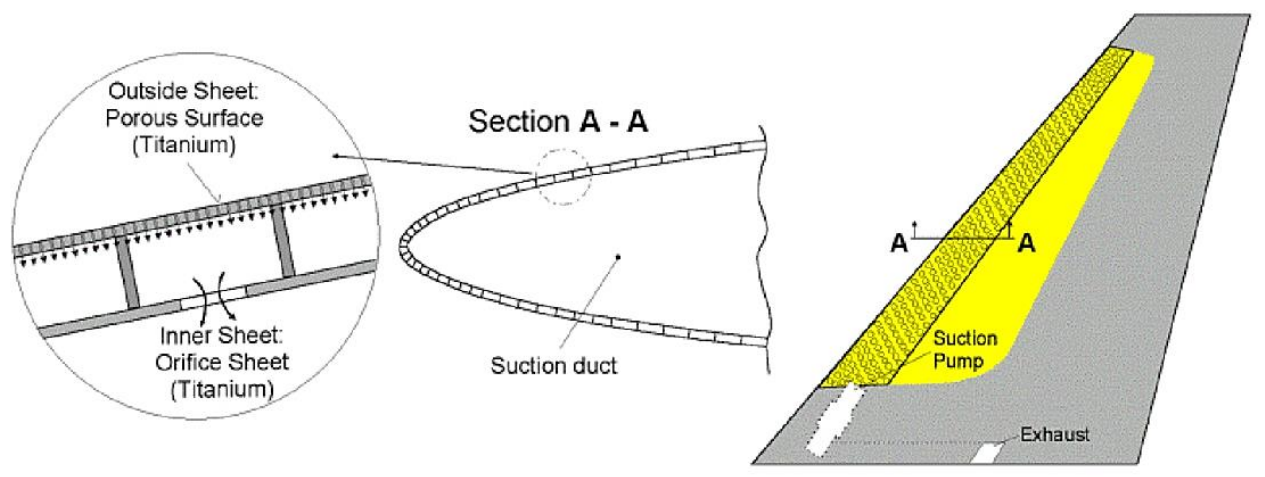

Fig 22: Layout of the simplified suction system [45]

It was tried to simplify the ALTTA approach even further. Therefore Horn [46] suggested a tailored hybrid outer skin to create the necessary suction distribution at the surface without having discrete chambers. The concept would not feature distinct chambers since the hybrid skin can be used to control the pressure difference between the plenum chamber and the outside pressure in span- and chord-wise direction. The tailored hybrid outer skin consists of a micro-perforated metal sheet with an underlying multilayer metal mesh (like depicted in Figure 23). Through the choice of the different sizes of the mesh in each layer, the desired pressure difference between the plenum chamber and the outside pressure can be tailored. Nevertheless, concepts for prohibiting flow in span- and chord-wise direction as well as for joining meshes of different size need to be created.

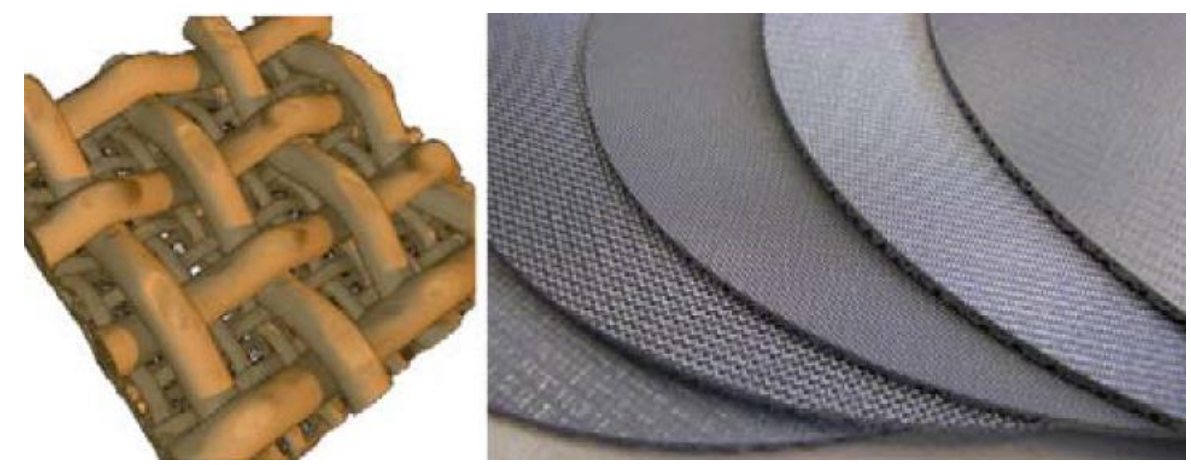

Fig 23: Multilayer metal mesh examples [46] 


\subsection{Anti-contamination system}

Very high surface cleanliness requirements exist for laminar flow areas since small 3D obstacles can already exceed the critical height at which the flow transitions from laminar to turbulent. The determination of an actual value for the critical height is difficult since it depends on many parameters like the flow velocity, angle of attack and others [51]. Nevertheless, the critical height is an important parameter in assessing insect contamination systems. Croom [47] researched during a $2.2 \mathrm{hrs}$ flight test flying below $500 \mathrm{ft}$ on a Bellanca Skyrocket the effect of insect residue height to transition of flow. She summarized that only $25 \%$ of the collected insects caused transition at sea level and only $9 \%$ caused transition at a height of $25000 \mathrm{ft}$.

Contamination of the leading edge of laminar flow areas due to the impact of insects is one threat which was investigated in the past. Coleman [48] states that the contamination due to insects mainly takes place below a height of $500 \mathrm{ft}$ since above this height the population of insects decreases rapidly. After assessing the data by Coleman as well as by Croom and Holmes, Humphreys [50] summarizes that above $1000 \mathrm{ft}$ the amount of collected insects is negligible. During the flight phases start, landing and taxiing applicable measures need to be taken to prohibit the contamination of exposed laminar flow leading edges, mainly the wing. No studies regarding the contamination of the horizontal and vertical tail plane could be found.

Coleman [48] also explains that the drag due to the induced velocity field of lifting surfaces at corresponding critical conditions rapidly exceeds the propulsive force of an insect leading to an uncontrollable motion. The insect could therefore be modelled as an inanimate particle to simulate its trajectory in the velocity field of an airplane. Based on a specific lift distribution, information about the impact of insects on the vertical and horizontal tail plane should be possible. Factors [47] other than the airfoil geometry, the airspeed and the altitude which influence the rate of insect accumulation are:

- temperature

- $\quad$ wind speed and

- humidity / moisture.

Once an insect strikes the leading edge area of a wing or tail plane, its residue that remains on the surface is dependent upon the characteristics of the skin material (e.g. surface free energy, surface roughness and rigidity), the impact angle and speed, ambient conditions (e.g. temperature, humidity, airflow over the impact site) and the insect type [49]. Upon a sufficiently high impact velocity, which Coleman concluded for the Drosophila Melanogaster (also known as the common fruit fly) to be about $10.9 \mathrm{~m} / \mathrm{s}$, the insects exoskeletal cuticle will rupture. The released haemolymph (equivalent to blood) acts as glue binding the broken body to the aircraft's skin [49]. It has also been reported that hail or rain together with the high velocity during flight can lead to a self-cleaning effect of aircraft surfaces regarding the maximum insect residue height [49].

To protect the leading edge against insect contamination, different approaches have been investigated by numerous researchers. The protection has to guarantee a clean surface at the beginning of the laminar flow operation. Humphreys [50] states that although the most significant contamination takes place close to the leading edge, the debris may typically be 
found as far aft as 15\% of the chord length. According to Croom [47] the following techniques have been investigated for insect contamination:

- paper coverings,

- scrapers, wipers,

- deflectors

- soluble films,

- resilient surface,

- liquid spray systems and

- porous leading edges.

Some of these techniques were found to be too complicated, costly or heavy to be investigated further. Examples for these types are the removable paper covers as well as mechanical scrapers or wipers. Kok [51] performed a review regarding considerations of insect residue contamination on aircraft surfaces which also covers existing methods for insect contamination alleviation and explains insect adhesion testing methods as well as the effects affecting insect impact residue accumulation.

For the leading edge of wings the shielding capability of a Krüger Flap (a leading edge high lift device) which is deployed from the underside of the wing, has been investigated in detail to keep the upper surface clean for laminar operation. Nevertheless, this restricts the design freedom of the high-lift system which could in total lead to a worse high-lift performance. Furthermore, only the upper side of the wing can be held laminar using the Krüger Flap. The assessment between the usage of a less favourable high-lift device with shielding capabilities instead of a more complex anti-contamination system has to be performed for each wing architecture separately depending upon the high-lift requirements as well as on the laminar wing performance. For the anti-contamination of the tail planes, Krüger Flaps are installed nor necessary regarding lift enhancement. Therefore other methods need to be applied if necessary to keep the surfaces clean, e.g. fluid injection approaches. It has been reported, that the monoethylene glycol (MEG) and water fluid solutions (for example as used for ice protection systems by TKS) acts as a solvent for the haemolymph which acts as a glue for the insect residue [47]. By using such a solvent-based solution the quantity of required fluid can be reduced in comparison to using plain water. The relation of the solvent to water plays an important role in the protection of the leading edge as well as the fluid flow rate as Figure 24 depicts. By adding a surfactant to the fluid solution, the necessary flow rate of 0.013 to $0.027 \mathrm{gal} / \mathrm{min} /\left(\mathrm{ft}^{2}\right.$ of projected leading edge frontal area) could be reduced even further [47]. 


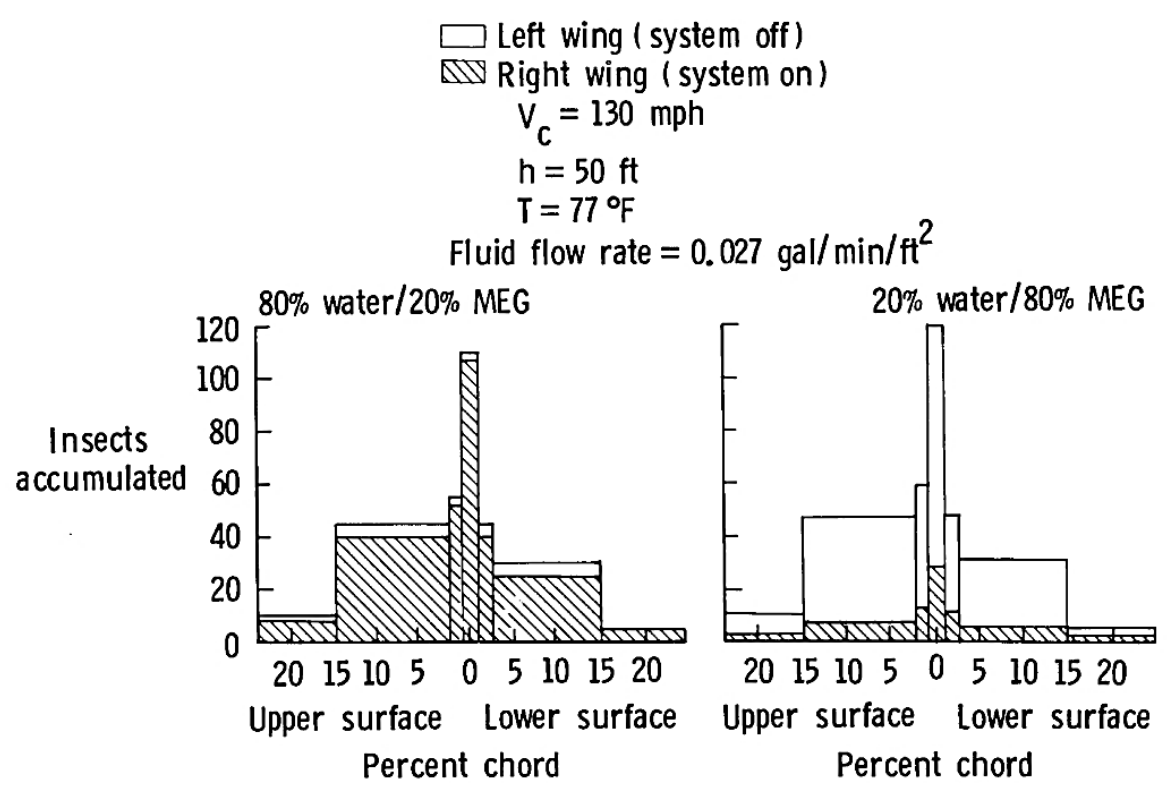

Fig 24: Effect of solvent to water ratio on insect accumulation [47]

\subsection{Ice and rain protection system}

Icing of aircraft surfaces is a common threat which can be dealt with by anti-icing systems to prohibit the growth of ice as well as de-icing systems to remove accumulated ice. Usually, the systems are applied to critical surfaces like the leading edge of the wing, pitot sensors at the fuselage or engine intakes. Nevertheless, higher surface cleanliness and suction distribution requirements can lead to an ice protection system for the tail planes as well, if a laminar boundary layer should be guaranteed. Icing can block the suction holes in the microperforated surface leading to an uneven suction distribution which can degrade the laminar boundary layer. Another risk arises due to the higher roughness of a surface with accumulated ice. Though the original A320 fin is not equipped with a hot air anti-icing system it was stated based on wind-tunnel studies during the European ALTTA project, that an antiicing system is necessary for a laminar fin [52]. Results from more recent projects regarding the necessity of an anti-icing system for the vertical or horizontal tail plane are not available and might need further wind-tunnel studies.

When designing an ice protection system, care must be taken to evaporate the ice completely. Otherwise the melted ice can run back to unprotected surfaces like the spoilers or flaps on the wing and freeze again [50]. Since only the leading edges of aerofoils are prone to icing, only they need protection against icing, run-back ice due to wrong design of the anti-icing system cannot be removed. Large transport-category airplanes usually use thermal pneumatic (bleed air) or thermal electric (heat mats) anti-icing systems as well as the application of a chemical prior to take-off in winter [53].

The thermal pneumatic anti-icing systems use hot bleed air from the engines to heat the leading edge of the wing in icing conditions. The heated surface leads to the evaporation of water upon impingement and thus prohibiting ice accumulation as well as run-back ice. Such systems typically consist of ducting, valves, manifolds and sensors to deliver the hot air to the components which need heating [53]. Such a system can be found on several conventional aircraft including the A350.

It has been reported, that the micro-perforated surface of the suction system increases the heat exchange effectivity of pneumatic anti-icing system through supplying the bleed air more uniformly. In conventional anti-icing architectures (for the wing), a single duct with multiple outlet ports heats the inside of the leading edge as depicted on the left side of 
Figure 25. Using the suction ducting in reverse operation it is possible to heat the skin more efficiently due to the high heat transfer coefficients between the air and the inside surface of the perforation. An additional advantage is that the hot bleed air is in direct contact with the ice because it emerges through the perforated surface. Limitations regarding the structural adhesive temperature of the bonding may complicate the whole system [54].

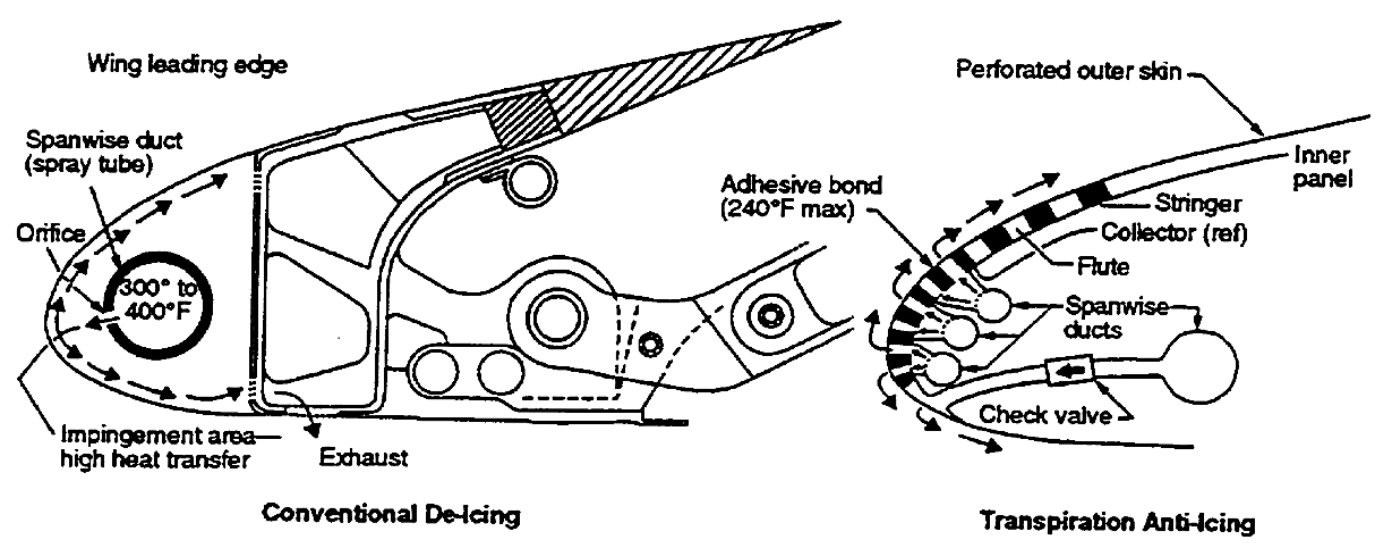

Fig 25: Comparison of ice protection method for the wing of the B757 [54]

Another option is the use of a chemical anti-ice system which could also be used to protect the leading edge from insect accumulation as explained in the previous chapter. Besides the thermal anti-ice protection with bleed air, this approach was also tested during the HYLTEC flight tests on the Do 228 aircraft. The thermal anti-ice system was tested on the inner test panel whereas a fluid/foam system was tested on the two outer test panels. The fluid/foam at first did not work as expected due to a too small chamber pressure. By increasing the chamber pressure, the leading edge could be de-iced at conditions much more severe than required for certification. The thermal de-icing system removed accumulated ice without problem and if kept running, the accretion of ice was prohibited [55]. Compared to thermal anti-ice systems, chemical systems have high cost of operation as well as a higher environmental impact. On the other hand they are reliable and maintenance friendly [56].

Depending on the need for anti-icing and/or anti-contamination systems for different laminar flow application areas, different combinations of methods can be preferable. For example, while a combination of a Krüger Flap for anti-contamination protection at the leading edge of the wing together with a thermal anti-ice system due to the close proximity to the engines could be preferable for the wing, for the horizontal or vertical tail plane a liquid system fulfilling both anti-contamination and anti-icing needs could be preferable. A trade-off study has to be done to evaluate the best possible approach for each boundary condition [35].

Besides potential anti-icing requirements, the whole suction system will have to be purged to remove entrained water due to rain or condensation. In the 757 flight test it was proposed, to reverse the airflow in a similar manner as for the anti-icing to remove the entrained water. It was stated, that the purging operation had to be performed in above-freezing conditions to avoid run-back ice due to the purged water. Furthermore, the purging had to be done sequentially due to the high airflow rate required to overcome surface tension [54]. The sequential procedure will be difficult to realise and adds weight and complexity for a chamberless suction approach or the ALTTA concept using the whole leading edge as the plenum chamber.

No information about the water intake of the micro-perforated surface due to flying through heavy rain could be found so far so that the entrained water cannot be estimated. In 
Powell [57] it was only stated that the intake of freezing-point depressant liquid as well as of rainwater through the porous surface is prevented by a small positive pressure difference e.g. as performed during the purge operation. Since even a low positive pressure difference already consumes energy, the question arises, how much energy is available during critical flight conditions like take-off and landing.

\subsection{Control and monitoring system}

For design of the monitoring system it has to be distinguished between a flight test monitoring concept and a final in-service monitoring concept. The architecture for the flight test monitoring is usually much heavier and more complex to accumulate a lot of different measurement data to understand the system behaviour due to different input signals or boundary conditions. Furthermore, the precise extent of the laminar boundary layer is important to be known to modify the calculation tools/methods used for the design of the suction system and for predicting the laminar extent of the boundary layer. Besides the state of the boundary layer, the pressure and mass flow inside the suction chambers provide information about the conditions of the suction system [35]. It has to be evaluated within sensitivity studies between the aerodynamics and systems disciplines if the active control of the suction system (e.g. the plenum pressure) based on different flight conditions (flight level, yaw angle,...) lead to a performance benefit with regard to additional system cost and complexity.

For an in-service HLFC system, the requirements regarding a monitoring system are different. The system should be started without pilot input once the start-up design altitude is reached. The start-up procedure may need additional measures to avoid high inrush currents. The pilot only needs to be informed upon malfunctioning of the system in case that fuel reserves for reaching the target destination might not be sufficient. The system therefore has to communicate with the fuel monitoring system in order to monitor the consumption with respect to a laminar operation. Another interface with the fuel planning exists since time in clouds, where the flow is turbulent independent of the suction level, also increase the fuel consumption. Other requirements regarding the control and monitoring system may arise based on additional anti-contamination and anti-icing systems as well as due to purging the whole system. For the anti-icing system, monitoring of the temperature is necessary to avoid overheating and thus damage to the materials.

Young [35] calculated the weight of the control system for the whole HTP of a Boeing 757-200 airplane, which is schematically depicted in Figure 26, to be $36.8 \mathrm{~kg}$ which is around $12 \%$ of the whole system weight $(76.3 \mathrm{~kg}$ for surfaces, ducts and valves, $97.9 \mathrm{~kg}$ for pump system and power as well as $84.1 \mathrm{~kg}$ for a decontamination system). Innovative concepts as well as a reduced complexity may lead to lesser system and components weight. 


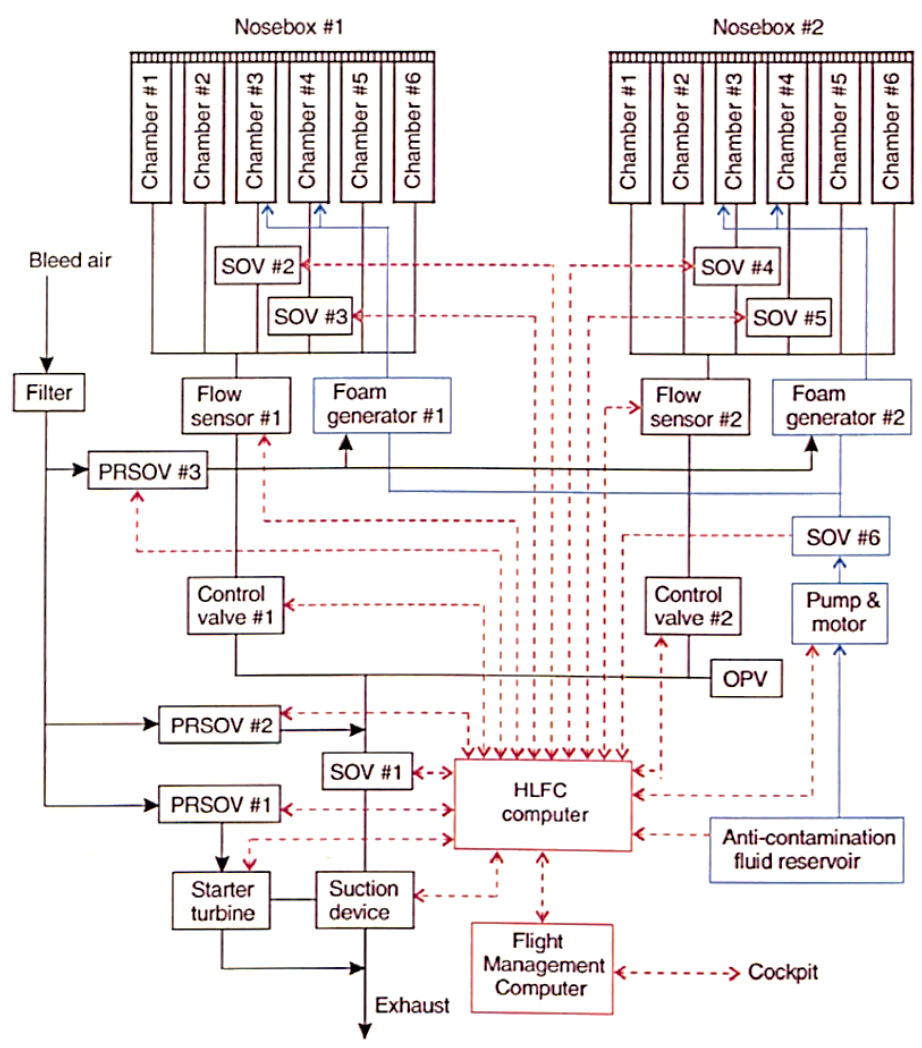

Fig 26: Schematic HLFC control system architecture for the B757 HTP [35]

\subsection{Safety and reliability considerations}

A failure condition for HLFC systems is the inability of the system to achieve the target fuel burn reduction. They were analysed by Young [35] for his aircraft performance models and are shown in Table.

Failures due to contamination of the suction surface through ice, confined rain or insects can be avoided by considering appropriate protection systems as explained earlier in this report. A failure of this system may lead to partial loss (depending on the amount of contamination) of laminar flow until the next manual cleaning and repair of the anticontamination system is performed. Wicke [58] performed studies regarding cleaning costs for a Natural Laminar Flow conceptual aircraft based on different contamination levels as well as with different fuel prices. It was found out, that already a low number of critical surface disruptions (disruptions which are greater than the critical height and therefore transition the flow from laminar to turbulent) lead to a significant fuel benefit penalty (e.g. 400 insects residues greater than the critical height result in a $4.4 \%$ fuel saving cutback). The appropriate time interval to clean the leading edge (if no active system is installed) is strongly dependent of the cleaning cost per event, the fuel price as well as the contamination rate and aircraft utilisation.

Temporary loss of laminar flow due to flying through cirrus clouds, in which ice particles penetrate the boundary layer and cause turbulent wakes, can only be avoided by considering weather effects during route planning. Based on the measurements of the 4 year long Global Atmospheric Sampling Program (GASP) conducted by NASA on four commercial Boeing 747 aircraft from 1975-1979 the probability of cloud encounters (TICTime in Clouds) during aircraft missions has been evaluated by Jasperson [59]. He 
concluded for the investigated routes that the probability of cloud encounter is not large enough to be a show-stopper for LFC. For example the probability of flying in clouds for more than $10 \%$ of the time is $27.4 \%$ on a route from the US East Coast to North-west Europe with an average cruise altitude between 33500 and $38500 \mathrm{ft}$. Although less frequent than flying through clouds, volcano ash or sand storms have the same effect on laminar flow as ice crystals [60].

Damage to the perforated surface (like bird strikes) cannot be avoided. Nevertheless, it has to be considered when designing the structural concept of the leading edge suction nose to prevent damage to the front spar. Other factors which affect laminar flow through changing the surface/profile form are hail, corrosion/erosion or the deviation of manufacturing quality with respect to roughness, waviness, steps and gaps. Most of these failure conditions can be avoided by choice of materials and manufacturing as well as quality control processes [60].

Table 2: Events and their impact on HLFC systems (adapted from [35])

\begin{tabular}{|c|c|l|c|c|}
\hline Description & Mission Phase & Consequence & Mitigation & $\begin{array}{c}\text { Influencing } \\
\text { factors }\end{array}$ \\
\hline Clouds & $\begin{array}{c}\text { Cruise, Top of } \\
\text { climb }\end{array}$ & $\begin{array}{l}\text { Complete loss of } \\
\text { laminar flow for finite } \\
\text { time }\end{array}$ & $\begin{array}{c}\text { Route planning, } \\
\text { pilot action }\end{array}$ & Weather \\
\hline $\begin{array}{c}\text { Contamination } \\
\text { (insects, ice) }\end{array}$ & Take-off, Climb & $\begin{array}{l}\text { Partial loss of laminar } \\
\text { flow for entire mission }\end{array}$ & $\begin{array}{c}\text { On-board system } \\
\text { cleaning by rain } \\
\text { and ice }\end{array}$ & Weather, \\
season, location \\
\hline System failure & $\begin{array}{c}\text { Take-off, Climb, } \\
\text { Cruise }\end{array}$ & $\begin{array}{l}\text { Partial or complete } \\
\text { loss of laminar flow for } \\
\text { remainder of mission }\end{array}$ & $\begin{array}{c}\text { System design, } \\
\text { maintenance }\end{array}$ & System reliability \\
\hline $\begin{array}{c}\text { Damage to } \\
\text { perforated } \\
\text { surface (e.g.: bird } \\
\text { strike) }\end{array}$ & $\begin{array}{c}\text { Take-off, Climb, } \\
\text { Cruise }\end{array}$ & $\begin{array}{l}\text { Partial or complete } \\
\text { loss of laminar flow for } \\
\text { remainder of mission }\end{array}$ & $\begin{array}{c}\text { Route planning, } \\
\text { pilot action, } \\
\text { surface design }\end{array}$ & $\begin{array}{c}\text { Weather, } \\
\text { component } \\
\text { design }\end{array}$ \\
\hline
\end{tabular}

Different studies regarding the system reliability, which influences the failure condition "system failure", have been conducted by Young [35], Pe [60] and Ohme [61]. Different preliminary suction system architectures with typical component reliability values were investigated by $\mathrm{Pe}[60]$ to calculate the overall failure rate. However, subsystems like an anti-contamination system, which can also reduce the reliability of the overall HLFC system, were not included in these calculations. For the single non-redundant suction system a mean failure rate per flight hour of $8.1 \cdot 10^{-5}$ was estimated by mainly having a series connection of components as depicted in Figure 27. The IMA (Integrated Modular Avionics) IMA is basically basically, the data line, the components, the processors and the control unit integrated. Young [35] calculated the failure rate per flight hour for the normal suction mode as $3.7 \cdot 10^{-4}$. The difference in the value is based on slightly different system architectures (compare Figure 26 with Figure 27) and different component failure rates due to 11 years of development between the two studies. Failure rates for anti-contamination or purge modes were calculated to be in the same ranges as the normal suction mode but since having only a short time of operation do not affect the overall reliability severely. He proposes to modify the failure rates with a duty cycle factor to account for the limited time of operation. 


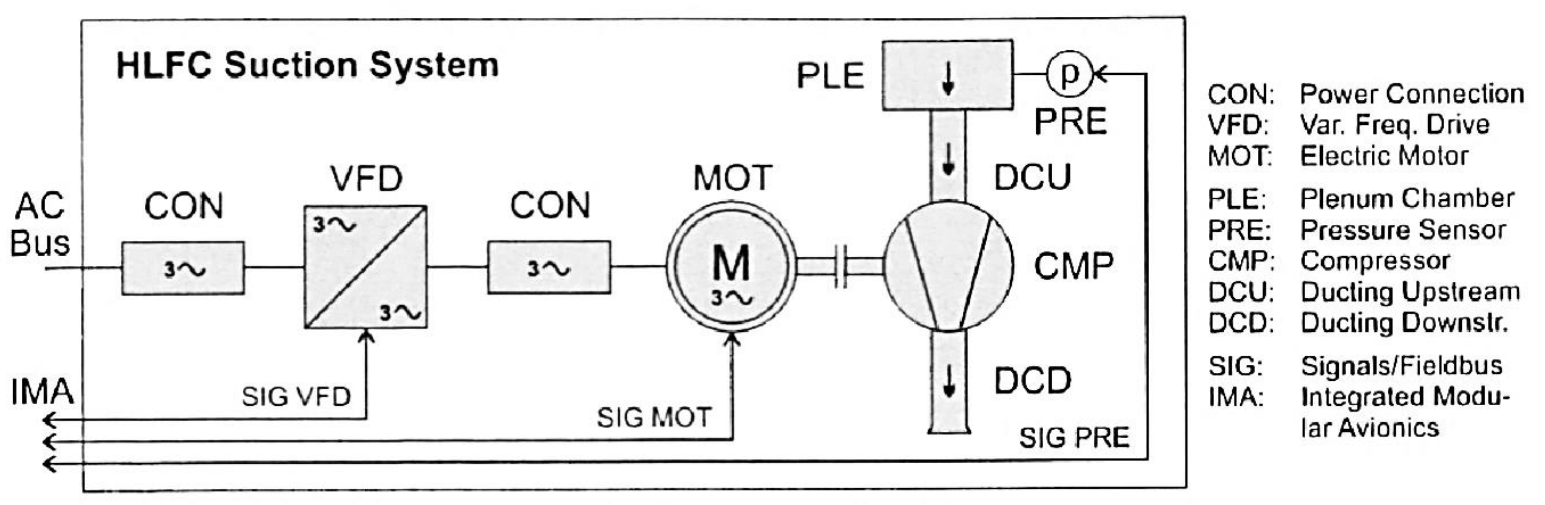

Fig 27: Single non redundant suction system [60]

Other architectures, which were investigated by Pe [60], were a cross-link HLFC suction system in which a left hand side was connected through a cross duct (XDC) to a right hand side (e.g. for wing and HTP) along with various isolation valves (ISV) as depicted in Figure 28. In this architecture, the compressor and drive system as well as the IMA (Integrated Modular Avionics) components were redundant while the plenum chamber and ducting were not redundant. Furthermore, different k-out of-n systems were analysed in which the probability for $\mathrm{k}$ remaining functional subsystems out of $\mathrm{n}$ total systems was calculated. For the cross-link concept a mean failure rate per flight hour of $4.3 \cdot 10^{-7}$ was calculated. The system mass is increased due to the oversizing of the compressor and drive system to operate both sides. Furthermore, the cross duct adds additional mass. The redundant suction system has a slightly smaller mean failure rate per flight hour of approximately $3.2 \cdot 10^{-7}$ although space constraints in the leading edge may prohibit a parallel architecture on each side.

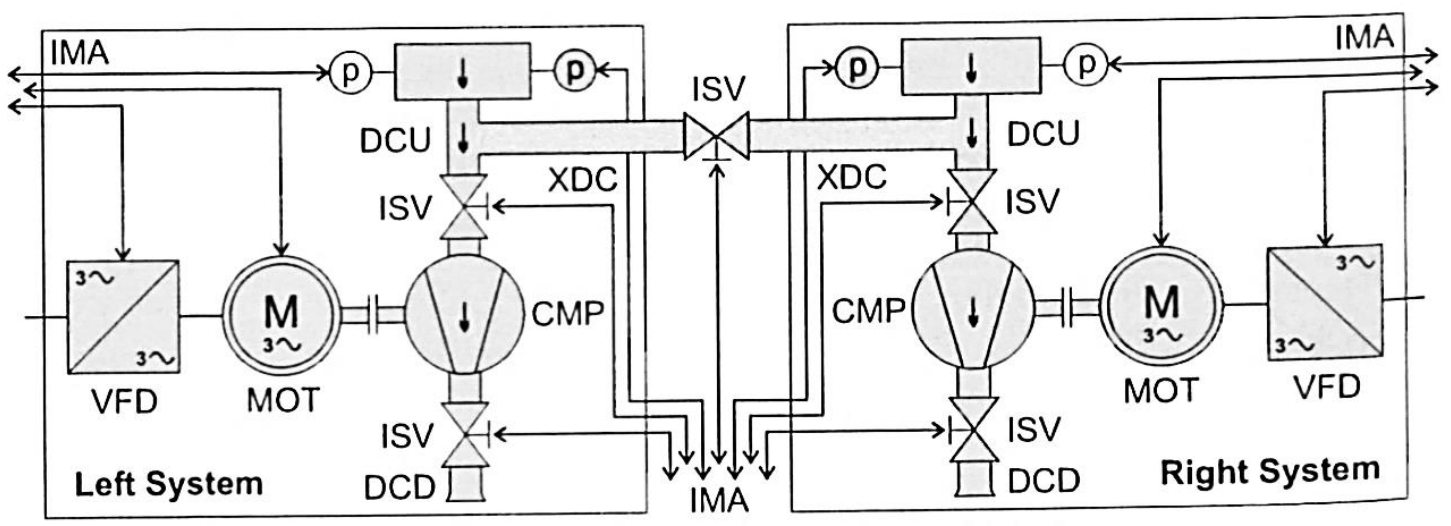

Fig 28: Cross-duct suction system architecture [60]

An increase in system reliability always decreases the system performance (as long as the system is not degraded) e.g. due to increased weight when choosing redundant components or additional pressure losses when adding more components to the system. Nevertheless, having a heavier but more reliable HLFC system can be beneficial since less contingency fuel needs to be transported resulting in an overall lighter aircraft. These tradeoff studies can only be performed on overall aircraft level when assessing the benefits of the decreased fuel burn due to laminar flow in contrast to the added weight based on different flight envelopes. 
The effect of HLFC system degradation on aircraft level has been studied by Ohme [61]. An HLFC system for the wing as well as the horizontal and vertical tail plane was included in a long-range aircraft model by adding an additional negative delta drag at their specific position. The worst case scenario for a degradation of the HLFC system regarding the resulting aircraft movements was the asymmetrical HLFC failure on one side of the wing in combination with an engine failure on the same side of the wing. It was shown based on calculations, that the control surface deflections for the critical failure case are small. Therefore, the asymmetrical failure of laminar flow surfaces does not lead to an uncontrollable state of an aircraft even when considering a combined engine failure leading to a safely controllable and manoeuvrable aircraft during all flight phases as required by the authorities.

Nevertheless, the HLFC system degradation can affect the remainder of the flight due to an increase in fuel burn (through reduced laminarity as well as increased trim drag) and therefore lead to diversions based on fuel calculations. If additional contingency fuel is carried on-board to account for HLFC failures, the effectivity of the overall system is decreased due to the additional fuel weight. To maximise the benefit, the airline's fuel planning tools shall consider the probability of cloud encounters when calculating the contingency fuel.

\section{Key projects in HLFC}

\subsection{HLFC research in the United States}

The laminar flow research gained momentum in the US, after a stagnation period during the 1960's. The OPEC (Organization of the Petroleum Exporting Countries) oil embargo resulted in increased fuel cost and shortage of fuel [2], resulting in the importance of laminar flow research once again. The laminar projects during the 1970's and 1980's under the NASA's Energy Efficient Transport Technology (EETT) program was formed to increase overall aircraft's fuel efficiency using various advanced innovative concepts such as winglets, aircraft surface coatings, laminar flow research etc. Significant progress has been made in the laminar flow technology since its inception in 1976. NASA performed an analytical study on the application of Hybrid Laminar Flow Control technology on the wing of a Boeing 757 aircraft [62]. The study showed approximately $60 \%$ and $40 \%$ of the wing upper and lower surfaces respectively can be laminarised. For a Mach number of $\mathrm{Ma}=0.80$ and a range of $3900 \mathrm{~km}$, a fuel saving of $8 \%$ was realized without any re-optimization of the variables to obtain the best possible fuel savings. A re-optimisation could lead to an even higher fuel saving. It was also shown that the aircraft has an increased available envelope with HLFC as compared to Natural Laminar Flow designs. Some recommendations were made from this analytical study: to perform more research needed in the definition of transition criterion for Tollmien-Schlichting (T-S) and Crossflow (CF) instabilities, to define the achievable smoothness and to address the severity arising out of the insectcontamination problem.

Since mid-1980's most of the laminar flow control research concentrated on the HLFC technology, where suction is only required in the leading edge region of the wing up to 10$20 \%$ of chord. HLFC overcomes many of the constraints of NLF and also the complexity is less compared to the LFC, where suction is applied over the entire surface. From 1981 to1988, various wind tunnel tests were carried out at the Langley research center. Werner Pfenninger devised a wind tunnel experiment for application of suction (slotted and 
perforated) to control the boundary stability characteristics in 1975. In 1978, the Langley 8Foot Transonic Pressure Tunnel (TPT) with a Mach number capability from approximately 0.2 to 1.3 was chosen as the preferred tunnel for carrying out LFC experiments, where both the slotted and perforated suction surfaces were tested. The slotted-suction model experiments happened during the years 1981 to 1985, and the perforated-suction during 1985 to 1987. The HLFC test was performed during the years 1987 to 1988 . The model used for testing was a 7 -ft chord, $23^{\circ}$ swept wing model. Using the slot-suction model, the HLFC simulation was attempted by simply applying suction near the leading edge region and progressively turning-off the suction at the rear portion. By using the suction at quarter-chord ( $25 \%$ chord), the full chord laminar flow moved to $53 \%$ chord laminar flow [2] at a Reynolds number of $\operatorname{Re}=10 \cdot 10^{6}$. In the year 1987 , the slotted suction model experiments were completed and the model was replaced with a perforated suction surface to perform HLFC testing [63]. The perforated upper surface was 0.025 inches thick and made of titanium. It was perforated by electron beam drilled holes with an approximate diameter of 0.0026 inches. The spacing between the holes was 0.025 inches. The experiment provided interesting results, by varying the Mach number from 0.80 to 0.826 , different pressure distributions were obtained as shown in Figure 29. Of these pressure distributions, the closest match between design and experimental data was obtained for $\mathrm{Ma}=0.82$ (Type 2). The extent of laminar flow for the three Mach numbers (Figure 29), when suction is applied for $25 \%$ chord is shown in Figure 30 . It shows that the extent of laminar flow was highest (around $65 \%$ ) for the highest Mach number, while for the lowest Mach number, the most uniform spanwise distribution (around $59 \%$ ) was obtained. These results reflect the extent of favourable pressure gradient above the HLFC model.

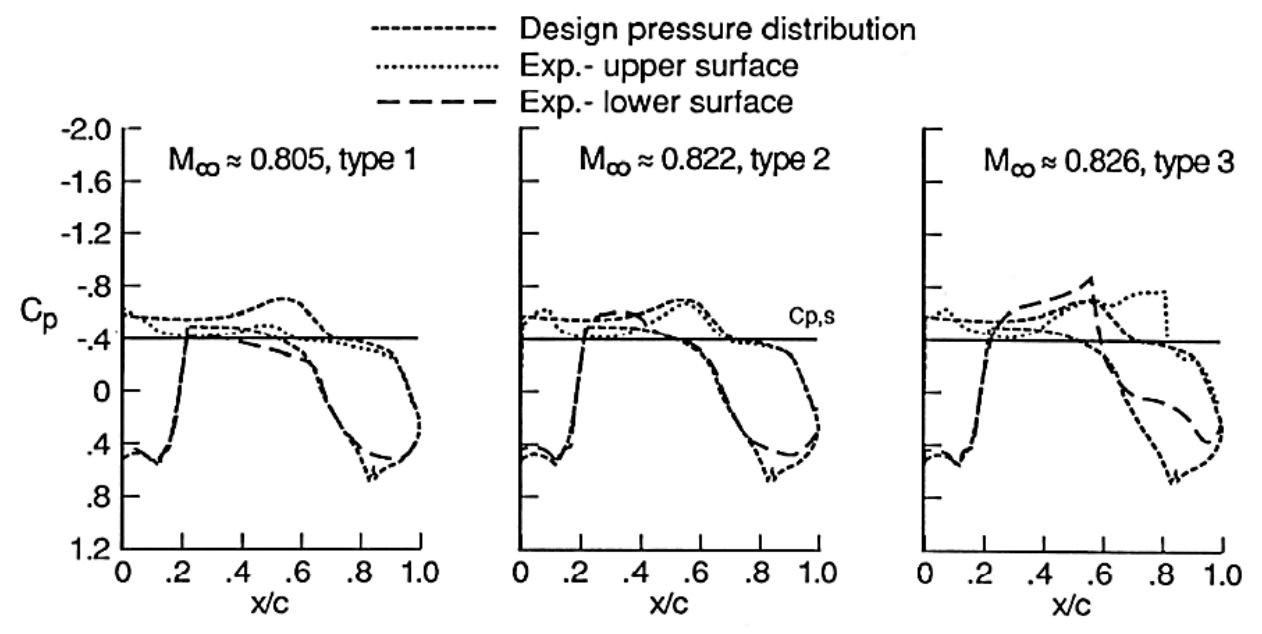

Fig 29: Three types of pressure distribution obtained on HLFC model. $R e=15 \cdot 10^{6}, \alpha=0.028^{\circ}$ [63] 


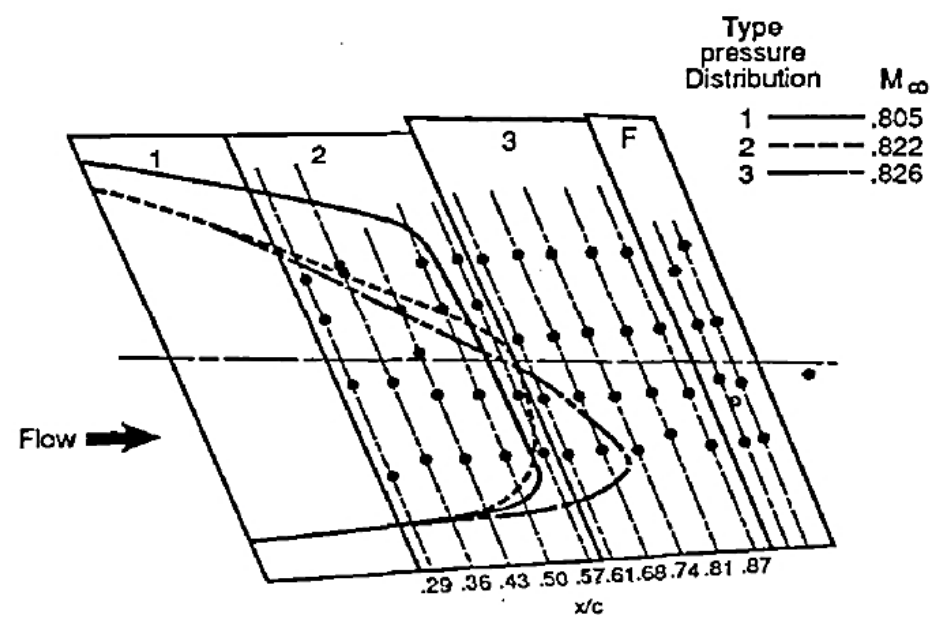

Fig 30: Transition boundaries for the three types of pressure distribution, $R e=15 \cdot 10^{6}$ [63]

The transition locations for Type 1 and 2 pressure distributions shown in Figure 29 is not much affected by Reynolds number changes, whereas Type 3 changes significantly as shown in Figure 31. Beyond Reynolds number of $\mathrm{Re}=17 \cdot 10^{6}$ and Mach numbers of $\mathrm{Ma}=0.826$, flow separation are more critical than transition location [63].

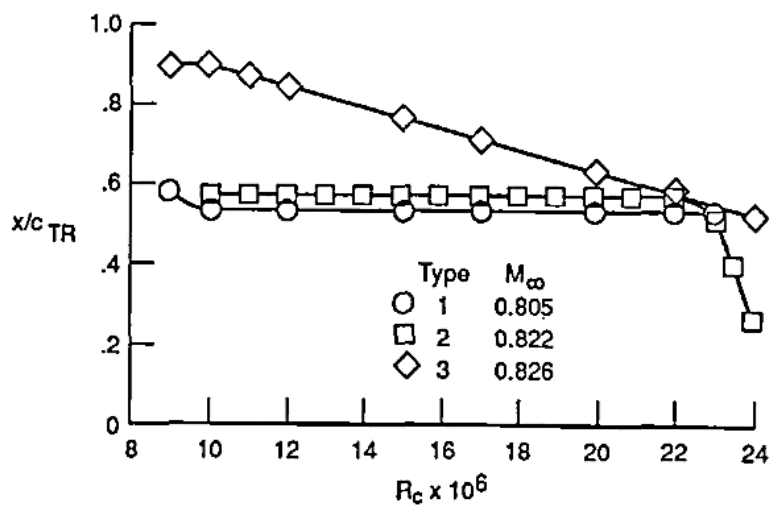

Fig 31: Variation of transition with Reynolds number for three types of pressure distribution [63]

The chord-wise extent of suction has an influence on the amount of laminar flow, at a Reynolds number of $\mathrm{Re}=15 \cdot 10^{6}$ and a Mach number of $\mathrm{Ma}=0.82$, as shown in Figure 32 . The result of the wind tunnel tests indicates that while the transition location changes only slightly between a chord suction of $5 \%$ and $15 \%$, a further increase beyond $15 \%$ chord suction leads to a high increase in the extent of laminar flow

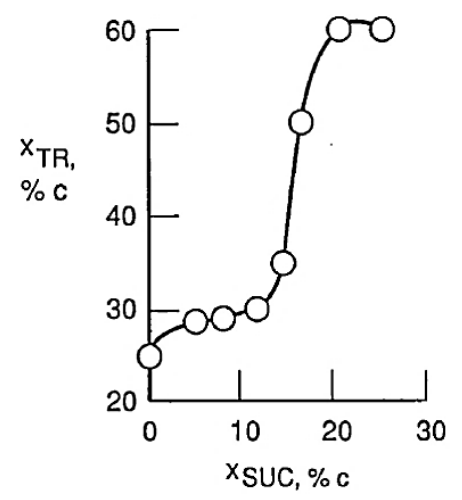

Fig 32: Transition location as a function of the chord-wise extent of suction at $\mathrm{Ma}=0.82$ and $\operatorname{Re}=15 \cdot 10^{6}[63]$ 
Another interesting result from the HLFC experiment is the comparison of transition locations on the chord for slotted LFC section and the perforated upper surface HLFC section. While the slotted LFC model seems to have laminar flow over nearly $100 \%$ chord at a Reynolds number of $\mathrm{Re}=10 \cdot 10^{6}$ and a transition location decrease to $61 \%$ chord for a Reynolds number of $\operatorname{Re}=15 \cdot 10^{6}$, the HLFC model has a constant transition location at $59 \%$ chord throughout the range of Reynolds number as shown in Figure 33.

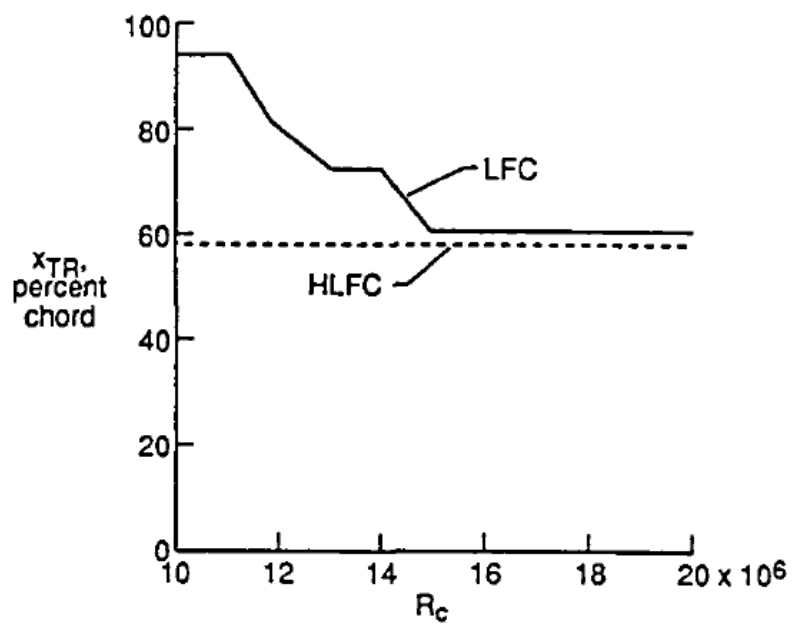

Fig 33: Transition location as a function of chord Reynolds number for the upper surfaces of the slotted LFC and HLFC models at $\mathrm{Ma}=0.82[63]$

Prior to the beginning of the NASA Leading-Edge Flight Test (LEFT) program from 1983 to 1986, many preliminary studies were performed by the Lockheed-Georgia Company starting from 1974 regarding a practical application of LFC [64]. The LEFT program addressed many environmental and technical issues [57] which are potentially stopping the implementation of the laminar flow control. Though the LEFT program mainly implemented LFC concept at the leading edge on both sides of the wing, it generated important results leading to the advancement of both LFC and HLFC concepts with regards to implementation and technology readiness. The flight test was performed on the NASA C-170 Jetstar aircraft, the port side wing leading edge was fitted with a Lockheed test section and the starboard side was fitted with a Douglas test section as shown in Figure 34.

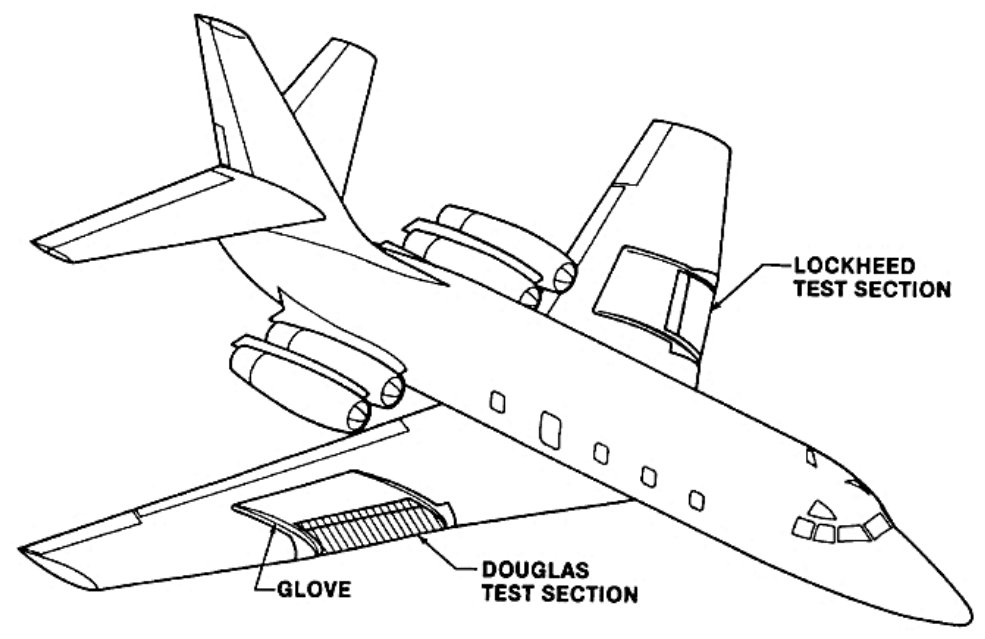

Fig 34: NASA Jetstar aircraft for flight test [57] 
The Douglas test section employed a retractable leading edge shield for contamination avoidance and ice protection in the lower altitude flight phases. It also employed the propylene glycol methyl ether (PGME) spray system for de-icing (Figure 35). The rainwater was prevented from entering by maintaining a positive pressure differential across the porous surface.

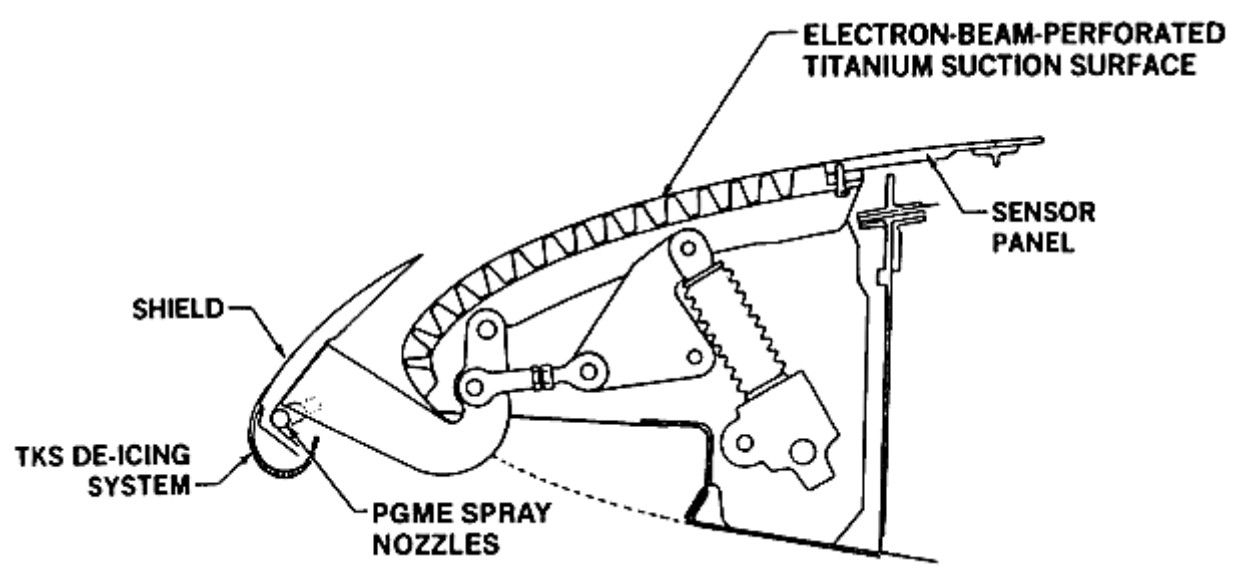

Fig 35: Douglas contamination-avoidance and ice protection systems [57]

The Jetstar flight test was the first to demonstrate the use of a titanium skin for the perforated suction panel. It was also very successful in testing the functionality of an anticontamination system to protect the leading edge. It was observed that the shield protection was sufficient to avoid insect contamination. Though some laminarity was lost when encountering ice particles in clouds, it was regained directly after leaving the turbulent conditions. The Gaster-bump and notch-bump were successful in preventing the Attachment Line contamination [57]. It was seen that there is no need for additional maintenance, and the LFC surface was operational without any degradation.

During mid-1986 to 1987, preliminary studies for conceptual design of HLFC system were performed as one of the main tasks for the Globe range military transport [64] and the associated benefits were analysed analytically. The obtained results are summarized in Table 3. The study also suggested the need for an experimental flight program with HLFC system on a swept wing aircraft to obtain data at high Reynolds numbers, and also concluded the industry is in need of a database for transport aircraft application.

Table 3: Benefits of HLFC for Globe range military transport compared to baseline turbulent design [64]

\begin{tabular}{|c|c|c|c|}
\hline Parameters & $\begin{array}{c}\text { HLFC } \\
\text { baseline }\end{array}$ & $\begin{array}{c}\text { NO HLFC on } \\
\text { Empennage }\end{array}$ & $\begin{array}{c}\text { NO HLFC on } \\
\text { lower surfaces }\end{array}$ \\
\hline Operating Empty Weight [\%] & 5.4 & 5.4 & 7.9 \\
\hline Gross Weight [\%] & -4.0 & -4.2 & -0.6 \\
\hline Fuel Consumption [\%] & -13.4 & -13.7 & -7.9 \\
\hline L/D ratio [\%] & 18.4 & 18.2 & 12.5 \\
\hline
\end{tabular}

Arcara [65] performed a benefit study on HLFC system on a commercial subsonic aircraft with projected 1995 technology improvements. The study used the conceptual design and analysis code called Flight Optimization System (FLOPS), which is used for multi-disciplinary studies of advanced concepts. It is assumed that the laminar flow reaches $50 \%$ chord on 
the upper wing surfaces as well as on horizontal and vertical tails. The analysis used conservative HLFC system weights and engine bleed air requirements. The obtained benefits as shown in Figure 36, include a 9.9\% reduction of take-off gross weight (TOGW), $5.7 \%$ reduction in operating empty weight (OEW) and $18.2 \%$ reduction in block fuel (BF), plus a $14.7 \%$ increase in the L/D ratio.
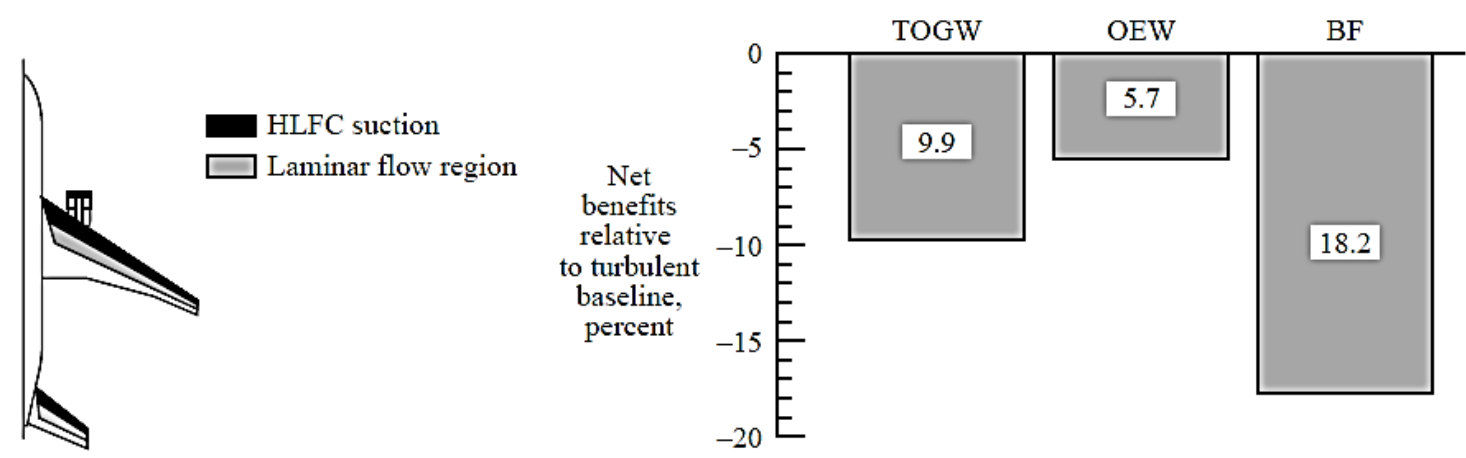

Fig 36: Potential benefits of HLFC on advanced subsonic transport aircraft. $M=0.85, R=6500 \mathrm{~nm}, 300$

$$
\text { passengers [65] }
$$

All the above mentioned analytical studies, and especially the Jetstar LEFT program improved confidence in the aeronautical community in the laminar flow technology and paved way for the Boeing 757 HLFC flight tests (1990 -1991). It was a cooperative flight test program involving NASA, US Air Force Wright Laboratory and Boeing. This test is historic as it is the first to demonstrate the feasibility of the HLFC concept in flight. The objectives was to perform high Reynolds number flight research, to develop a database for HLFC effectiveness and to develop and validate an integrated practical high-lift, anti-ice and HLFC system. The leading edge box of $20-\mathrm{ft}$ span, outboard of the engine nacelle pylon of the B757's port wing, was replaced with an all metal surface. The new leading edge box consisted of titanium perforated outer skin, subsurface suction flutes, and collection ducts to allow suction control of the boundary layer cross flow and disturbance growth [66]. The micro-perforated titanium skin was laser drilled with over $19 \cdot 10^{6}$ closely spaced holes ([12, 67]).

The hot air anti-icing system and Krüger flap was also integrated. The Krüger flap acts as a protection and insect shield. To meet the surface smoothness and waviness requirements, only minor clean-up was required, as the test flight included original B757 surface and contour. The design point of $\mathrm{Ma}=0.80$ at a lift co-efficient of $\mathrm{C}_{1}=0.50$ was chosen for the flight test. The information obtained from such a flight test was very important for further analysis and for future research. A range of instrumentation was included, to procure relevant flight test data, which is shown in Figure 37. 

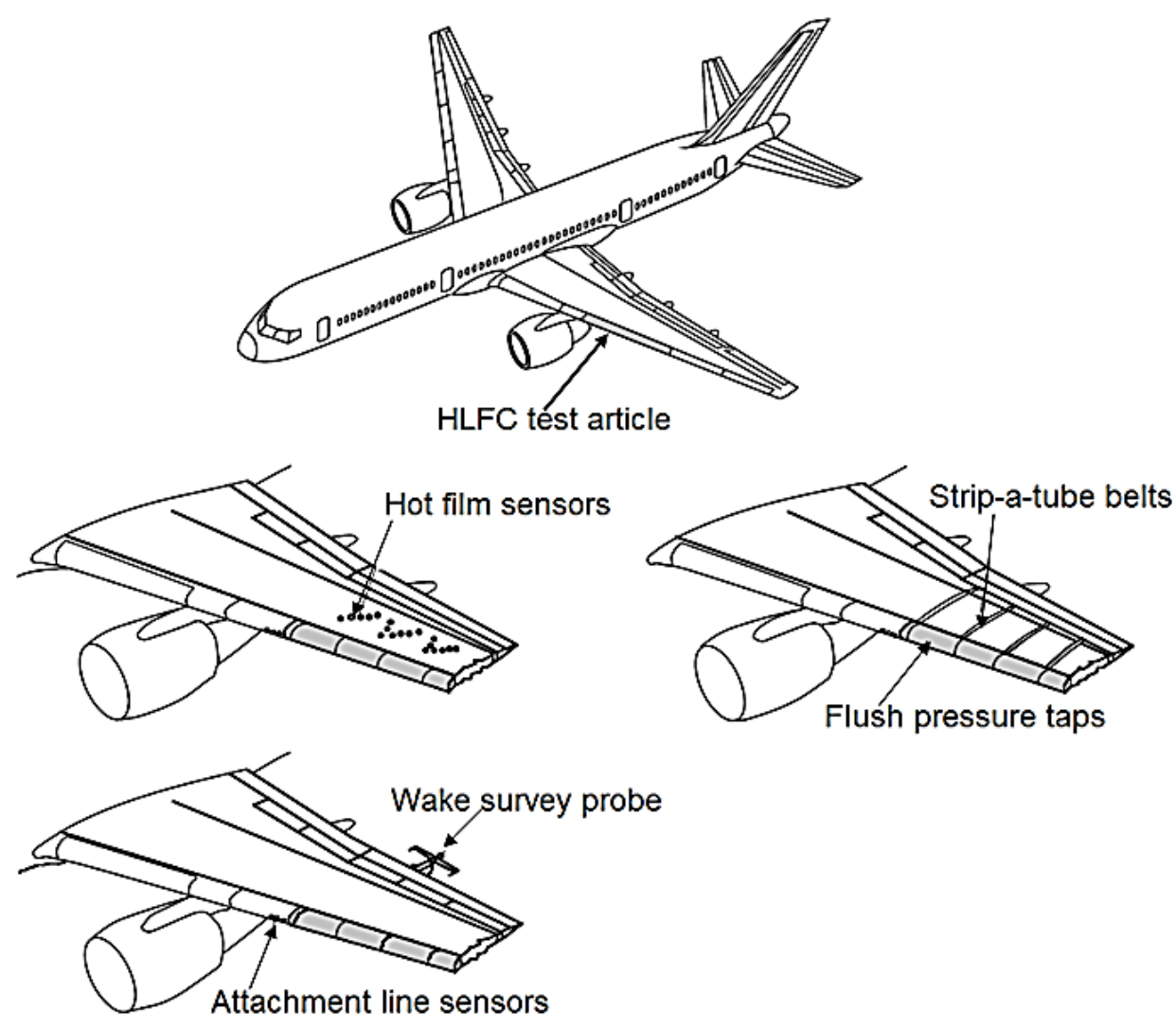

Fig 37: Boeing 757 flight test aircraft with HLFC test section, ([2], [66])

The leading edge panel along with the stringers and panel support is shown in Figure 38 and the suction system airflow path during operation is shown in Figure 39.

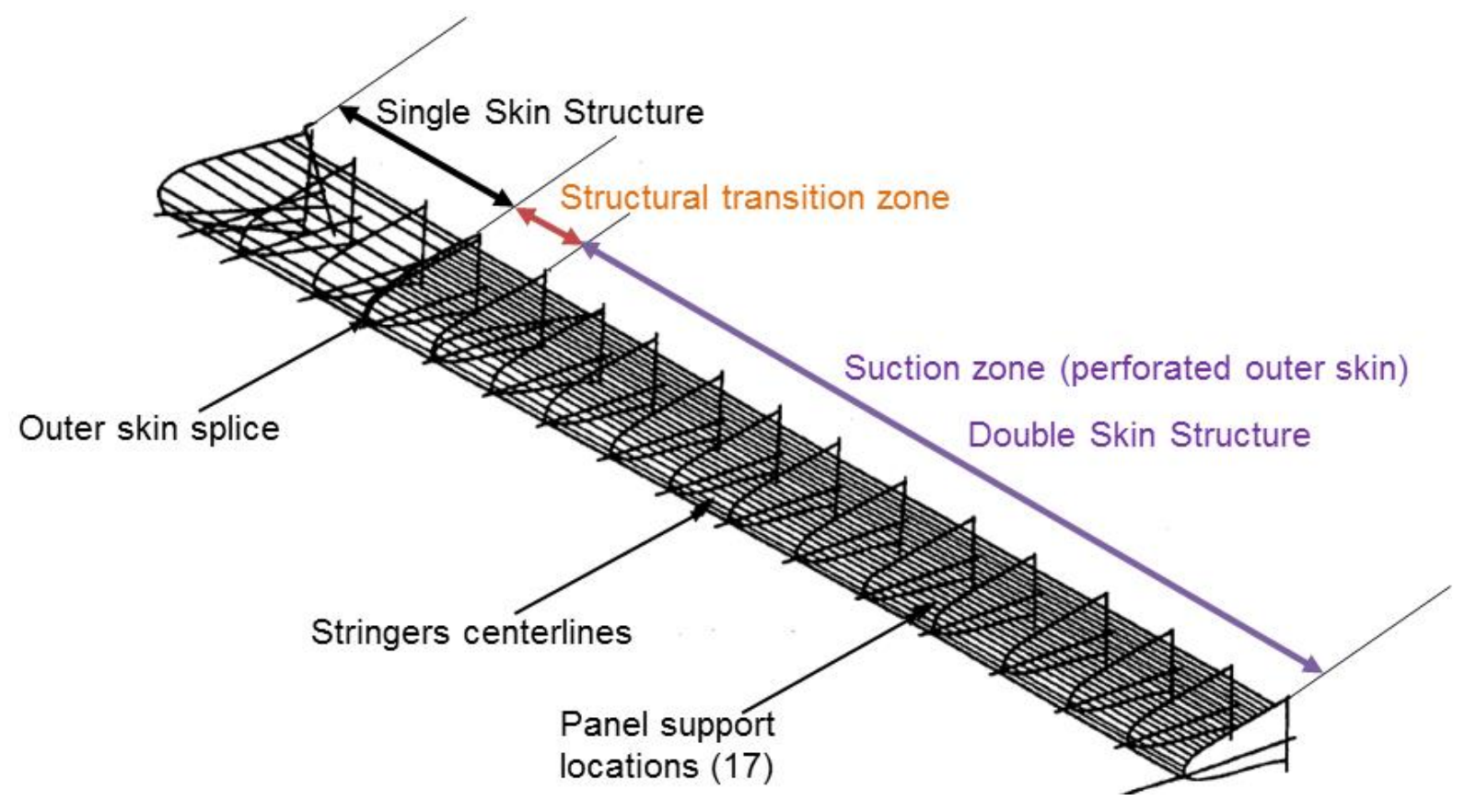

Fig 38: Leading edge panel and stringer outline [74] 


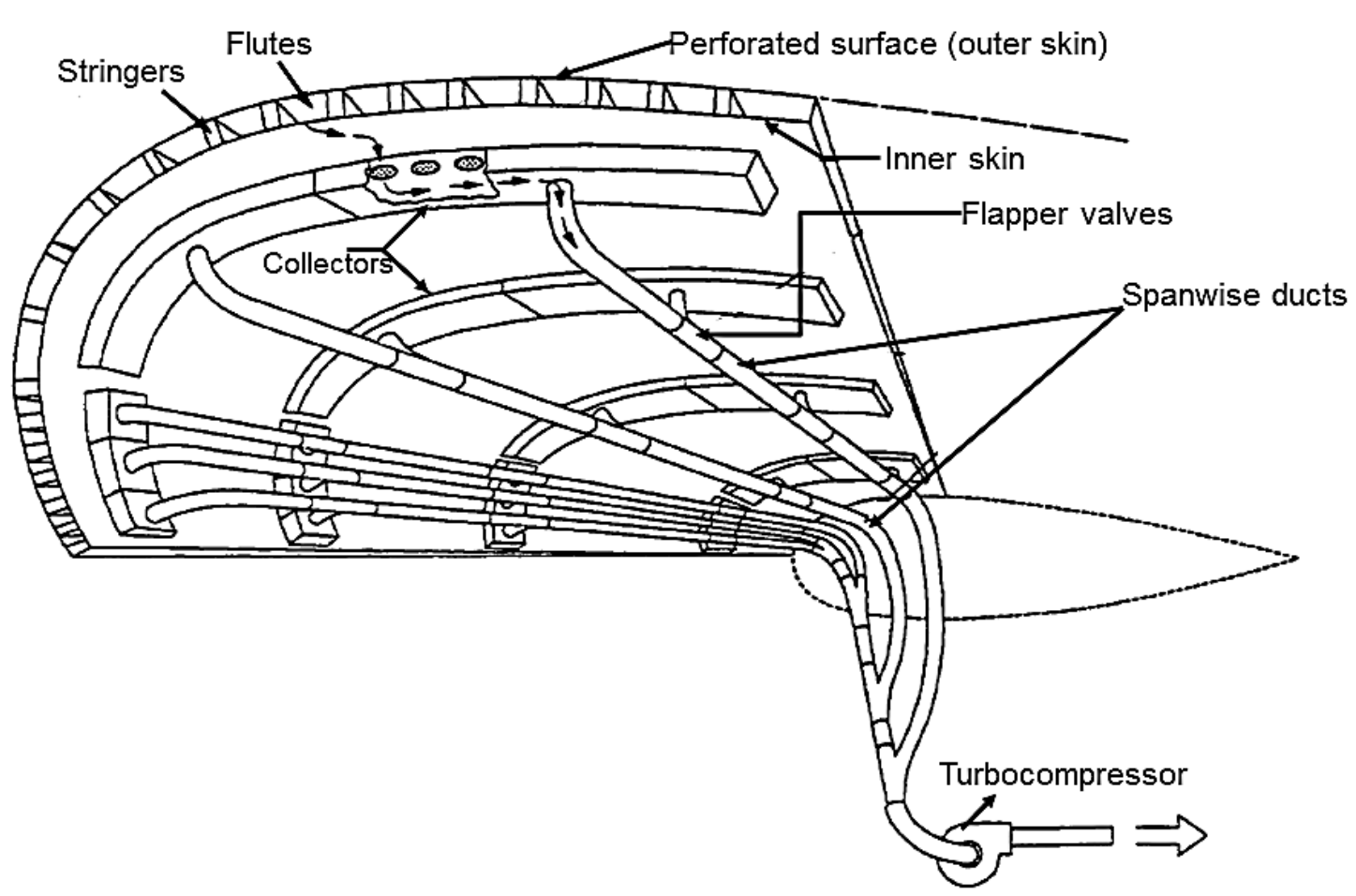

Fig 39: Suction system airflow path during normal operation [75]

The instrumentation included flush mounted and strip-a-tube belts for static pressure measurement capability, hot film sensors for transition detection, infrared camera for boundary layer transition detection, and wake survey probe for inferred local drag reduction determination. The flight testing began in February 1991 and consisted of 31 flights and 150 flight test hours, it investigated HLFC on the wing upper surface only. Higher benefits are possible from upper surface as it produces twice as much drag as the lower surface [68]. The results demonstrated that the HLFC concept was extremely effective in delaying boundary layer transition. The wake rake measurements (Figure 40) indicated a local drag reduction of $29 \%$ with operating HLFC system and an overall drag reduction of $6 \%$ for the aircraft $([12,67])$.

The hot film sensors / gauges indicated the extent of laminar flow beyond 65\% (Figure 41 ), but surprisingly the amount of suction rate required was only one-third of that predicted during the early design phase. This led to a significant uncertainty in the design tools as a consequence of the flight test. 


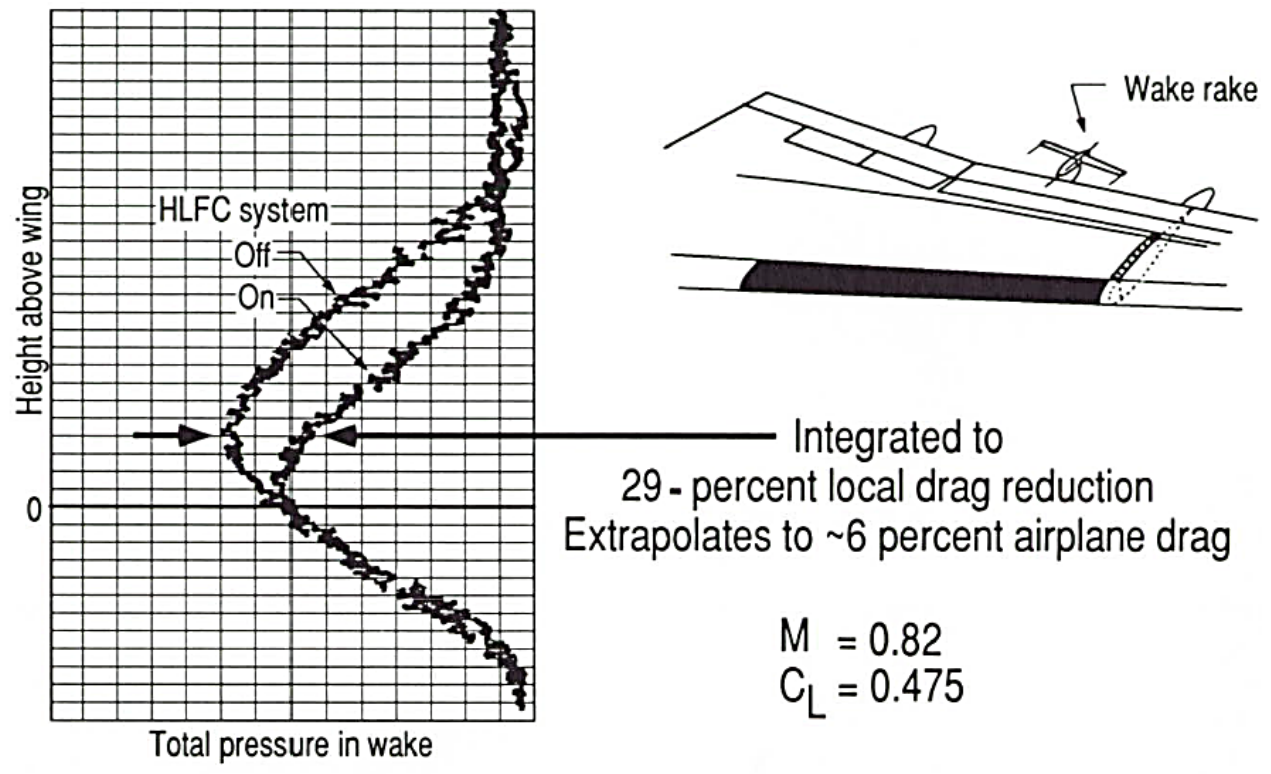

Fig 40: Wake rake measured drag reduction on the B757 flight tests [12, 67].

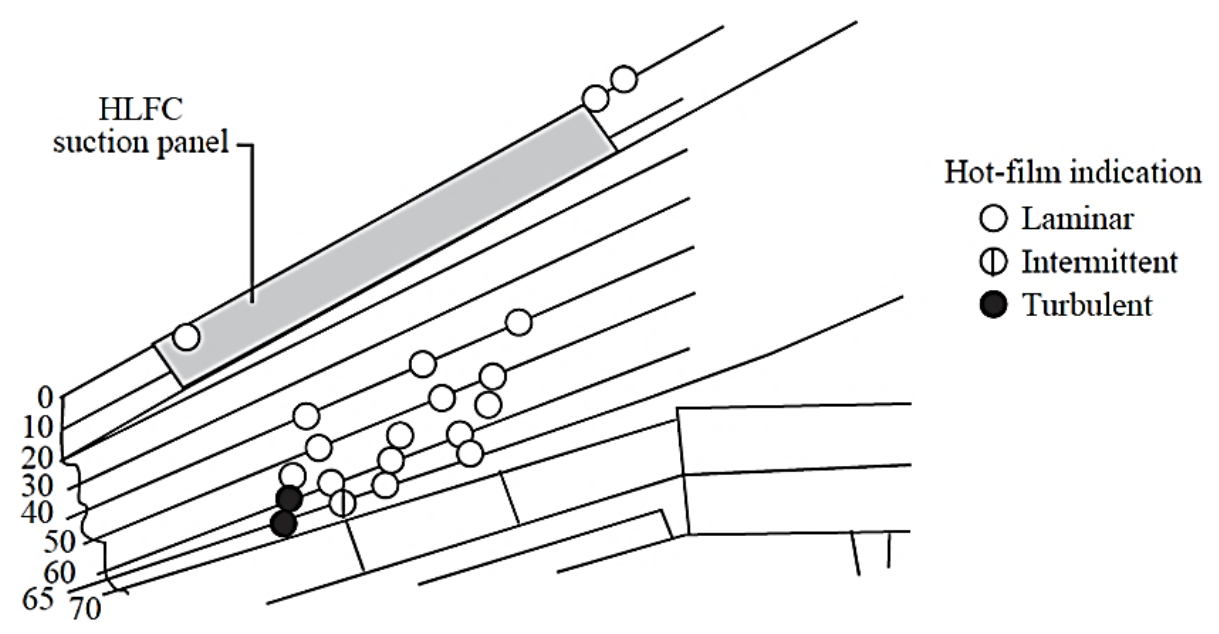

Fig 41: Laminar flow extent at $\mathrm{Ma}=0.82, \mathrm{~h}=38600 \mathrm{ft}$ and $\mathrm{c}_{\mathrm{l}}=0.48$ [66]

The success of the Boeing 757 flight experiment encouraged the aeronautic community to attempt the demonstration of HLFC concept application to the external surface of a large bypass turbofan jet engine nacelle. The project initiated in 1991 was led by General Electric Aircraft Engines with Rohr, Allied Signal and NASA also being involved. The engine used for testing was GEAE CF6-50C2 installed on the starboard side of A300 / B2 commercial transport aircraft. It was modified to incorporate two HLFC panels, one inboard and one outboard as shown in Figure 42. The panels were manufactured to very stringent surface waviness specifications, and consisted of a micro-perforated composite material [66]. As a proven method in previous LFC designs, the surface where the suction was applied had subsurface circumferential flutes, into which the air is sucked. It was ducted to an industrial turbo-compressor unit driven by engine bleed, located at the storage bay of the aircraft. 

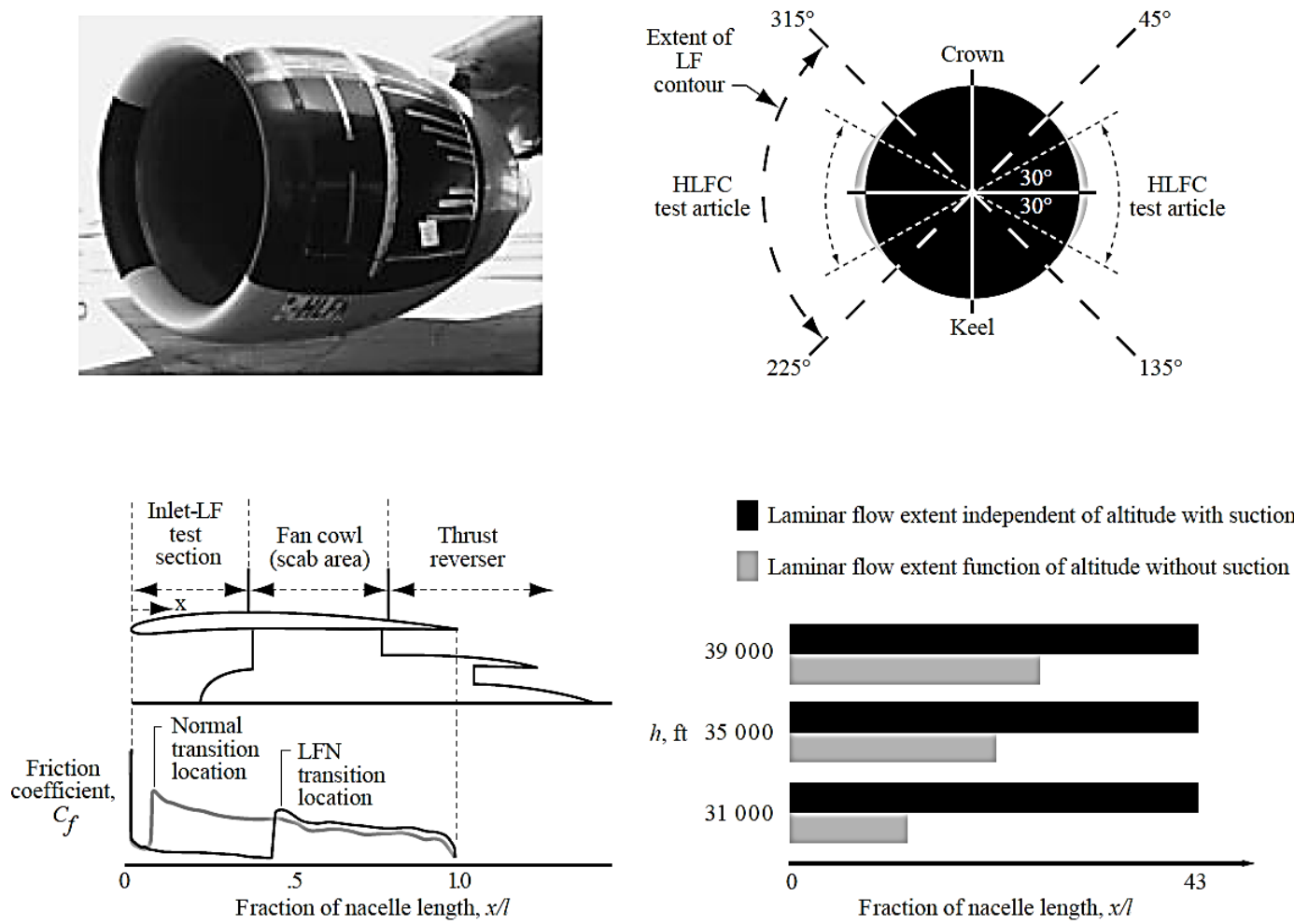

Fig 42: GEAE CF6-50C2 HLFC nacelle test article and obtained laminar flow [66]

Many sensors and other measurement and instrumentation techniques were utilized to create a database for the flight test. It included a boundary-layer rake for quantifying boundary layer build-up, hot film sensors for boundary layer transition detection, surface embedded microphones to assess noise field influence on the state of the boundary layer, charge patch for atmospheric particle concentration measurement and infrared imaging for global laminar boundary layer transition detection. The flight testing was extended for a period of 50 flight hours and consisted of 16 flights. The HLFC concept proved to be extremely effective, resulting in laminar flow to $43 \%$ engine nacelle length, independent of altitude. Even without suction, some laminarity was maintained, but the extent of laminar flow diminished as altitude was decreased, as shown in Figure 42.

As seen earlier, the uncertainty in the Boeing 757 flight test results concerning the required suction rate (due to difference between the predicted and experimental values) led to the HLFC wind tunnel experiments from 1993 to1995. The advantage of using HLFC in terms of the direct operating costs (DOC) amounts to negligible because of this uncertainty. It was seen as a show stopper, so there is a need to understand deeply the complex flow physics over swept wing geometry. This is considered important as the design tools used for HLFC technology had an unacceptable risk for the commercial market. The model installed in the wind tunnel was a $7 \mathrm{ft}$ span and $10 \mathrm{ft}$ chord $35^{\circ}$ swept wing oriented floor to ceiling. Using the instrumentation such as infrared (IR) camera and hot wire sensors, 3000 images and 6000 velocity profiles were obtained respectively [2]. The surface temperature difference at the transition location occurring due to the difference in skin friction at the laminar and turbulent boundary layer is shown in the IR images.

An unprecedented extent of Computational Fluid Dynamics (CFD) numerical simulations were utilized for this experiment. CFD was used: 
- in the design of the test wing in order to produce the desired growth characteristics in the airfoil shape,

- in the design of suction-surface perforation pattern to get enhanced Crossflowdisturbance growth and

- in the hot-wire traverse system to have minimal influence on the measured disturbance growth [18].

In order to study the Crossflow effects, the Tollmien-Schlichting disturbances were suppressed by wall cooling.

The design concept for the suction hole size in the Boeing 757 flight test experiment was believed to have been done conservatively, due to lack of detailed data and physical understanding. The hole size was chosen to be as small as the laser drilling process would allow, and the spacing was small enough to provide the required porosity. Such a design is costly and more knowledge is needed to know how large the hole size and spacing could be before "over-suction" occurs. This lets the individual suction holes act as receptivity sites.

Hence, the ultimate aim for the wind tunnel experiment was to provide high-quality data, needed to develop next-generation transition prediction tools and to study the suction-hole receptivity issue in detail [18]. Streett performed crossflow (CF) disturbance growth simulations utilizing the numerical HLNS method. Various flow fields were studied to identify the best possible one which has minimum CF growth disturbances. It was seen that there is resumption in growth of disturbances for a flow field with leading edge suction peak, and there is decay in the chordwise direction for the flow field with no peak, as shown in Figure 43. The graphs show the chordwise-normal boundary layer $(\mathrm{BL})$ edge velocity near the leading edge as abscissa and normalized chord length as ordinate, the parameter $\beta$ is called the Hartree pressure gradient parameter which indicates whether there is pressure rise or pressure drop in the basic boundary layer. This decay leads to the stabilization of shortwavelength CF disturbances aft of the initial leading edge expansion and reduces the growth of longer wavelength disturbances.
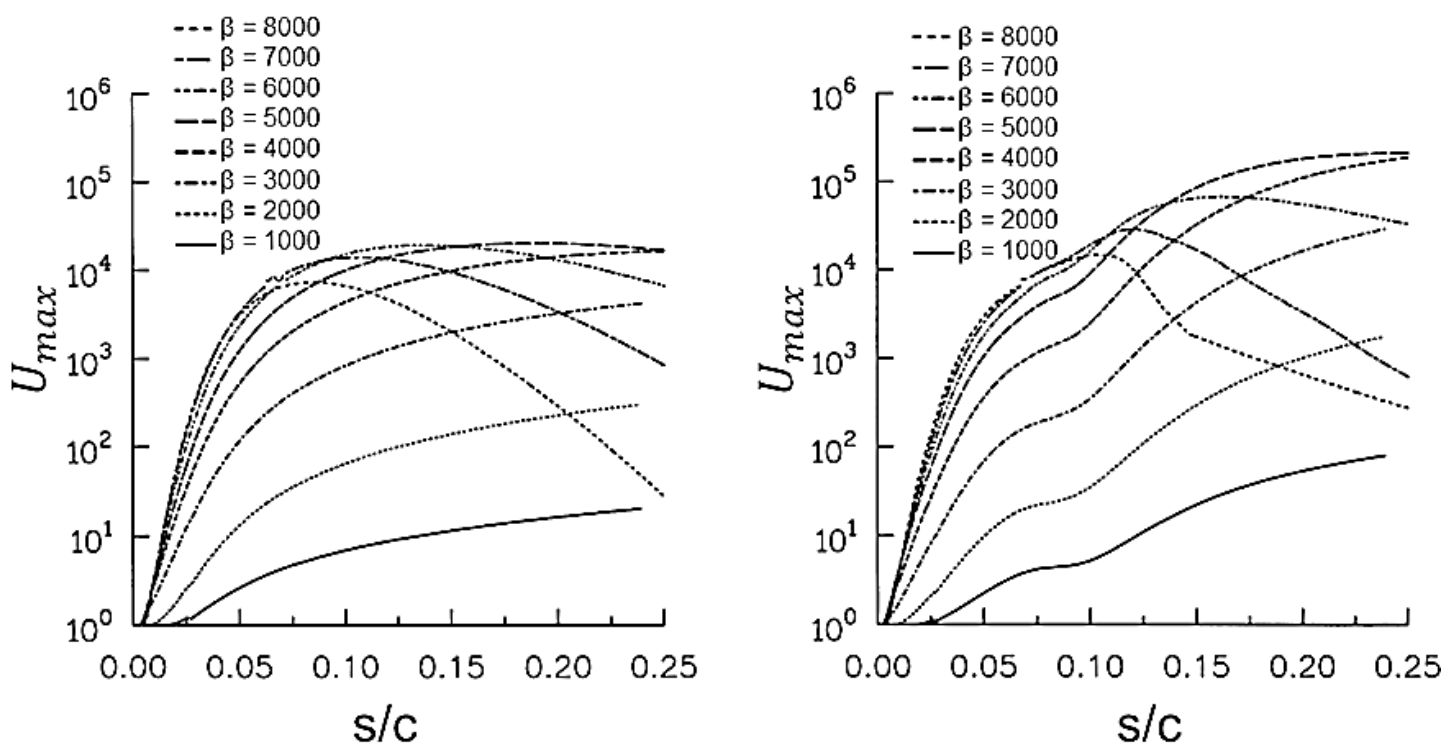

Fig 43: Amplitude of stationary CF disturbances with various spanwise wavelength for flow fields: without peak (left) and with peak (right) [18] 
It was seen that the CF physics is changed considerably, when a leading edge suction peak is added. This resumption of disturbance growth in the flowfield without suction peak is the main issue behind the uncertainty in the application of transition prediction tools based on linear stability theory. The reason is the local growth rate which is integrated under assumptions of the nature of the disturbance growth, when local growth rates are computed via linear stability theory (LST) in the N-factor method [18]. The LST theory gives little guidance for the assumptions for such growth rate unfortunately. On the other hand, the HLNS method computes the disturbance growth directly instead of integration of local growth rate. The chosen flowfield for the wind tunnel experiment is shown in Figure 44.
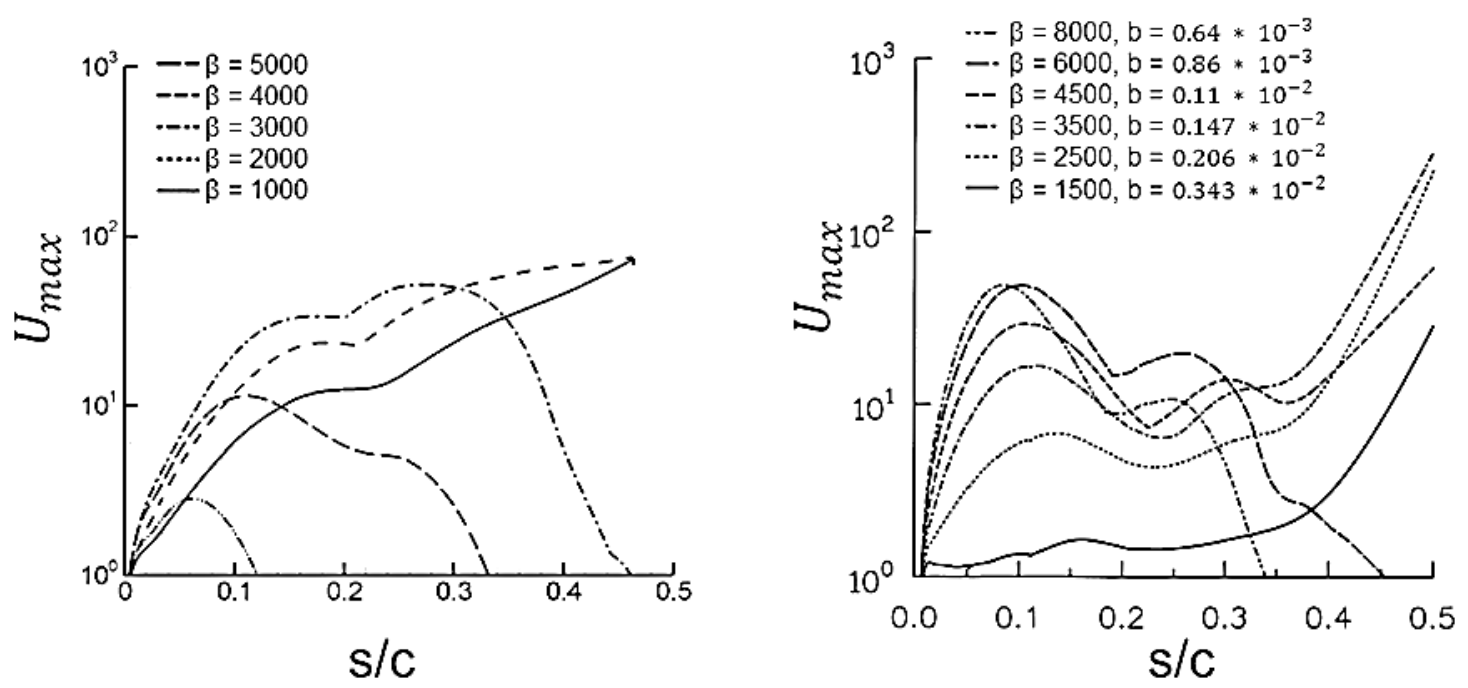

Fig 44: Amplitude of stationary CF disturbances with various spanwise wavelengths for flowfields: without suction (left) and with suction (right), [18]

For the experiment, it was deemed necessary to measure velocities ahead of the leading edge suction peak. This led to the relatively large leading edge radius and curvature change in that region. The final airfoil profile and pressure distribution for the experimentation are shown in Figure 45.

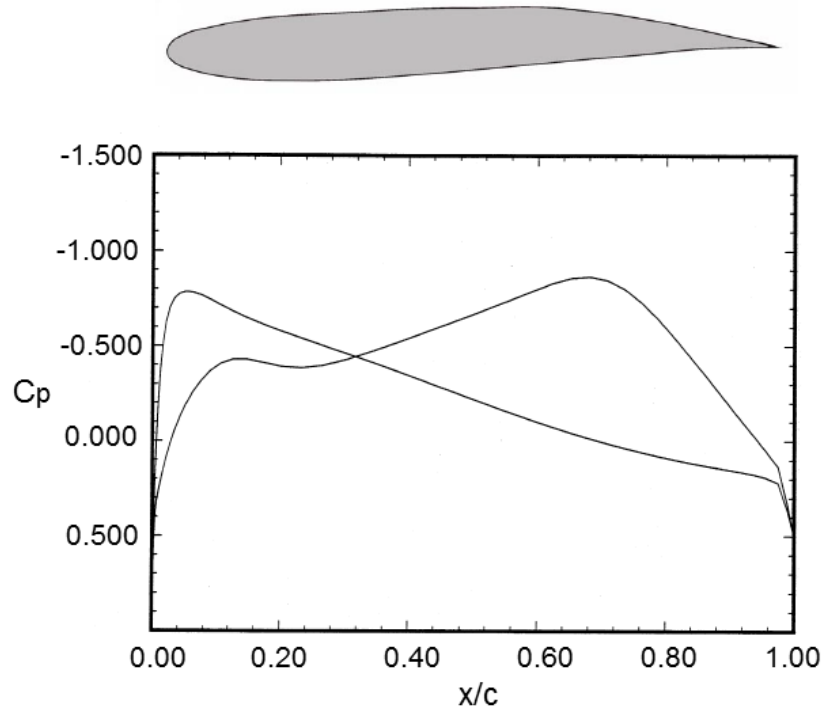

Fig 45: Final wind tunnel airfoil profile and pressure distribution [18] 
It was decided to test four different leading edge suction surface configurations [18]:

- Conservative hole size and spacing based on 757 flight test article, smallest hole that can be drilled by laser

- Maximum coupling to CF: large holes and hole spacing / pattern angle set to match CF vortex evolution

- Relaxed criteria on hole size and spacing

- Solid surface

The wind tunnel tests were conducted at a fixed Mach number of 0.24 and chord Reynolds number between 5 million and 25 million [69]. The leading edge suction surface panels were divided into 20 individual chambers as shown in Figure 46.

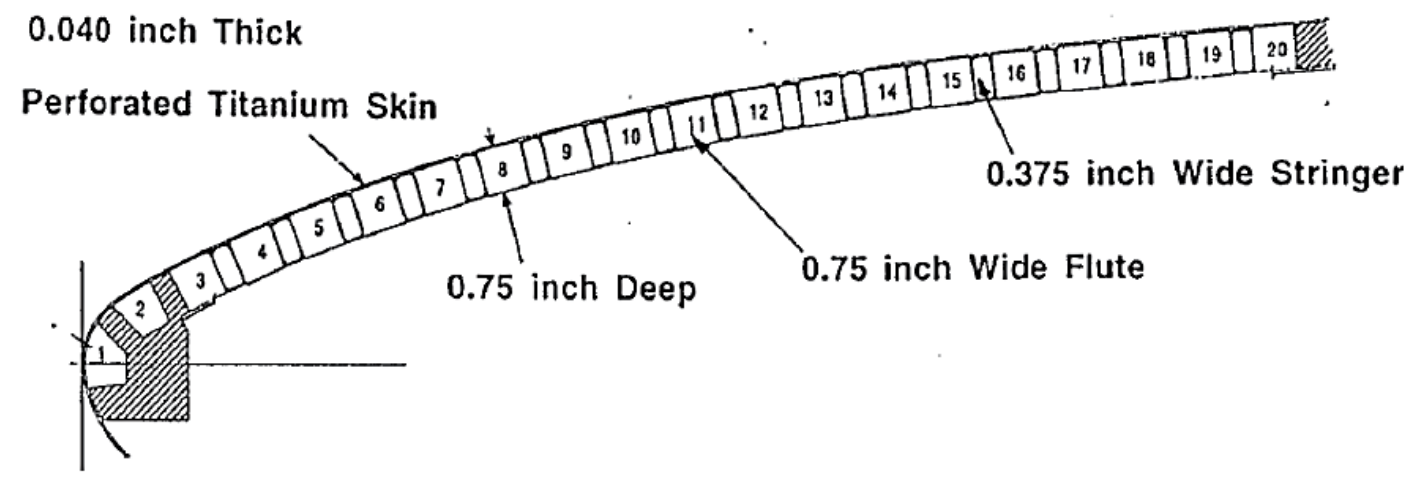

Fig 46: Leading edge panel cross section showing flute arrangement [69]

The data acquired from the wind tunnel tests consisted of mean surface pressures, infrared images, and hotwire measurements of steady and time-dependent velocities. This unique dataset was useful for the understanding of suction effects on Crossflow growth and transition. It also cautioned the experimentalists when designing and experimenting where travelling Crossflow is an important factor.

It is understood that, after all the research activity mainly concerned with the active HLFC concept for the wing in the US, there was also a growing interest in the passive suction concept as seen in section 4.1. Boeing implemented a passive HLFC system in the Boeing 787-9 aircraft vertical tail plane VTP. The benefits acquired by such a system are not available in open literature for comparison with other active concepts.

\subsection{HLFC research in Europe}

Major research projects including laminar flow flight demonstrators were started in Europe at the end of the 1980s and were obviously triggered by the success of American projects like the Lockheed/McDonnell Douglas Jetstar or the Boeing 757 projects [70]. At first, the projects mainly aimed at NLF, afterwards the HLFC was investigated in more detail [2, 5 and 35] presented a thorough overview of the research results and flight tests until 2002 in the US as well as in Europe. The triggered laminar research led to two European Forums on Laminar Flow Technology in 1992 (Hamburg) and 1996 (Bordeaux) respectively as well as a European Drag Reduction Workshop in 2000 (Potsdam). DASSAULT Aviation in cooperation with ONERA started a comprehensive research programme on laminar flow in the 1980s through partial funding of the French government [71]. In a first phase a NLF outer leading 
edge on the wing of a Falcon 50 was tested from 1985 to 1987. In a second phase from 1987 to 1990 a HLFC-system was tested on the inner leading edge of the same aircraft type to address issues regarding the anti-icing/cleaning-system, the suction system as well as a device to counter attachment line transition. The leading edge cleaning mechanism using a TKS (Tecalemit-Kilfrost-Sheepbridge Stokes) liquid system was very effective since no pollution problem was noted on the protected side while on the unprotected side 600 insects per square meter were identified. Due to the close proximity to the fuselage a Gaster Bump was necessary to reduce fuselage induced turbulences (Attachment Line transition). The positioning of the bump in spanwise direction played an important role regarding the transition location [71].

After the successful results on the Falcon 50 jet, Dassault started a succeeding project called FLAM (Falcon LAMinar) which was running from 1990 to 1997. The aircraft was changed from the Falcon 50 to the bigger Falcon 900. A HLFC system was applied to both inboard wings to test the sturdiness of the system at operational level [71]. The HLFC system was certified in 1995 and afterwards put into service for two years accumulating 1000 hours under hybrid laminar flow at various climatic conditions [72].

At around the same time as Dassault, Airbus started the three phase Laminar Fin Programme in cooperation with DLR and ONERA in 1987 as the first step of the LaTec (Laminar Technology) strategy. The Airbus A320 was estimated to have the highest fuel burn saving when compared to the $A 310$ and $A 340$ as shown in Table 4 by preliminary calculations. The phases of the program were analytical studies from 1987 to 1988, wind tunnel testing from 1990 to 1992 and flight test from 1992 to 1994 . The goal was flight tests using a wing glove in 1995 to 1996 as well as the industrial application at the end of the 1990s [73]. The suction system for the A320 fin consisted of a three-stage axial compressor which was controlled and monitored by a central data processor. The overall installation equipment for the flight tests is depicted in Figure 47. The central data processor worked as the interface of the suction system to the aircraft data management. Turbulent reference flight tests took place in 1995 to qualify measurement equipment and the Gaster Bump as well as to acquire turbulent reference data. The HLFC flight tests finally took place in 1998. The design was rather complex and voluminous and even occupied some cabin space in the last rows of the A320. The leading edge was completely filled by suction ducts. Additionally a sophisticated control system with nine individually controlled valves and flow meters was needed. Though this design aspect was perfectly fine for experimental verifications, it cannot be suited for airline operations. It could be concluded that the system internal noise was not as critical as expected and that a properly working passive device like the Gaster Bump, can reduce the number, position and size of suction chambers. Furthermore it was stated that the surface quality requirements derived from wind tunnel experiments are less critical for flight tests. Overall, the HLFC system on the A320 fin can improve fuel efficiency ,but operational issues like anti-icing and anti-contamination systems as well as an economical manufacturing of the whole system [5] needs to be addressed. Furthermore, the suction system would have to be simplified to reduce the weight penalty of installing the new system. 


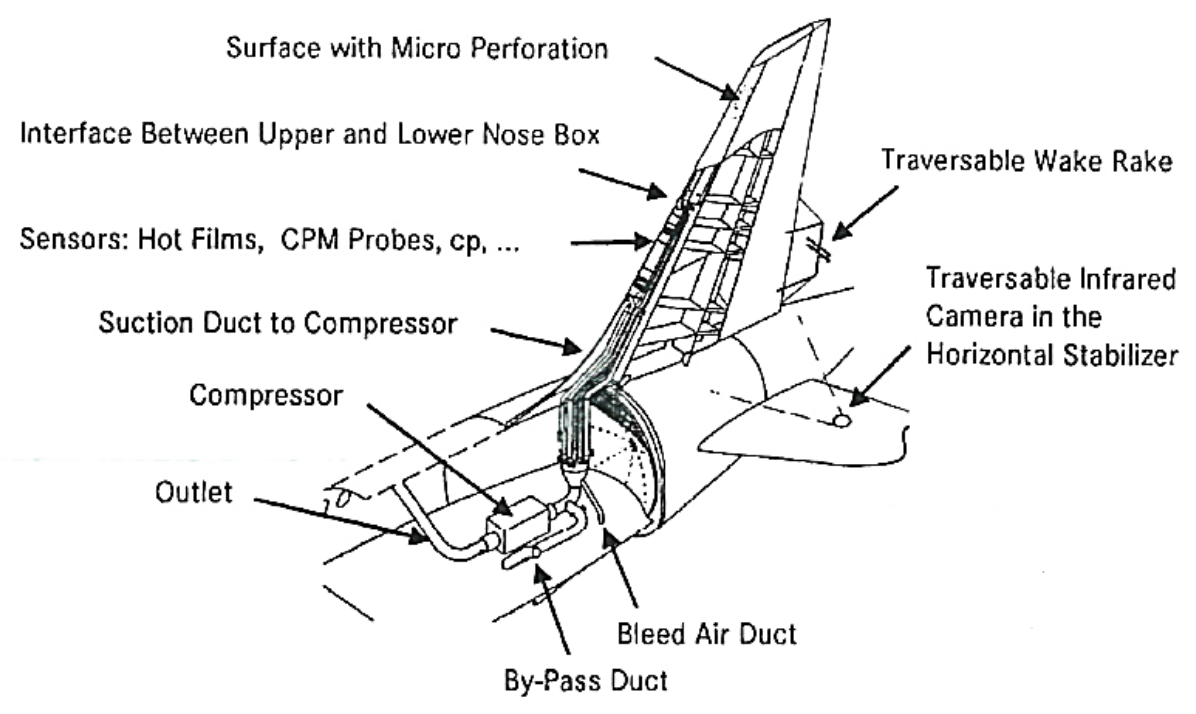

Figure 47: Installation of Flight Test Components for A320 HLFC Fin [76]

Table 4: Preliminary calculations of HLFC benefits on Airbus fins and horizontal tail planes [73]

\begin{tabular}{|c|c|c|c|}
\hline \multirow{2}{*}{$\begin{array}{c}\text { HLFC application } \\
\text { area }\end{array}$} & \multicolumn{3}{|c|}{ Fuel burn saving [\%] } \\
\cline { 2 - 4 } & $\mathrm{A} 320$ & $\mathrm{~A} 310$ & $\mathrm{~A} 340$ \\
\hline Fin & 1.1 & 0.7 & 0.5 \\
\hline Horizontal tail & 2.1 & 1.4 & 1.2 \\
\hline Net Gain & 3.2 & 2.1 & 1.7 \\
\hline
\end{tabular}

Two years after the beginning of the Laminar Fin Programme, the European Community supported the ELFIN project (European Laminar Flow INvestigations - 1989 to 1992) consisting of 24 European partners. The objective was to investigate the limits of NLF, starting work in the field of HLFC and to develop numerical design tools. Experimental data was generated through large scale wind tunnel tests both on HLFC wings and nacelles as well as through flight tests. The data was used to validate the numerical stability codes. Suction was applied to the leading edge (up to $x / c=0.1$ ) of the model at a leading edge sweep angle of $28^{\circ}$ and a Mach number of 0.7 . At $44 \%$ chord length the flow would transition to turbulent due to increased Tollmien-Schlichting instabilities. The results of these experiments led to the investigation of 1:2 scaled A320 HLFC fin model in preparation for future flight tests [70].

After the basic flow investigations in the ELFIN project, the LARA project (LAminar flow Research Action - 1993 to 1994) was triggered to research more application oriented issues like contamination protection (liquid anti-contamination system as well as a Krüger shielding device), roughness criteria and suction requirements. At the same time, the follow-up project ELFIN II started in 1993 and was ongoing until 1995. The focus of this project was again numerical work to improve boundary layer prediction as well as off-design conditions for laminar flow over the wing and engine nacelles [70]. 
The project HYLDA (HYbrid Laminar Flow Demonstration on Aircraft - 1996 to 1999) was sponsored by the European Community and included 23 partners. The objective was to investigate the factors needed to advance the Technology Readiness Level (TRL) of HLFC for the wing, the engine nacelle as well as the A320 fin to flight demonstration [35]. The project also utilised the A320 HLFC Fin from the LaTec project [5].

The project HYLTEC (Hybrid Laminar Flow Technology - 1998 to 2001) was the next European HLFC project aiming at a full-scale development of an HLFC wing to counter issues regarding manufacturing and contamination due to insects or ice. Besides critical issues regarding manufacturing, systems and operational issues, studies regarding a retrofit for in-service aircraft were performed as well as experimental data generated to validate new prediction and design tools [35].

A wing glove for one side of DLR's test aircraft Do 228 has been developed as part of HYLTEC. It featured several methods of anti-contamination systems (Krüger shield, fluid, coatings) as well as different ice protection methods (fluid, bleed) which are schematically depicted in Figure 48. With this new wing designs, flight tests have been conducted in four test campaigns in the end of 2001. The flow transition could be delayed between $25 \%$ to $50 \%$ depending on the flap deflection and suction velocity. Problems arose from the fluid deicing system due to a too low chamber pressure. Nevertheless, those areas covered by fluid were de-iced sufficiently. The thermal anti-ice system removed the accumulated ice with ease once it was turned on and was even more effective than the standard thermal ice protection system due to the microperforated surface. On the Krüger flap test panel, only three insects $(0.7 \%$ of total amount counted on outside reference panel) were counted after a total of 11 anti-contamination test flights. The fluid anti-contamination system did not perform as good as the Krüger shield and accumulated roughly $11 \%$ of the insects of the reference panel [55].

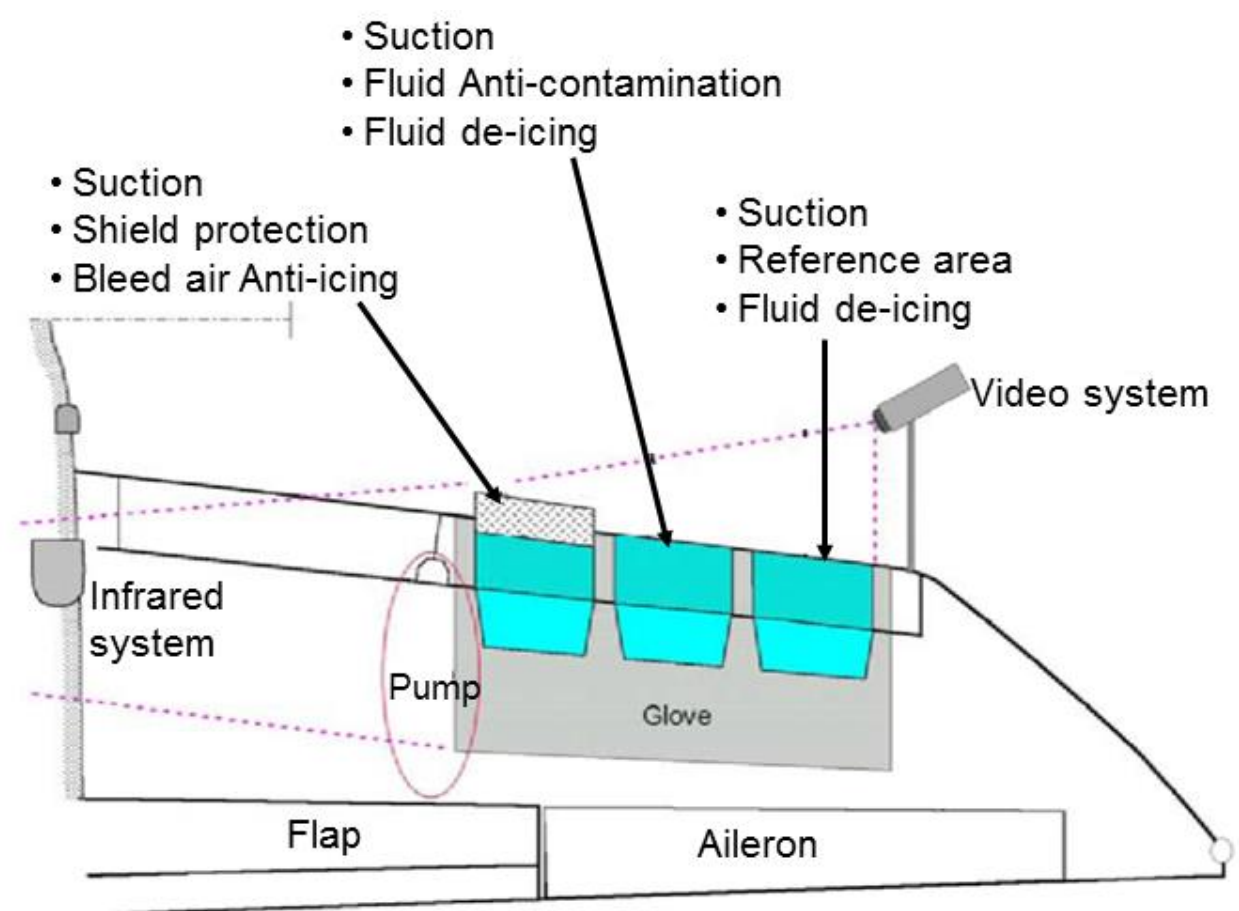

Figure 48: Test panels and instrumentation on Do 228 test aircraft [55] 
Another aspect of HYLTEC was the gaining of service experience with and without insect contamination protection on a SAAB 2000 aircraft flying regular routes across Northern Europe. For that purpose, two small test sections on each side of the wing have been installed which featured a number of porous surfaces but no active suction system. One panel was protected by a fully automatic liquid anti-contamination system while the other panel was unprotected. The airline service tests were started mid of 1999 and were stopped after 15 months with approximately 200 to 250 flights each month. Durability aspects of the perforated surfaces like erosion, corrosion and damage were monitored during that timeframe to address issues like choice of materials for the perforated surface as well as operational and certification issues. After 1748 flight hours on 1933 flights and varying meteorological and entomological conditions, no visible sign of erosion or damage due to ground handling could be found. The active panel was always free of insects and ice when inspected. On the other hand, the unprotected panel showed signs of insect debris but they were mainly smeared out having little or no perceptible thickness while at the adjoining rubber boots numerous insect hits above the critical height were reported. The average usage of the liquid for anti-contamination was $0.082 \mathrm{l} / \mathrm{min}$ per metre of span [78].

The ALTTA project (Application of Hybrid Laminar Flow Technology on Transport Aircraft (2000 to 2003) utilised the A320 HLFC fin, which was developed in earlier projects, as baseline for further studies. The objective was a more robust and simpler and thus lighter system which was designed for operational rather than experimental conditions [35]. The schematic of the newly developed simplified suction system design utilising a double-skin surface for the chambering was already depicted in Figure 22. The weight of the double-skin leading edge (without system installations) is comparable to the standard leading edge of the fin. The remaining part of the leading edge is the plenum chamber and the pressure difference between plenum and outside pressure leads to a suction airflow in the chambers. Due to the orifices in the double-skin the system is self-adapting and therefore works without flow meters or valves. When designing the suction system, the pressure losses through the micro-perforated surface were calculated from formulas derived in HYLDA (see [43]) which were increased by $30 \%$ to allow for manufacturing tolerances. The design condition for the HLFC system was a flight level of $31000 \mathrm{ft}$ with a Mach number of 0.78 and no yaw angle or rudder deflection. The calculated values for the design condition are depicted in Figure 49 utilising an exhaust Mach number of 0.2 [45]. 


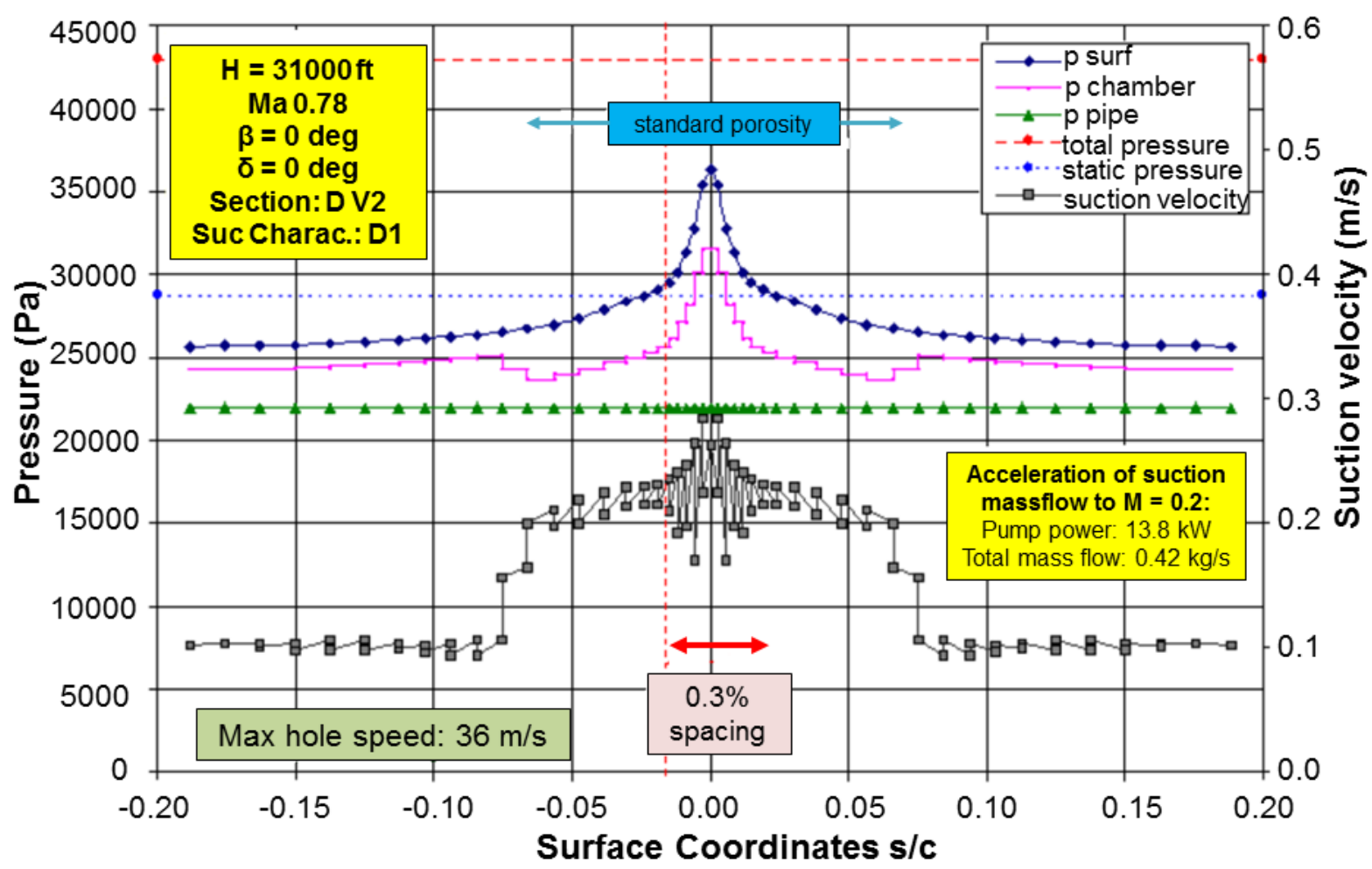

Figure 49: Different pressures and suction velocities for the design condition [45]

The pump power and therefore the weight and size of it are determined by the lowest height, so that the HLFC system can laminarise the flow. Figure 50 depicts the relationship between the two parameters pump power and flight level. It is recommended to design the system for a starting altitude of around $29000 \mathrm{ft}$ in the second segment climb based on performance studies [45]. The optimum starting flight level for HLFC has to be found in a multi-disciplinary way between aerodynamics, systems and the overall assessment group.

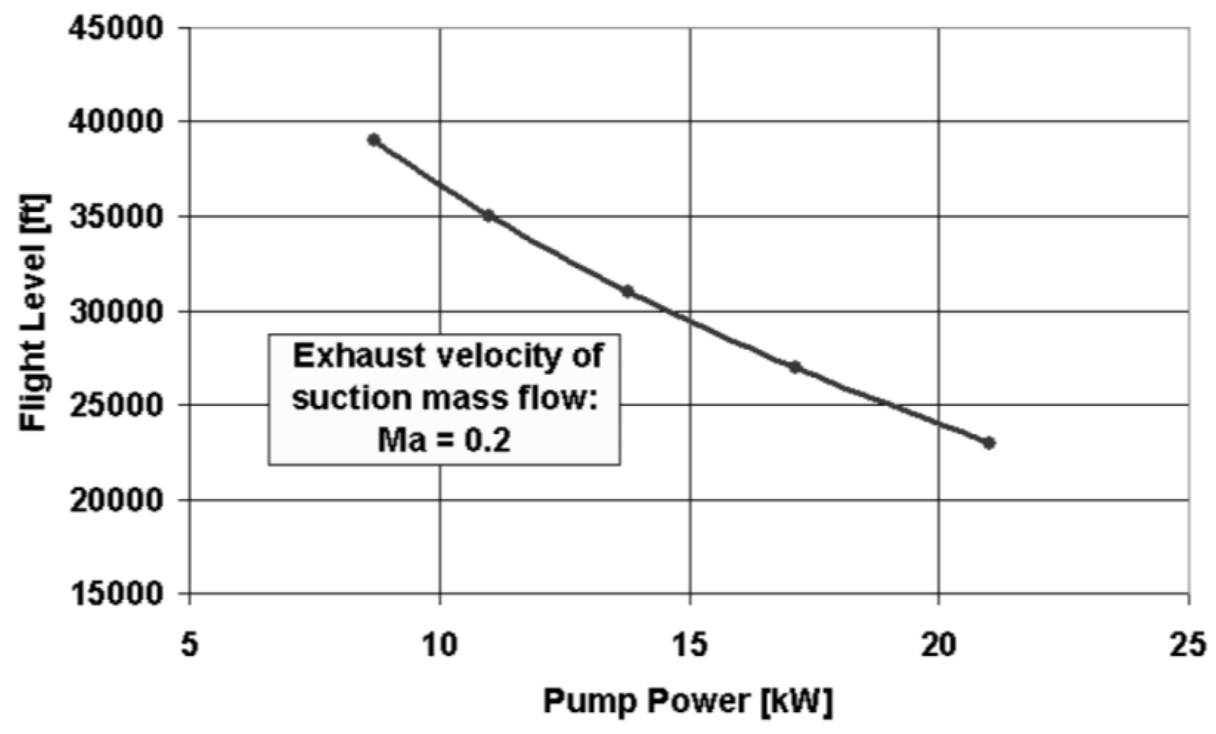

Figure 50: Pump power as a function of flight level [45]

In the context of the LuFo IV HIGHER-LE (High Lift Enhanced Research Leading Edge) compound project which started in 2009 , different research institutes worked together to 
assess an HLFC system deployed on a conceptual long-range HLFC research baseline aircraft. For that purpose, a suction system synthesis was performed by the Hamburg University of Technology. The aerodynamic calculations were performed by DLR's Institute of Aerodynamics and Flow Technology and the overall assessment was performed by RWTH Aachen's ILR Institute using the tool MICADO (Multidisciplinary Integrated Conceptual Aircraft Design and Optimization). Despite the baseline configuration, an optimized wing planform was developed to reduce the total system mass as well as the required power [37].

In VER ${ }^{2} S U S$ (Verification and Validation of a Simplified Suction System), which was part of the HIGHER-LE compound project, a simplified suction system for the fin of the A320 was developed. The number of suction chambers could be significantly reduced to obtain a lighter system. The enhanced suction system was successfully tested in the German-Dutch Wind Tunnels Large Low-Speed Facility (DNW-LLF). With these tests not only the designs were validated but also the whole process chain to develop such a simplified suction system [79].

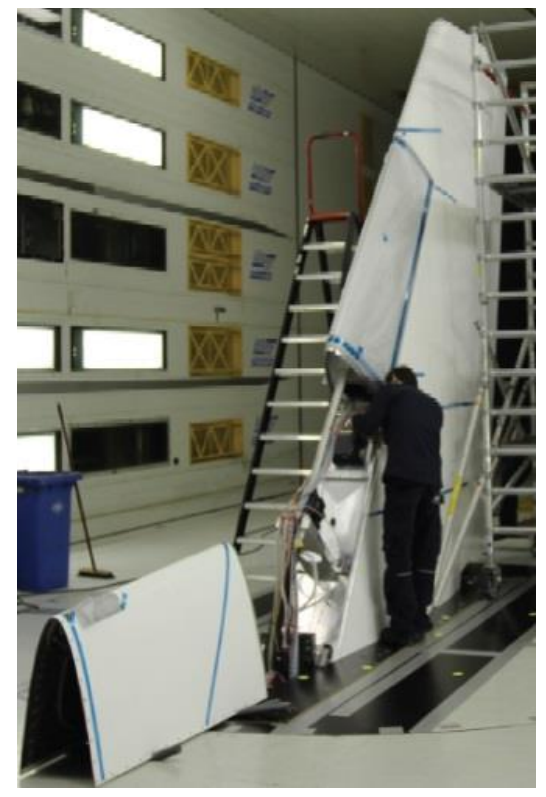

Figure 51: Installation of the HLFC fin on middle section at DNW-LLF wind tunnel [84]

The section of the fin to be tested shall be identical with a suitable section for flight tests. The verification and validation of the simplified suction system is done to pave the way for a flight test of the simplified suction system during the European AFLoNext (Active FlowLoads \& Noise Control on Next Generation Wing) which started mid of 2013. In the course of AFLoNext, an HLFC system will be installed and flight tested on the fin of DLR's Airbus A320 ATRA (Advanced Technology Research Aircraft). Schrauf [80] states that the consortium partners plan to install a passive suction system which is driven by the pressure differences occurring naturally on the aircraft. Nevertheless, an active system will most likely also be installed to assess the difference in benefit between the two solutions. The design principles of the simplified suction system on the fin are also going to be transferred to the wing to allow for large scale testing. Furthermore, the suction system on the HLFC research baseline aircraft of HIGHER-LE will be assessed in a multidisciplinary way on aircraft level. 
The assessment includes tasks regarding operational reliability, effects on fuel and power consumption as well as the costs of the technology.

DLR also started an internal laminar flow control project called Laminar Aircraft Research (LamAiR) in 2009. In the project, NLF was investigated for a novel forward swept wing configuration as well as an HLFC system for the vertical fin of an A320. The goal of the A320 HLFC system was to further simplify the ALTTA-concept. After the end of the project in 2012 a follow-up project was launched in 2014 named TuLAM (Toughen up Laminar Technology) to further improve and simplify the chosen suction concept and the Technology Readiness Level (TRL). TuLAM dealt with the chamberless suction nose concept, which was first proposed in LamAiR as shown in Fig. 52 Furthermore, DLR's Institute of Flight Systems was chosen as additional project partner to address system issues and integration topics.

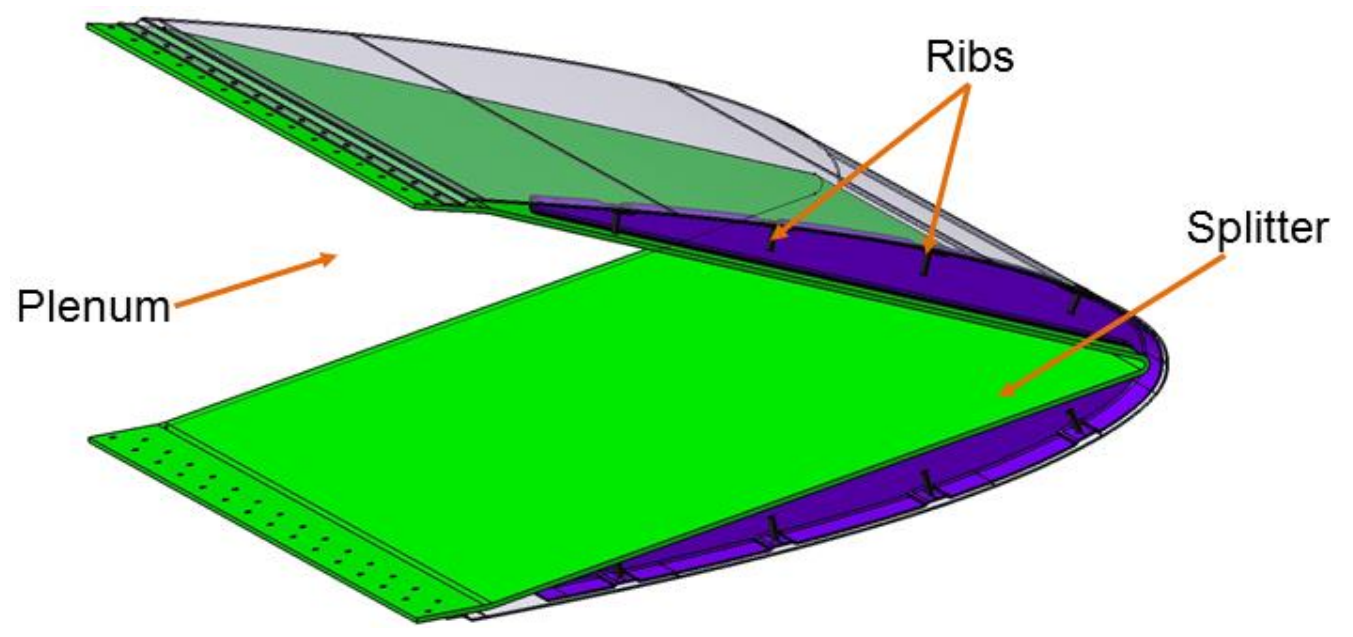

Figure 52: Chamberless HLFC suction nose concept

In July 2015, an European funded research project named ECHO (Evaluation of Certified HLFC elevator Operation) was started with the aim of developing HLFC technology for the horizontal tail plane (HTP) for long range aircraft. It is planned to develop a prototype and to evaluate it for flight tests, ultimately increasing the $T R L$ for application in commercial aircraft.

\subsection{Summary}

Research in laminar flow control has been active for the past four decades both in the US and in Europe. Various analytical studies and flight tests have been performed under various projects, the timeline view of all main HLFC programs is shown in Figure 53. There was a great deal of knowledge transfer and lessons learned from the experiences of each of the programs. The OPEC embargo was one of the main drivers of the laminar flow technology as seen earlier, since the technology offers to reduce drag and hence fuel consumption. Some of the earlier laminar flow research started in the US in 1976 under the Energy Efficient Transport Technology program. Soon, the demonstration of the success of the HLFC studies in the US generated interests in Europe to pursue research, and hence research began in NLF and LFC in 1984. Under the Falcon LAMinar program, the first HLFC flight test was started. A summary of flight tests in both the US and Europe is summarized in Table 5 and Table 6. 


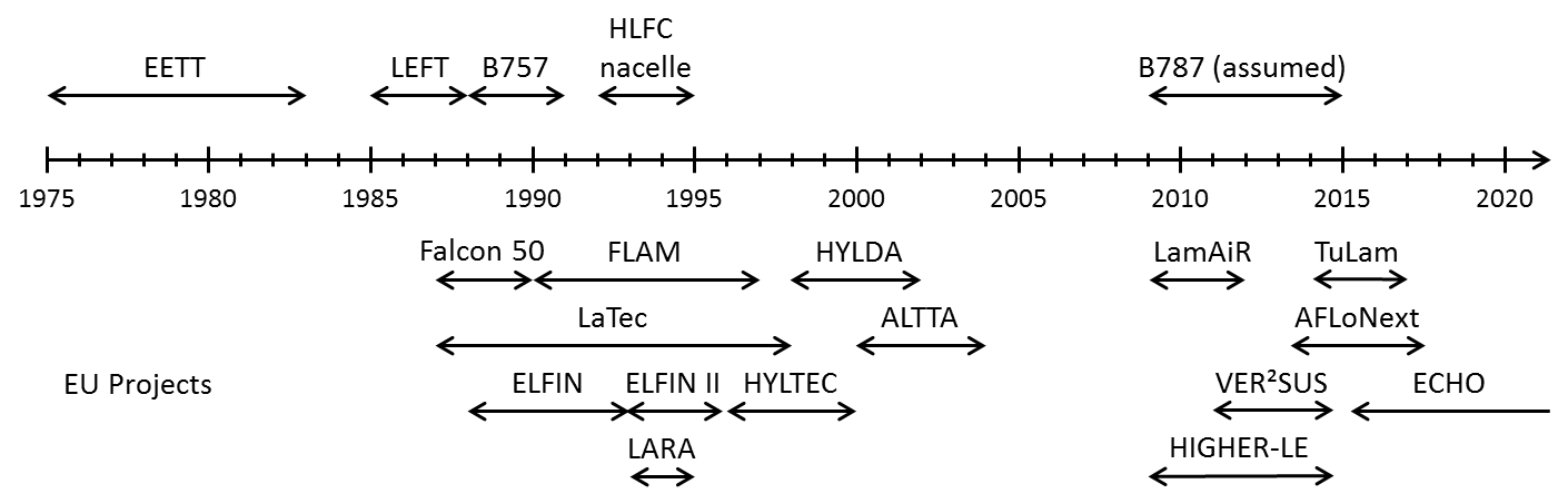

Figure 53: Timeline showing various laminar flow programs for subsonic transport aircraft from the US and the European Union

Table 5: Summary of HLFC Flight test programs in the US

\begin{tabular}{|c|c|c|c|c|c|c|}
\hline Duration & $\begin{array}{l}\text { Project / } \\
\text { Program }\end{array}$ & $\begin{array}{c}\text { Study / } \\
\text { Experime- } \\
\text { ntal type }\end{array}$ & $\begin{array}{l}\text { Model / } \\
\text { Aircraft }\end{array}$ & Other Details & $\begin{array}{c}\text { Partners / } \\
\text { Stakeholders }\end{array}$ & Remarks \\
\hline $1976-1982$ & EETT & $\begin{array}{l}\text { HLFC } \\
\text { benefits - } \\
\text { analytical } \\
\text { study } \\
\end{array}$ & $\begin{array}{c}\text { Boeing } \\
757\end{array}$ & & NASA, Boeing & $\begin{array}{l}\text { Estimated } 8.2 \% \text { fuel } \\
\text { savings }\end{array}$ \\
\hline $1985-1987$ & $\begin{array}{c}\text { LEFT } \\
\text { Program }\end{array}$ & Flight test & JetStar & $\begin{array}{l}\text { Study conducted to compare } \\
\text { both slotted and perforated } \\
\text { suction sections. The study } \\
\text { greatly helped for future HLFC } \\
\text { projects }\end{array}$ & $\begin{array}{l}\text { Lockheed, } \\
\text { Douglas }\end{array}$ & $\begin{array}{l}\text { The Anti-contamination } \\
\text { system was tested in- } \\
\text { flight for positive results }\end{array}$ \\
\hline $1987-1991$ & $\begin{array}{l}\text { Boeing } \\
757 \text { flight } \\
\text { test } \\
\text { program }\end{array}$ & Flight test & $\begin{array}{c}\text { Boeing } \\
757\end{array}$ & $\begin{array}{l}65 \% \text { laminarity achieved with } \\
\text { just one-third of suction amount } \\
\text { predicted using design tools, } \\
\text { which gave rise to uncertainty. } \\
\text { Extensive wind tunnel } \\
\text { experiments conducted in } 1995 \\
\text { to have a reliable database for } \\
\text { future HLFC concepts }\end{array}$ & $\begin{array}{l}\text { NASA, US Air } \\
\text { Force Wright } \\
\text { Laboratory, and } \\
\text { Boeing }\end{array}$ & $\begin{array}{l}29 \% \text { drag reduction was } \\
\text { achieved and an } \\
\text { estimated } 6 \% \text { drag } \\
\text { reduction on the aircraft }\end{array}$ \\
\hline 1991 - 1992 & $\begin{array}{c}\text { GE AE } \\
\text { CF6-50C2 } \\
\text { HLFC } \\
\text { nacelle } \\
\text { test }\end{array}$ & Flight test & $\begin{array}{c}\text { A300 } \\
\text { aircraft } \\
\text { with GEAE } \\
\text { CF6-50C2 } \\
\text { engines } \\
\end{array}$ & & $\begin{array}{l}\text { General Electric } \\
\text { Aircraft } \\
\text { Engines, Rohr, } \\
\text { Allied Signal } \\
\text { and NASA }\end{array}$ & $\begin{array}{l}\text { Upto } 43 \% \text { laminarity was } \\
\text { achieved }\end{array}$ \\
\hline $\begin{array}{l}2008-2013 \\
\text { (approxima } \\
\text { tely) }\end{array}$ & $\begin{array}{c}\text { Boeing } \\
787 \text { flight } \\
\text { test }\end{array}$ & Flight test & $\begin{array}{c}\text { Boeing } \\
787\end{array}$ & No open literature available & NASA, Boeing & $\begin{array}{l}\text { A passive HLFC system } \\
\text { was successfully } \\
\text { installed }\end{array}$ \\
\hline
\end{tabular}


Table 6: Summary of HLFC Flight test programs in Europe

\begin{tabular}{|c|c|c|c|c|c|c|}
\hline Duration & $\begin{array}{l}\text { Project } \\
/ \\
\text { Progra } \\
\text { m }\end{array}$ & $\begin{array}{l}\text { Study / } \\
\text { Experime- } \\
\text { ntal type }\end{array}$ & $\begin{array}{c}\text { Model } \\
/ \\
\text { Aircraft }\end{array}$ & Other Details & $\begin{array}{c}\text { Partners / } \\
\text { Stakeholders }\end{array}$ & Remarks \\
\hline 1990 - 1997 & FLAM & Flight test & $\begin{array}{l}\text { Falcon } \\
900\end{array}$ & & & $\begin{array}{l}2 \text { year HLFC wing flight } \\
\text { tests on a Falcon } 900 \\
\text { airplane with a total of } \\
1000 \text { hours }\end{array}$ \\
\hline $1986-1998$ & LaTec & Flight test & A 320 & & & $\begin{array}{l}\text { Airbus A320 HLF fin } \\
\text { project, flight tests in } \\
1998\end{array}$ \\
\hline 1996 - 1999 & HYLDA & Flight test & A 320 & $\begin{array}{l}\text { 3E/LATEC and HYLDA } \\
\text { funded flight tests with } \\
\text { A320, HLFC applied at } \\
\text { vertical tail }\end{array}$ & & $\begin{array}{l}\text { Technical feasibility } \\
\text { proven } \\
\text { No show stopper for HLFC } \\
\text { was found }\end{array}$ \\
\hline $1998-2001$ & HYLTEC & Flight test & $\begin{array}{l}\text { Saab } \\
2000 \\
\text { and } \\
\text { Do228 }\end{array}$ & $\begin{array}{l}\text { HLFC wing flight test on } \\
\text { DLR Do228 test vehicle in } \\
2002 \text { including protection } \\
\text { systems against icing and } \\
\text { insect contamination }\end{array}$ & $\begin{array}{l}\text { Airbus (D/F/E), } \\
\text { Apparatebau Gauting, } \\
\text { Aerospace Systems and } \\
\text { Technologies, BAE } \\
\text { Systems, DERA, DLR, } \\
\text { FFA, Nord-Micro, } \\
\text { ONERA, Saab, SONACA, } \\
\text { University of Limerick, } \\
\text { TU Berlin }\end{array}$ & $\begin{array}{l}\text { Operational flight tests, } \\
\text { lab tests, manufacturing } \\
\text { issues } \\
\text { Laminar flow retrofit } \\
\text { studies for medium range } \\
\text { Airbus aircraft } \\
\text { Generation and analysis } \\
\text { of experimental data, two } \\
\text { wind tunnel tests at } \\
\text { ONERA, two flight tests } \\
\text { (Saab } 2000 \text { and Do228) } \\
\text { and data analysis for A320 } \\
\text { HLF campaign }\end{array}$ \\
\hline
\end{tabular}

\section{Conclusions}

The paper explained the theoretical basis behind the HLFC system and reviewed the system design and prevailing issues, important projects, analytical studies and flight tests which were intentioned to improve major technical aspects and difficulties of hybrid laminar flow control (HLFC) technology, for application in commercial aircraft. There is a growing concern for environmental protection and the important factor to be considered is the fuel consumption. The HLFC technology was found very promising and has good potential to enhance aircraft fuel efficiency, subsequently with improved payload and range capabilities. The technology has evolved in many proportions over the years, through the lessons learned from each project. These improvements have made the technology more and more feasible. The development of HLFC systems is a complex, multi-disciplinary task, which needs technical solutions from various disciplines for proper systems integration. A great deal of work has been performed in the aerodynamic domain in the past decades to assess the potential benefits of the technology, and there is a growing need to deal with various systems, and structural issues. The systems aspect involves identification and assessment of various possible system solutions in-order to find the most optimal system architecture, and also the possible penalty it poses on the aircraft fuel consumption. In addition, the safety and reliability of various possible system architectures needs to be assessed thoroughly for certification purposes. Since HLFC technology involves usage of micro-perforated surfaces in the airframe, prior attention is required to address issues such as anti-contamination, iceprotection, which requires both optimal and novel solutions. Although many different 
solutions were proposed earlier with regards to anti-contamination and ice-protection, as detailed in this paper, issues concerned with system weight and drag penalty needs to be taken into account, when weighing the options. When addressed with optimal and novel system solutions, the HLFC seems an attractive option for application in commercial aircraft in the years to come.

\section{Acknowledgments}

The authors would like to thank for the support from EU CleanSky2 ECHO project.

\section{References}

[1] Braslow, A. L.: A History of Suction-Type Laminar-Flow Control with Emphasis on Flight Research. Monographs in Aerospace History Number 13, Washington 1999.

[2] Joslin, R. D.: Overview of Laminar Flow Control, NASA Technical Publication, Washington 1998.

[3] Liddle, S. C.; Jabbal M.; Crowther, W. J.: Systems and Certification Issues for Civil Transport Aircraft Flow Control Systems. The Aeronautical Journal Volume 113, 2009.

[4] Stanewsky, E.; Rosemann, H.: Active Flow Control Applied to Military and Civil Aircraft. RTV/AVT (AGARD) Symposium, Braunschweig 2000.

[5] Henke, R.: A320 HLFC Fin Flight Tests Completed. Air \& Space Europe, Volume 1, Number $2,1999$.

[6] Green, E. J.: Laminar Flow Control - Back to the future. 38th Fluid Dynamics Conference and Exhibit, June 2008, AIAA 2008 - 3738.

[7] Young F. D. et al: A Brief Introduction to Fluid Mechanics. 5th Edition, John Wiley \& Sons, 2011.

[8] Anderson Jr., D. J.: Ludwig Prandtl's Boundary Layer. Physics Today, December 2005 edition.

[9] http://www.lairgacy.com/2013/06/laminar-flow-aircraft-possibility-or.html, last accessed 8.12.2015.

[10] http://www.smartwingdesign.org/_include/img/work/full/TS.png last accessed 27-09-2016.

[11]AGARD Report 786: Special Course on Skin Friction Drag Reduction. AGARD-R-786, North Atlantic Treaty Organization, March 1992.

[12] Madallon, D.V.: Simulated Airline Service flight Tests of Laminar Flow Control with Perforated Surface Suction System, NASA Technical Paper 2966, March 1990. 
[13] Mack L.M.: Boundary layer linear stability theory, AGARD Report No 709, 1984.

[14] Arnal D., Casalis G.: Laminar-turbulent transition prediction in three-dimensional flows, Progress in Aerospace Sciences pp 173-191, 2000.

[15] Smith AMO, Gamberoni N. Transition, prerssure gradient and stability theory. Douglas Aircraft Co. Rept. ES26388, El Segundo, California, 1956.

[16] Van Ingen: A suggested semi-empirical method for the calculation of the boundary layer transition region. University of Technology, Department of Aerospace Engineering, Report, UTH-74, 1956, Delft.

[17] Malik, M. R.: Stability Theory Applications to Laminar Flow Control. Research in Natural Laminar Flow and Laminar-Flow Control, NASA Conference Publication 2487, Part 1, 1987.

[18] Streett, C. L.: Designing a Hybrid Laminar Flow Control Experiment - The CFD-Experiment Connection. 41st Aerospace Sciences Meeting and Exhibit, AIAA Paper 2003-979, Reno 2003.

[19] Streett, C. L.: Direct Harmonic Linear Navier-Stokes Method for Efficient Simulation of Wave Packets. 36th Aerospace Sciences Meeting and Exhibit, AIAA Paper 1998-0784, Reno 1998.

[20] Herbert T., Bertolotti F.P. : Stability analysis of nonparallel boundary layers. Bull Am Phys Spc 32:2079-2806, 1987.

[21] Emmons H: The laminar-turbulent transition in a boundary layer-part I. J Aeronaut Sci 18:490-498, 1951.

[22] Dhawan S, Narasimha R: Some properties of boundary layer flow during transition from laminar to turbulent motion. J Fluid Mech 3:418-436, 1958.

[23] Jones W.P., Launder B.E.: The calculation of low Reynolds number phenomena with a twoequation model of turbulence. Int J Heat Mass Transfer 15:301-314, 1973.

[24] Pasquale D.D., Rona A, Garrett, S.J., A selective review of CFD transition models. AIAA 2009-3812, 39th AIAA Fluid Dynamics Conference, San Antonio, Texas, 22-25 June 2009.

[25] Wilcox D.C.: Simulation of Transition with a Two-Equation Turbulence Model," AIAA Journal, Vol. 32, No. 2, 1994.

[26] Langtry R.B, Sjolander S.A.: Prediction of transition for attached and separated shear layers in turbomachinery, AIAA Paper 2002-3643. 38th AIAA/ASME/SAE/ASEE Joint Propulsion Conference, Indianapolis, Indiana.

[27] Walters, D. K. and Leylek, J. H., "A New Model for Boundary-Layer Transition Using a Single-Point RANS Approach,” Journal of Turbomachinery, Vol. 126, Jan. 2004, pp. 193202.

[28] Gostelow J.P., Blunden A.R., Walker G.J.: Effects of free-stream turbulence and adverse pressure gradients on boundary layer transition. ASME J Turbomach 116:392-404, 1994. 
[29] Suzen Y.B., Huang P.G: Modeling of flow transition using an intermittency transport equation, ASME J Fluids Eng 122(2):273-284, 2000.

[30] Suzen Y.B., Xiong G., Huang P.G.,: Predictions of transitional flows in low-pressure turbines using intermittency transport equation. AIAA J 40(2):254-266, 2002.

[31] Mayle, R. E. and Schultz, A., "The Path to Predicting Bypass Transition," ASME Journal of Turbomachinery, Vol. 119, 1997, pp. 405-411.

[32]Zheng X., Liu, C., Liu, F., and Yang, C., "Turbulent Transition Simulation Using the k- $\omega$ Model," International Journal for Numerical Methods in Engineering, Vol. 42, 1998, pp. 907926.

[33] Smagorinsky, J., Monthly Weather Revue, Vol. 91, No. 3, 1963, pp. 99-164.

[34] Germano, M., Piomelli, U., Moin, P., and Cabot, W. H., "A Dynamic Subgride-Scale Eddy Viscosity model,” Journal Physic of Fluids, Vol. A 3, No. 7, 1991, pp. 1760-1765.

[35] Young, T. M.: Investigations into the Operational Effectiveness of Hybrid Laminar Flow Control Aircraft. PhD Thesis, Cranfield University, 2002.

[36] Schrauf, G. H.: Status and perspectives of laminar flow. The Aeronautical Journal, Volume 109, 2005.

[37] Risse, K. et al: Conceptual Wing Design Methodology for Aircraft with Hybrid Laminar Flow Control. 52nd Aerospace Sciences Meeting held at the AIAA SciTech Forum, Maryland 2014.

[38] Robert, J.-P.: Drag Reduction: An Industrial Challenge. AGARD Special Course on Skin Friction Drag Reduction, AGARD-R-796, 1992.

[39] Wilson, R. A. L.: The Introduction of Laminar Flow to the Design and Optimisation of Transport Aircraft. PhD Thesis, Cranfield University, 1997.

[40] https://www.flightglobal.com/news/articles/farnborough-aero-secrets-of-boeings-newdreamliner-401784/, last accessed 14.09.2015.

[41]Schrauf, G. H.: The Need of Large-Scale HLFC Testing in Europe http://www.aflonext.eu/files/pdf/schrauf_2013_HLFC_research-needs_v2.pdf, last accessed 14.09.2015.

[42] Pe, T.; Thielecke, F.: Synthesis and Topology Study of HLFC System Architectures in Preliminary Aircraft Design. 3rd CEAS Air \& Space Conference 2011.

[43] Bieler, H.; Preist, J.: HLFC for Commercial Aircraft - First ELFIN Test Results. First European Forum on Laminar Flow Technology, Hamburg 1992.

[44] Seitz, A.; Horstmann, K.-H.: Design Studies on NLF and HLFC Applications at DLR. 27th International Congress of the Aeronautical Society, Nice 2010.

[45] Schrauf, G. H.; Horstmann, K.-H.: Simplified Hybrid Laminar Flow Control. European Congress on Computational Methods in Applied Sciences and Engineering (ECCOMAS), Jyväskylä 2004. 
[46] Horn, M.: Bauweisen und Fertigungskonzepte für Hybride Laminarhaltung. DLRK Kongress 2012.

[47] Croom, C. C.; Holmes, B. J.: Insect Contamination Protection for Laminar Flow Surfaces. NASA Report N88-14954, 1988.

[48] Coleman, W. S.: Roughness Due to Insects. Boundary Layer and Flow Control Volume II, Pergamont Press, Oxford 1961.

[49] Young, T. M.: Laboratory Testing of Insect Contamination for Laminar Flow Applications using an Insect-Impact Test Facility, 28th International Congress of the Aeronautical Sciences, Brisbane 2012.

[50] Humphreys, B.: Contamination Avoidance for Laminar Flow Surfaces. First European Forum on Laminar Flow, Hamburg 1992.

[51] Kok, Mariana et al: Critical Considerations in the Mitigation of Insect Residue Contamination on Aircraft Surfaces - A Review. Progress in Aerospace Sciences Volume 75, 2015.

[52] ALTTA Final Technical Report, 2003.

[53]Federal Aviation Administration: Aviation Maintenance Technician Handbook - Airframe, Volume 2, 2012.

[54] Boeing Commercial Airplane Group: High Reynolds Number Hybrid Laminar Flow Control (HLFC) Flight Experiment. IV. Suction System Design and Manufacture, NASA/CR-1999209326, Hampton 1999.

[55] Horstmann, K.-H. et al: HYLTEC Laminar Flow Systems Flight Tests: Flight Testing of Anti-Icing and Anti-Contamination Systems on the DLR Do228 Test Vehicle. CEAS Conference, London 2003.

[56] Thielecke, F.: Flugzeugsysteme 3. Lecture notes, TU Hamburg-Harburg Institute of Aircraft Systems Engineering, Hamburg 2012.

[57] Powell G. A.: The Right Wing of the L.E.F.T. Airplane. Research in Natural Laminar Flow and Laminar Flow Control, NASA Conference Publication 2487, Part 1, 1987.

[58] Wicke, K. et al: Insect Contamination Impact on Operational and Economic Effectiveness of Natural-Laminar-Flow Aircraft. 29th Congress of the International Council of the Aeronautical Sciences (ICAS), St. Petersburg 2014.

[59] Jasperson, W. H. et al: GASP Clound Encounter Statistics: Implication for Laminar Flow Control Flight. Journal of Aircraft Volume 21, Noumber 11, 1984.

[60]Pe, T., Thielecke, F.: System Reliability Analysis of HLFC Suction System Architectures. Workshop on Aircraft System Technologies, Hamburg 2013.

[61] Ohme, P., Vechtel, D.: Criticality and Sensitivity Analysis of a Hybrid Laminar Flow Control System on Aircraft Level. Institute Report, DLR Institute of Flight Systems, Braunschweig 2010. 
[62] Hybrid Laminar Flow Control study final technical report, Energy Efficient Transport Program, NASA-CR-165930, 1982.

[63] Bobbitt P. J. et al: Results for the Hybrid Laminar Flow Control experiment conducted in the NASA Langley 8-ft Transonic Pressure Tunnel on a 7-ft chord model, 1992.

[64]Lange H. R.: Lockheed Laminar Flow Control Systems Development and Applications. Research in Natural Laminar Flow and Laminar Flow Control, NASA Conference Publication 2487, Part 1, 1987.

[65] Arcara Jr, P. C.; Bartlett, D. W.; McCullers, L. A.: Analysis for the Application of Hybrid Laminar Flow Control to a Long-Range Subsonic Transport Aircraft. SAE Paper 912113, 1991.

[66] Collier Jr., F. S.: An Overview of Recent Subsonic Laminar Flow Control Flight Experiments. AIAA 24th Fluid Dynamic conference, July 1993, Florida, AIAA 93 - 2987.

[67] Madallon, D. V.: Hybrid Laminar Flow Control Flight Research, Research and Technology, NASA TM-4331, 1991.

[68] Sawyers, D. M.; Wilson, R. A. L.: An Assessment of the Impact of Hybrid Laminar Flow on a Large Subsonic Aircraft. 2nd European Forum for Laminar Flow Technology, Bordeaux, June 1996.

[69] Eppink J., Wleizen R.: Data Analysis for the NASA / Boeing Hybrid Laminar Flow Control Crossflow Experiment. 41st AIAA Fluid Dynamics Conference and Exhibit, AIAA 2011 3879 .

[70] Dziomba, B.: European Laminar Flow Projects. Aerodays 1993: Second Community Aeronautics R\&D Conference, Naples 1993.

[71]Bulgubure, C.; Arnal, D.: Dassault Falcon 50 Laminar Flow Flight Demonstrator. First European Forum on Laminar Flow Technology, Hamburg 1992.

[72] Fiton, J.: Lessons Learned from Dassault's Falcon 900 HLFC Demonstrator. CEAS/DragNet European Drag Reduction Conference, Potsdam 2000.

[73] Thibert, J. J.; Quest, A.; Robert, J. P.: The A320 Laminar Fin Programme. First European Forum on Laminar Flow Technology, Hamburg 1992.

[74] High Reynolds Number Hybrid Laminar Flow Control (HLFC) Flight Experiment III Leading Edge Design, Fabrication and Installation. NASA-CR-1999-209325, 1999.

[75] High Reynolds Number Hybrid Laminar Flow Control (HLFC) Flight Experiment IV Suction System Design and Manufacture. NASA-CR-1999-209326, 1999.

[76] Henke, R.: Airbus A320 HLF Fin Flight Tests. CEAS / DragNet European Drag Reduction Conference, Potsdam 2000.

[77] Anderson Jr., D. J.: Ludwig Prandtl's Boundary Layer. Physics Today, December 2005 edition. 
[78] Humphreys, B. E.; Totland, E. J.; Horstmann, K.-H.: Flight Testing of Laminar Flow Materials and Systems to Gain Experience with Respect to Operational Aspects. European Congress on Computational Methods in Applied Sciences and Engineering (ECCOMAS), Barcelona 2000.

[79] Rohardt, C.-H. et al: Simplified-HLFC / Entwurf eines Seitenleitwerks mit HybridLaminarhaltung für den Airbus A320. Deutscher Luft-und Raumfahrtkongress, Bremen 2011.

[80]Schrauf, G. H.: The Need of Large-Scale HLFC Testing in Europe http://www.aflonext.eu/files/pdf/schrauf_2013_HLFC_research-needs_v2.pdf, last accessed 14.09.2015.

[81]Pe, T.; Thielecke, F.: Methodik zur Leistungsabschätzung von HLFC-Absaugsystemen im Flugzeugvorentwurf. Deutscher Luft- und Raumfahrtkongress 2010.

[82] http://www.mit.edu/course/1/1.061/OldFiles/www/dream/SEVEN/SEVENTHEORY.PDF, last accessed 16.12.2015

[83] Meyer, J. et al: System Layout and Instrumentation of a Laminar Flow System for the DLR Do 228 Test Vehicle. CEAS Conference, London 2003.

[84]DLR's Institute of Aerodynamics and Flow Technology Braunschweig Newsletter, 2015. http://www.dlr.de/as/en/Portaldata/5/Resources/dokumente/newsletter/2015_II_Newsletter.pd f, last accessed 30.11.2015. 